\title{
DETERMINAÇÃO DOS SALÁRIOS NA AGROPECUÁRIA BRASILEIRA - PERÍODO DE 1971 a 1996
}

\section{JEFFERSON ANDRONIO RAMUNDO STADUTO}

\author{
Tese apresentada à Escola Superior de \\ Agricultura "Luiz de Queiroz”, Universidade de \\ São Paulo, para obtenção do título de Doutor \\ em Ciências, Área de Concentração: Economia \\ Aplicada.
}

P I R A C I C A B A

Estado de São Paulo - Brasil

Fevereiro - 2002 


\title{
DETERMINAÇÃO DOS SALÁRIOS NA AGROPECUÁRIA BRASILEIRA - PERÍODO DE 1971 a 1996
}

\section{JEFFERSON ANDRONIO RAMUNDO STADUTO}

Engenheiro Agrônomo

\author{
Orientador: Prof. Dr.CARLOS JOSÉ CAETANO BACHA
}

\author{
Tese apresentada à Escola Superior de \\ Agricultura "Luiz de Queiroz”, Universidade de \\ São Paulo, para obtenção do título de Doutor \\ em Ciências, Área de Concentração: Economia \\ Aplicada.
}

P I R A C I C A B A

Estado de São Paulo - Brasil

Fevereiro - 2002 


\section{Dados Internacionais de Catalogação na Publicação (CIP) DIVISÃO DE BIBLIOTECA E DOCUMENTAÇÃO - ESALQ/USP}

Staduto, J efferson Andronio Ramundo

Determina ção dos salários na a gropecuária brasileira - período de 1971a 1996 / J efferson Andronio Ramundo Staduto. - - Piracic aba, 2002.

$141 \mathrm{p}$.

Tese (doutorado) - Escola Superior de Agricultura Luiz de Queiroz, 2002. Bibliografia.

1. Mercado de trabalho 3. Salário mínimo 4. Salário rural 5. Trabalhador nã o-qua lific a do 6. Tra ba lha dor rural I. Titulo

CDD 338.13

"Permitida a cópia total ou parcial deste documento, desde que citada a fonte - $\mathrm{O}$ autor" 
Ofereço à minha filha Isadora.

Dedico à minha família e à Minha esposa Yonissa. 


\section{AGRADECIMENTOS}

À Universidade Estadual do Oeste do Paraná e aos colegas do Departamento de Economia do Campus de Toledo por terem me apoiado no período de meu afastamento.

À Escola Superior de Agricultura "Luiz de Queiroz" e, especialmente, ao Departamento de Economia, Administração e Sociologia pela oportunidade que me ofereceram para cursar o Programa de Pós Graduação em Economia Aplicada.

À CAPES pelo auxilio financeiro, concedendo bolsa de auxílio, o qual viabilizou a realização deste trabalho.

Ao meu orientador Prof. Dr. Carlos José Caetano Bacha pela troca de idéias nos momentos importantes e pelas contribuições na elaboração do trabalho, bem como na compreensão nos momentos difíceis.

À professora Dra. Mirian Rumenos Piedade Bacchi pelas contribuições dadas ao trabalho, fazendo o papel extra-oficial de co-orientadora, e pelas trocas de idéias.

Aos professores Doutores Rodolfo Hoffmann e Alexandre Lahoz Mendonça de Barros pelas contribuições e pela grande solicitude.

Aos funcionários do LES pela contínua disposição em contribuir com o nosso trabalho. 
Aos colegas do curso e, especialmente, aos amigos. Dentre eles cito os nomes de Jaênes, Claílton e Espedito, sem ser injusto com os demais. Tivemos momentos difíceis, os quais foram superados em conjunto e, naturalmente, desfrutamos dos momentos felizes. 


\section{SUMÁRIO}

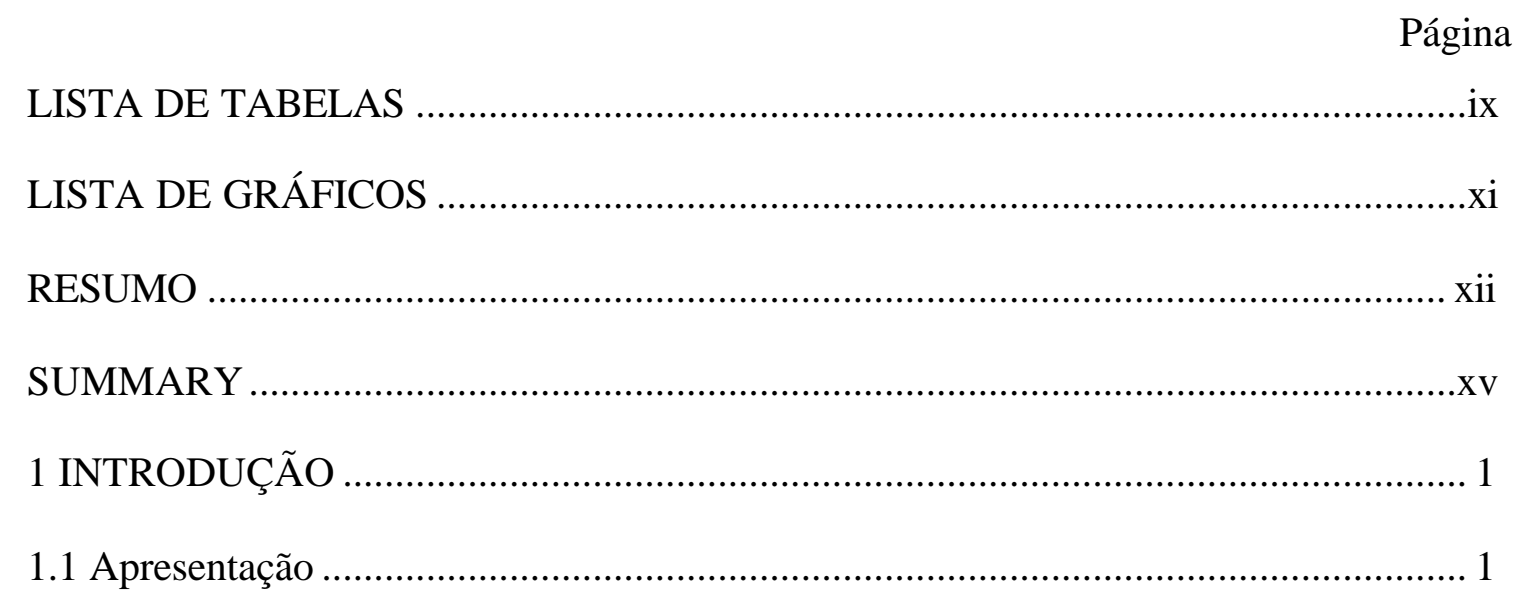

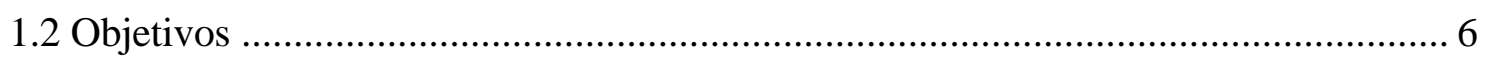

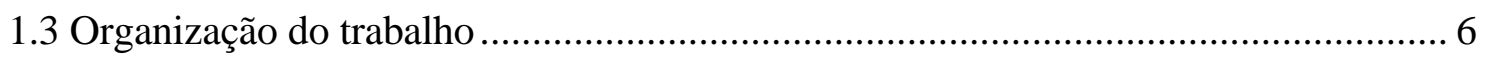

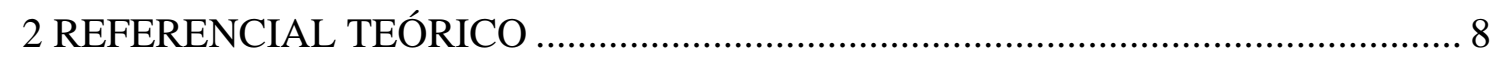

2.1 Mercado de trabalho no modelo neoclássico ..................................................... 9

2.1.1 Mercado de trabalho em concorrência perfeita ............................................ 10

2.1.2 Mercado de trabalho em concorrência perfeita com restrição ............................ 13

2.1.3 Mercado de trabalho monopsônico ................................................................ 16

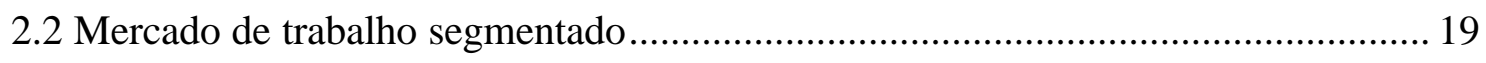

2.3 Modelo de determinação dos salários considerando segmentação do mercado de

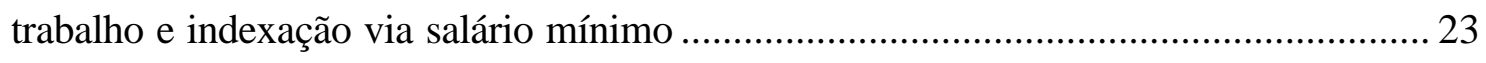

3 EVOLUÇÃO DA LITERATURA SOBRE MERCADO DE TRABALHO E

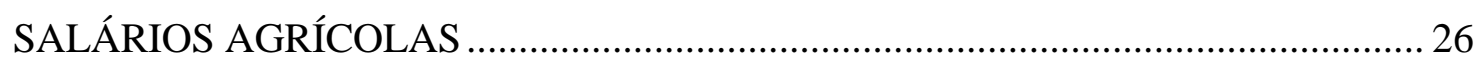


3.1 Mercado de trabalho da mão-de-obra não-qualificada....................................... 27

3.1.1 O mercado de trabalho e o salário mínimo ...................................................... 28

3.2 Evolução do mercado de trabalho agropecuário brasileiro .................................. 31

3.3 Literatura sobre determinação dos salários agrícolas......................................... 38

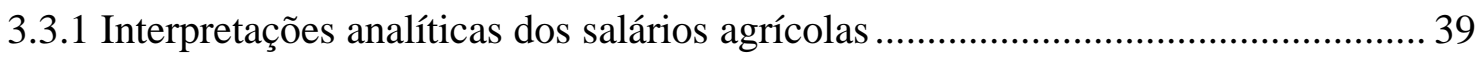

3.3.2 Pesquisas econométricas sobre os salários agrícolas ..................................... 44

4 MODELOS ECONOMÉTRICOS DE DETERMINAÇÃO DO SALÁRIO

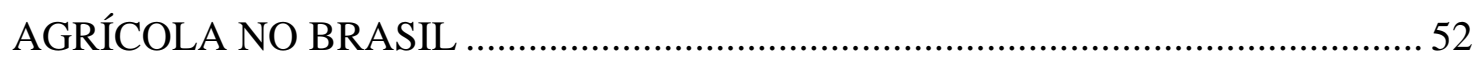

4.1 Modelos empíricos de determinação de salário agrícola ....................................52

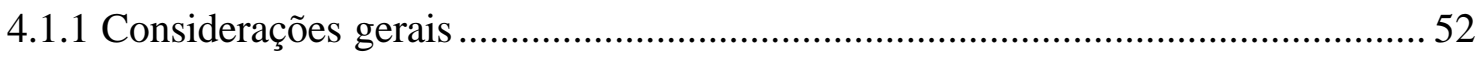

4.1.2 Modelo de determinação do salário agrícola dos trabalhadores temporários .......54

4.1.3 Modelo de determinação do salário agrícola dos trabalhadores permanentes ...... 60

4.2 Procedimentos econométricos para estimar as equações (18) e (25)...................... 63

4.3 Definição das variáveis e fontes de dados...................................................... 70

5 APLICAÇÃO EMPÍRICA DOS MODELOS DE DETERMINAÇÃO DE

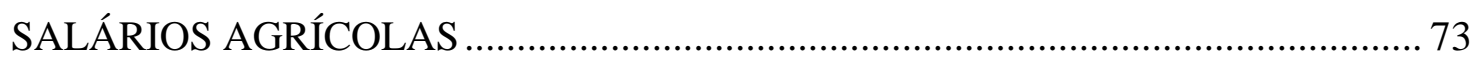

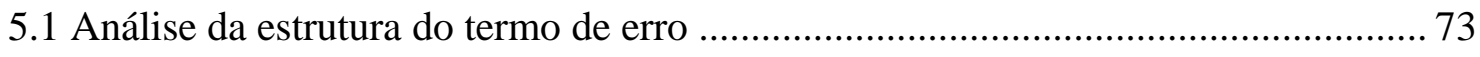

5.2 Equações de determinação dos salários agrícolas ............................................ 77

5.2.1 Equação de determinação dos salários dos trabalhadores temporários................. 80

5.2.1.1 Determinação dos salários dos trabalhadores temporários no Brasil ................. 81

5.2.1.2 Determinação dos salários dos trabalhadores temporários na região menos

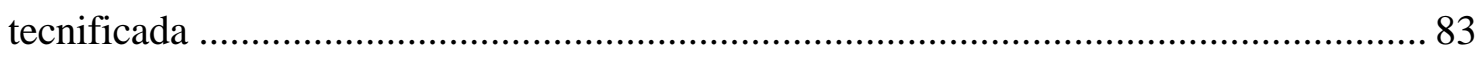

5.2.1.3 Determinação dos salários dos trabalhadores temporários na região mais

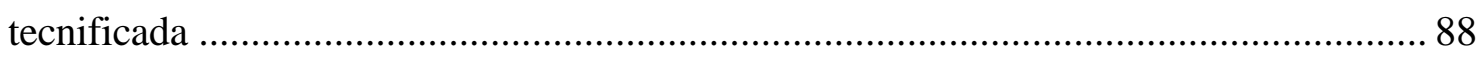


5.2.2 Equação de determinação dos salários dos trabalhadores permanentes................92

5.2.2.1 Determinação dos salários dos trabalhadores permanentes no Brasil............... 93

5.2.2.2 Determinação dos salários dos trabalhadores permanentes na região menos

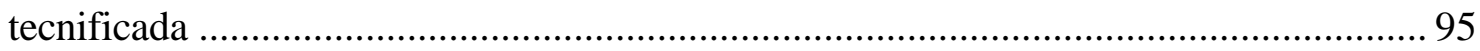

5.2.2.3 Determinação dos salários dos trabalhadores permanentes na região mais

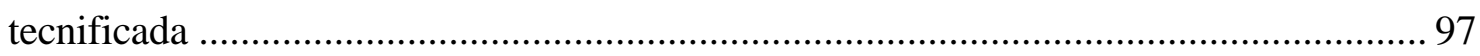

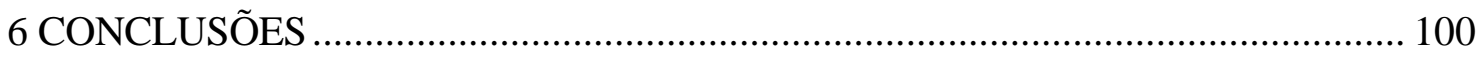

REFERÊNCIAS BIBLIOGRÁFICAS ........................................................... 105

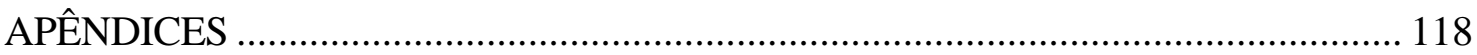




\section{LISTA DE TABELAS}

Página

1 Teste Durbin-Watson das equações de determinação dos salários dos trabalhadores temporários e permanentes, respectivamente, equações (18) e (25)

2 Teste de heterocedasticia de grupo (teste LM) dos dados das equações de determinação dos salários dos trabalhadores temporários e permanentes no Brasil e nas regiões menos e mais tecnificadas.....................................

3 Resultados das estimativas das equações de determinação dos salários dos trabalhadores temporários pelo método de Fuller \& Battese no período de 1971 a 1996

4 Resultados das estimativas das equações de determinação dos salários dos trabalhadores permanentes pelo método de Fuller \& Battese no período de 1971 a 1996.

5 Dados utilizados na estimação das equações (18) e (25)

6 Resultados estimativas das equações de "quebra" de tendência dos salários dos trabalhadores agrícolas temporários e permanentes para as regiões menos e mais tecnificadas.

7 Resultados das estimavas das equações de determinação dos salários dos trabalhadores temporários e permanentes pelo método Fuller \& Battese 


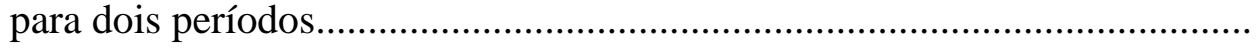

8 Resultados das estimativas das equações de determinação dos salários dos trabalhadores temporários e permanentes pelo método Fuller \& Battese

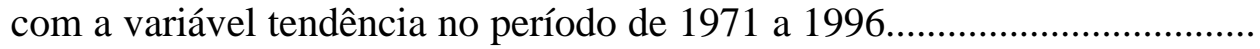




\section{LISTA DE GRÁFICOS}

Página

1 Equilíbrio no mercado de trabalho em concorrência perfeita......................... 12

2 Equilíbrio no mercado de trabalho em concorrência perfeita com restrição... 14

3 Equilíbrio no mercado de trabalho monopsônico........................................... 18

4 Salário mínimo indexando o salário agrícola............................................. 25

5 Relação média entre os salários dos trabalhadores temporários equivalente a 25 dias de trabalho e o salário mínimo das regiões menos e mais

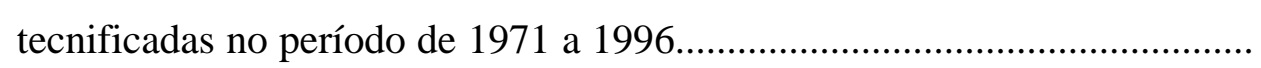

6 Relação média entre os salários dos trabalhadores permanentes e o salário mínimo das regiões menos e mais tecnificadas no período de 1971 a

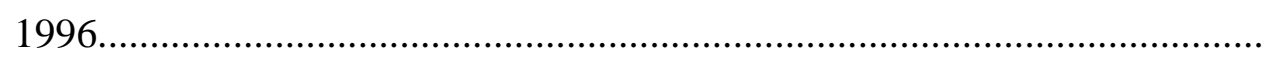




\title{
DETERMINAÇÃO DOS SALÁRIOS NA AGROPECUÁRIA BRASILEIRA -PERÍODO DE 1971 a 1996
}

\author{
Autor: JEFFERSON ANDRONIO RAMUNDO STADUTO \\ Orientador: Prof. Dr. CARLOS JOSÉ CAETANO BACHA
}

\section{RESUMO}

Este trabalho analisa o comportamento dos salários agrícolas e estima modelos de determinação de salário de equilíbrio para os trabalhadores temporários e permanentes no Brasil e nas regiões com o setor agropecuário menos e mais tecnificado. Para efeito de análise, tomou-se em consideração o período de 1971 a 1996. O mercado de trabalho agrícola foi segmentado em duas categorias de trabalhadores: temporários e permanentes. Para tanto, considerourse que nesse mercado de trabalho há duas estruturas salariais distintas (para trabalhadores temporários e permanentes) e que os processos históricos de formação dessas duas categorias de trabalhadores têm características particulares. Para analisar a determinação dos salários agrícolas em termos de regiões, as unidades da Federação foram agrupadas segundo o grau de tecnificação: região menos tecnificada (Acre e os estados da região Nordeste, exceto Piauí) e a região mais tecnificada (estados das regiões Centro-Oeste, Sudeste e Sul). Nos modelos econométricos desenvolvidos foram considerados aspectos inerentes ao mercado de trabalho agrícola e aspecto institucional, no caso o salário mínimo. As equações foram estimadas com os dados em pooling. As análises estatísticas indicaram que os termos de 
erro das equações estimadas têm estruturas de "componentes" (two way). Para tanto, aplicou-se o procedimento econométrico de Fuller \& Battese. Os resultados indicaram que a equação estimada de determinação dos salários dos trabalhadores temporários no Brasil não apresentou bons resultados, sendo que os coeficientes do salário mínimo $(W M)$ e a da relação de preços recebidos e pagos pelos produtores rurais $(\mathrm{Pa})$ não foram estatisticamente significativos. No entanto, nas equações estimadas nas regiões menos e mais tecnificadas, o $W M$ foi altamente significativo estatisticamente. Já o coeficiente estimado da variável $P a$ não foi significativo estatisticamente para as demais equações. O coeficiente do salário alternativo $(W U)$ foi de sinal positivo e significativo estatisticamente em todas as equações estimadas para o segmento do mercado de trabalho temporário. O coeficiente da produtividade do trabalho (Pmo) também foi significativo estatisticamente e com sinal positivo, exceto para a equação da região mais tecnificada, na qual o sinal foi negativo, isto é, contrário ao esperado. Neste caso verificou-se um processo de transferência de renda do trabalho para o fator de produção capital. As estimativas das equações dos salários dos rabalhadores permanentes no Brasil e nas regiões menos e mais tecnificadas apresentaram comportamentos semelhantes. Das três variáveis explicativas ( $\mathrm{WM}, \mathrm{Pa}, \mathrm{Pmo}$ ) consideradas nos modelos, apenas o coeficiente de $P a$ não foi significativo estatisticamente. De modo geral, o coeficiente com maior valor e o mais significativo foi o salário mínimo. Ele tem funcionado como um indexador dos salários agrícolas, tal como evidencia a literatura sobre a mão-de-obra não-qualificada do setor urbano. No entanto, a institucionalização do salário mínimo no mercado de trabalho agrícola não foi suficiente para garantir que os salários dos trabalhadores temporários e permanentes na região menos tecnificada fossem igual ou superior ao mínimo. Apesar do grande crescimento da produtividade do trabalho (Pmo), esta afetou mais significativamente os salários da mão-de-obra permanente. Por outro lado, no caso dos trabalhadores temporários na região mais tecnificada, observe-se uma transferência de renda do fator trabalho ao capital (is to é, o coeficiente de Pmo foi negativo). Dos resultados econométricos obtidos no presente trabalho, pode-se afirmar que a determinação dos salários agrícolas, de modo geral, tem 
um forte componente institucional (salário mínimo) e os fatores de mercado têm papel menos relevante. 


\title{
DETERMINATION OF THE BRAZILIAN AGRICULTURAL WAGES - FROM 1971 TO 1996
}

\author{
Author: JEFFERSON ANDRONIO RAMUNDO STADUTO \\ Advisor: Prof. Dr. CARLOS JOSÉ CAETANO BACHA
}

\section{SUMMARY}

This paper analyzes the performance of rural wages and it also estimates wage equations for temporary and permanent workers. The analyzed time period is 1971 through 1996, and three aggregations of wages were considered: for the entire Brazil, for the region with more sophisticated agriculture and for the region with less sophisticated agriculture. Agricultural labor force was divided into two categories: temporary and permanent workers. It was considered that agricultural labor market has two different wage structures, for temporary and permanent workers, and the historic process of labor market formation created particular features for these workers. The analysis was conducted considering wages paid for entire Brazil and for two regions. The states were aggregated according to their agriculture's technical level. The state of Acre and Northeast Brazil's states, except the state of Piaui, form the less sophisticated agricultural region. The states of Center-Western, Southeast and Southern Brazil form the more sophisticated agricultural region. In order to determine the econometric equations, both market-oriented variables and institutional variables were considered as independent variables. Minimum wage is the institutional variable considered. By using pooling techniques, rural wage equations were estimated. The error has a component 
structure. Due to that, the Fuller \& Battese technique was used. The results for temporary workers' wage equation was not good when wages were aggregated for the entire Brazil. The coefficients for minimum wage $(W M)$ and the ratio between received and paid prices $(\mathrm{Pa})$ were not statistically significant. Better econometric results appeared for temporary workers' wage equations when wages were aggregated in two regions. The coefficients of minimum wage $(W M)$ were statistically significant. The coefficient of $\mathrm{Pa}$, however, was not statistically significant. The coefficient of alternative wage $(W U)$ was positive and statistically significant. The same results appeared for the labor productivity coefficient (Pmo), except for the temporary workers' wage equation for the more sophisticated region. In the latter region, income transfer happened from the temporary workers to the capital owners. Similar results were found for permanent workers' wage equations estimated for the entire Brazil and its two regions. All independents variables but $P a$ were statistically significant. Generally, the biggest and the most statistically significant coefficient appeared for the minimum wage variable. It has worked as an indexation for the rural wages, in the same way that the economic literature proved it for the unskilled, urban workers. However, the minimum wage law is not enough to prevent the rural workers in receiving a wage below the minimum wage. Despite the huge labor productivity increase, Pmo affected more the permanent workers' wages. In the more sophisticated region, there is an income transfer from temporary workers to the capital owners, because the estimated coefficient of Pmo is negative. From the above results, it is possible to state that rural wage is strongly determined by institutional forces, such as minimum wage, and market forces have a smaller influence on rural wages. 


\section{INTRODUÇÃO}

\subsection{Apresentação}

Este trabalho analisa o comportamento dos salários agrícolas e estima modelos de determinação do salário de equilíbrio para os trabalhadores temporários e permanentes no Brasil e nas regiões com o setor agropecuário menos e mais tecnificado. Para efeito de análise, toma-se em consideração o período de 1971 a 1996, para o qual se têm informações sistemáticas.

Os estudos sobre a determinação dos salários da mão-de-obra não-qualificada no Brasil são fundamentais para compreender o funcionamento desse mercado de trabalho e a distribuição funcional da renda (participação relativa dos salários e lucros na renda). A literatura localiza esse tipo de mão-de-obra em vários ramos industriais, mas em especial na construção civil, especialmente na ocupação de servente de pedreiro. $\mathrm{O}$ setor agropecuário é tradicionalmente analisado como um mercado de trabalho formado por mão-de-obra não-qualificada, sendo esta última normalmente enquadrada nas categorias de trabalhadores permanentes e temporários. Esses trabalhadores são empregados nas mais diversas ocupações possíveis no universo produtivo da agricultura e pecuária brasileira. 
A rápida mudança na estrutura produtiva brasileira, ocorrida na segunda metade do século XX, alterou a posição de liderança do setor agropecuário na composição da renda nacional e na geração de emprego. O setor agropecuário passou para uma situação de menor destaque em relação à que tinha em períodos anteriores.

Neste contexto, ocorreu intensa migração do meio rural para o urbano, sendo este um dos componentes que formou o mercado de trabalho de mão-de-obra nãoqualificada urbana, principalmente nos períodos iniciais de rápido crescimento urbano. A grande transferência de trabalhadores agrícolas para as atividades urbanas traçou um sentido de integração entre os mercados de trabalho urbano e agrícola.

Nas fases finais desse crescimento e consolidação do setor urbano, a integração desses dois mercados de trabalho ainda ocorre através do processo descrito (migração campo-cidade), mas em menor intensidade. Mais recentemente, tem ocorrido a mobilidade dos trabalhadores agrícolas entre as atividades agrícolas e não-agrícolas dentro do próprio meio rural.

Apesar da redução de importância do setor agropecuário na composição da renda nacional nas últimas décadas, a População Economicamente Ativa (PEA) rural ainda responde por cerca de $24 \%$ do total da PEA nacional (PNAD, 1999). Trata-se de um setor que absorve número expressivo de trabalhadores não-qualificados na economia nacional.

Recentemente, os estudos de Silva (1999) e Del Grossi \& Silva (1999) mostraram, de maneira mais precisa, que a fonte de renda da população que vive no meio rural não resulta exclusivamente das atividades agrícolas. A importância do trabalho não-agrícola na composição da renda familiar no meio rural é uma das características importantes da agropecuária brasileira ${ }^{1}$. Segundo Del Grossi \& Silva (1999), há trabalhadores que vivem no meio rural dedicando-se somente às atividades

\footnotetext{
${ }^{1}$ Este aspecto já tinha sido ressaltado por Schuh \& Alves (1971).
} 
não-agrícolas; outros combinam atividades agrícolas e não-agrícolas; e há, ainda, aqueles que se dedicam exclusivamente às atividades agrícolas.

As atividades não-agrícolas vêm assumindo maior importância na renda das famílias residentes no meio rural. No entanto, as atividades agrícolas e, em particular, os salários agrícolas ainda têm forte impacto na renda da PEA do setor agropecuário. Segundo Kageyama (1997), em 1995 o subemprego agrícola, ou seja, os indivíduos da PEA agrícola com baixa renda, estavam radicados em algumas formas familiares de trabalho: conta própria, autoconsumo e não-remunerados. Os trabalhadores assalariados estão em ocupações de melhor qualidade em relação aos não-assalariados. Este problema agrava-se nas regiões de agropecuária mais atrasada, como nos estados do Nordeste e em Tocantins. A região Sul também tem níveis altos de subemprego, apesar de não ser tão grave quanto nas demais regiões.

As ocupações não-agrícolas têm remunerações maiores que as atividades agrícolas. Esse diferencial de salário deveria fazer com que os trabalhadores mudassem de ocupação, mesmo que houvesse algum tipo de custo de deslocamento de domicílio. No entanto, os trabalhadores agrícolas não encontram trabalho em outras ocupações ou enfrentam barreiras para entrar nesse mercado por falta de qualificação. Apesar das pesquisas recentes quantificarem a importância da renda não-agrícola no meio rural, o trabalho na atividade agrícola assume papel vital no bem-estar das famílias que têm os seus membros empregados no setor agropecuário.

Dentro deste quadro sobre ocupações no meio rural brasileiro, é importante a distinção entre salário e rendimento do trabalho. O salário é a remuneração em dinheiro recebida pelo trabalhador pela venda de sua força de trabalho por certo período de tempo. No caso dos salários agrícolas, a venda da força de trabalho é efetuada para as unidades produtivas do setor agropecuário. Por outro lado, o rendimento do trabalho, segundo o critério da Pesquisa Nacional por Amostra de Domicílio (PNAD), é a remuneração bruta mensal a que normalmente o trabalhador tem direito, ou o que ele conseguiu obter. Portanto, o rendimento do trabalho depende do salário e da quantidade 
de tempo de serviço vendida pelo trabalhador. Na contabilização do rendimento do indivíduo nas PNADs, são totalizados os provimentos do trabalho principal, do secundário e dos demais trabalhos que a pessoa exerceu. Não é considerado o valor da produção para o consumo próprio. Neste estudo são analisados os determinantes somente dos salários dos trabalhadores agrícolas.

A análise do salário agrícola não pode ser realizada sem se considerar o processo de modernização da agropecuária brasileira. Os trabalhos de Ávila \& Evenson (1995), Gasques \& Conceição (1997), Dias \& Bacha (1998), Conceição (1998), Bonelli \& Fonseca (1998) e Barros (1999) demonstram que, nas últimas três décadas, o processo de modernização da agropecuária brasileira resultou em um consistente aumento da produtividade total dos fatores na agricultura ${ }^{2}$. As medidas parciais de produtividade do trabalho e da terra, conforme publicações de Hoffmann et al. (1985), Kageyama (1986) Hoffmann \& Jamas (1990), Carvalho (1993) e Guerreiro (1995), também apontam para o aumento da produtividade dos fatores. Esses autores evidenciam a importante participação da produtividade do trabalho para o desempenho do setor agropecuário.

$\mathrm{O}$ crescimento da produção agropecuária brasileira demonstra que o impasse existente nos anos 60 sobre a capacidade do setor em responder às necessidades do setor urbano-industrial foi superado. Isto ocorreu, em parte, devido ao aumento da produtividade dos fatores por meio da incorporação de tecnologia. No entanto, poucas respostas foram dadas sobre como esse desempenho positivo do setor agropecuário está afetando a remuneração dos trabalhadores agrícolas.

Nas diversas regiões, a produtividade dos fatores teve comportamento diferenciado, acompanhando a intensidade do processo de modernização da agropecuária nacional e de outros fatores institucionais. Há uma vasta literatura ${ }^{3}$ que analisa o impacto diferenciado das políticas setoriais no processo de modernização da

\footnotetext{
${ }^{2}$ A produtividade total dos fatores pode ser entendida como as alterações no produto em decorrência das mudanças qualitativas dos insumos, ou seja, o aumento do produto que não é devido ao aumento quantitativo do uso dos insumos.

${ }^{3}$ Ver Barros (1979), Mello (1979), Fonseca \& Staduto (1994) e Staduto \& Freitas (2001).
} 
agropecuária nas regiões brasileiras. De modo geral, estas publicações destacam, em particular, o papel do crédito rural oficial, o qual disponibilizou fundos prioritariamente para algumas regiões e produtos. As regiões mais beneficiadas foram o Centro-Oeste, Sudeste e Sul e, por outro lado, as regiões Norte e Nordeste obtiveram menos vantagens neste processo.

As consequiências da modernização do setor agropecuário foram o aumento da produção e produtividade de maneira diferenciada, em razão da intensificação técnica desigual no processo produtivo. Com efeito, é de se esperar que os salários agrícolas também tendem a apresentar um comportamento que refletem a modernização do setor, as características regionais e os ciclos de expansão e contração da economia nacional ou regional.

Além dessas variáveis que podem influenciar os salários agrícolas, há, também, fatores institucionais, como o salário mínimo. No entanto, pouco se conhece sobre o papel do salário mínimo na determinação dos salários agrícolas. Se o salário mínimo funcionar como um indexador dos salários agrícolas, os efeitos da modernização da agropecuária sobre os salários agrícolas poderão ser reduzidos.

No contexto descrito acima, torna-se evidente a importância de se analisar o comportamento e os determinantes dos salários agrícolas no Brasil, bem como nas regiões menos e mais tecnificadas, nas últimas três décadas. Neste período, consolidaram-se também algumas mudanças na estrutura da economia nacional, tais como a redução da renda e do emprego do setor agropecuário e a expansão do setor urbano-industrial, entre outras mudanças. 


\subsection{Objetivos}

O objetivo geral do presente trabalho é analisar o comportamento dos salários agrícolas e estimar modelos de determinação de salário de equilíbrio dos trabalhadores temporários e permanentes no Brasil e nas regiões com o setor agropecuário menos e mais tecnificado. Para tanto, considerou-se o período de 1971 a 1996, para o qual há dados sistemáticos. Este período também coincide com os anos de intensificação do processo de modernização do setor agropecuário brasileiro.

Os objetivos específicos do trabalho são:

a) elaborar o modelo teórico de determinação dos salários agrícolas que considere a segmentação do mercado de trabalho e o papel do salário mínimo como indexador;

b) analisar a evolução da literatura sobre o mercado de trabalho agropecuário e o papel assumido pelo salário mínimo neste mercado;

c) formular modelos e procedimentos econométricos necessários à determinação dos salários de equilíbrio dos trabalhadores temporários e permanentes no Brasil; e

d) comparar os modelos estimados de determinação dos salários de equilíbrio dos trabalhadores temporários e permanentes entre as regiões menos e mais tecnificadas.

\subsection{Organização do trabalho}

O presente trabalho compõe-se de seis capítulos, incluindo esta introdução. No capítulo 2, apresenta-se o referencial teórico do estudo. No capítulo 3, avalia-se a literatura sobre o mercado de trabalho da mão-de-obra não-qualificada e a evolução do mercado de trabalho agropecuário e dos salários agrícolas, destacando-se lacunas que 
motivaram a realização deste estudo. No capítulo 4, são apresentados os modelos econométricos de determinação dos salários agrícolas de equilíbrio para as categorias dos trabalhadores temporários e permanentes, definindo as equações que são estimadas. Além disso, também são discutidos os procedimentos para obter as variáveis que compõem as equações estimadas. No capítulo 5, são apresentados e analisados os resultados da estimação dos modelos. Finalmente, no capítulo 6, são apresentadas as conclusões do trabalho. 


\section{REFERENCIAL TEÓRICO}

O presente trabalho utiliza o corpo teórico neoclássico para definir os modelos de determinação de salário agrícola de equilíbrio em concorrência perfeita no Brasil e regiões (com o setor agropecuário menos tecnificado e mais tecnificado). Este corpo teórico tende a ser mais adequado para investigar o mercado de trabalho agrícola, considerando que, no seu conjunto, a mão-de-obra agrícola é não-qualificada, ainda que pese a forte tendência de crescimento dos postos de trabalho especializados nas atividades agropecuárias.

Quando se compara a mão-de-obra agrícola com o grau de especialização e de especificidade dos postos de trabalho alcançados por alguns ramos de atividades dos setores de indústria e de serviço, conclui-se que a agropecuária, como um todo, é bastante incipiente quanto ao número de postos de trabalho com maior especialização. Portanto, a mão-de-obra no setor agropecuário, em sua grande maioria, pode ser considerada não-especializada.

Este capítulo é composto por três seções. Na primeira (item 2.1), é apresentada a teoria neoclássica do mercado de trabalho. Esta seção, por sua vez, é subdividida em três partes: mercado de trabalho em concorrência perfeita sem restrições (subitem 2.1.1), mercado de trabalho em concorrência perfeita com restrições (subitem 2.1.2) e mercado de trabalho monopsônio (subitem 2.1.3). Na segunda seção (item 2.2), 
é apresentada uma breve abordagem teórica dos mercados de trabalho segmentados ${ }^{4}$. $\mathrm{Na}$ terceira seção (item 2.3), elabora-se um modelo segmentado do mercado de trabalho onde o salário mínimo surge como indexador do salário demandado pelos trabalhadores.

\subsection{Mercado de trabalho no modelo neoclássico}

Considerando inicialmente os autores clássicos, verifica-se que eles deram grandes contribuições e lançaram as bases para as teorias mais modernas sobre mercados de trabalho e determinação dos salários. Os fundamentos clássicos do mercado de trabalho foram, até recentemente, aplicados em alguns modelos duais de desenvolvimento econômico ${ }^{5}$. No entanto, a teoria clássica, mais recentemente, não tem sido aplicada como instrumental analítico para estimar os modelos de determinação de salários. A teoria neoclássica em competição perfeita no mercado de trabalho pode ser vista como uma evolução dos modelos clássicos e, portanto, ela é mais utilizada na análise da determinação de salários, principalmente nos setores mais concorrenciais da economia.

A teoria neoclássica de alocação dos fatores é aplicada em várias pesquisas publicadas, principalmente, na literatura internacional. Esses estudos procuram fundamentar analiticamente as motivações dos agentes econômicos para mudar de atividade. Por exemplo, a teoria de alocação dos fatores analisa o deslocamento da força de trabalho dos pequenos produtores para o mercado de trabalho, ou as motivações que levam os trabalhadores a empregarem-se em outros setores da economia. Apesar de ser aplicada em vários estudos, a teoria neoclássica de alocação dos fatores é uma

\footnotetext{
${ }^{4}$ Os fundamentos das abordagens do mercado de trabalho segmentado são apresentados neste capítulo em razão de fornecer elementos para uma melhor concepção analítica do mercado de trabalho agrícola. Além disso, eles contribuem para a formulação do modelo empírico deste trabalho.

5 O trabalho de Lewis (1969) foi o propulsor para os modelos duais. Jorgenson (1975) compara os modelos duais que adotam pressupostos dos mercados de trabalho clássico e neoclássico.
} 
abordagem que apenas tangencia o tema central desta pesquisa, que é a determinação dos salários agrícolas. No Apêndice 1 são apresentados alguns estudos empíricos aplicando aquela teoria.

\subsubsection{Mercado de trabalho em concorrência perfeita}

A teoria da síntese neoclássica ${ }^{6}$ foi formulada a partir do artigo publicado por Hicks (1937) sobre as pressuposições teóricas de John Maynard Keynes no seu livro "Teoria Geral do Emprego, do Juro e da Moeda", publicado em 1936. A partir das críticas de Hicks a Keynes, a abordagem analítica sobre o mercado de trabalho tornou-se alvo das atenções nos debates teóricos.

$\mathrm{Na}$ Teoria Geral, Keynes fazia um ataque aos postulados dos autores que ele denominava como clássicos. Entretanto, apesar da tentativa de Keynes de diferenciar a sua teoria em relação aos autores clássicos, segundo Hicks (1937), ela era essencialmente a mesma, sendo apenas um caso particular, quando ocorresse rigidez salarial acima do salário de equilíbrio. Neste sentido, a contribuição de Keynes seria mais limitada, restringindo-se à construção de uma teoria que relaciona o "lado real" da economia com o "lado monetário". Segundo Lima (1992):

"ao permitir que a tradição neoclássica retratasse duas posições doutrinárias opostas, quais sejam, a clássica e a keynesiana, o referido modelo acabou produzindo uma concordância generalizada sobre uma assertiva equivocada, a saber, que Keynes teria meramente realizado um exercício teórico tipicamente ortodoxo".(Lima, 1992, p.32)

\footnotetext{
${ }^{6}$ Vários autores referem-se à teoria da síntese neoclássica simplesmente como teoria neoclássica, e ainda há outros autores que a chamam de teoria keynesiana, referindo-se ao modelo IS-LM e suas variações.
} 
Dessa forma, para os economistas com formação neoclássica, Keynes teria estudado um caso particular na economia, o que não constituiria uma teoria geral. Notase que há uma polêmica aberta sobre a contribuição da teoria de Keynes sendo que, de certa forma, o mercado de trabalho é o eixo de tais discussões.

Segundo Amadeo \& Estevão (1994), o ponto de partida para a análise da teoria neoclássica é o mercado de trabalho. A determinação do salário não é uma mera repetição dos argumentos pré-keynesianos, ou seja, dos clássicos, pois os neoclássicos apresentam novos instrumentos de análise (Swaelen, 1982). Conforme Solimano (1988), os modelos pré-keynesianos do mercado de trabalho enfatizam o pleno emprego como o estado normal de funcionamento da economia. No enfoque dos economistas neoclássicos sobre o mercado de trabalho, embora sejam mantidas as hipóteses de equilíbrio de mercado, é enfatizado o papel da incerteza e da informação imperfeita na geração de flutuações do emprego durante os ciclos econômicos.

No modelo neoclássico para o mercado de trabalho, o nível de emprego é determinado pela igualdade entre a oferta e demanda por trabalho. A oferta de trabalho deriva-se da maximização de uma função utilidade do indivíduo, que tem uma relação positiva com o consumo de bens e lazer. Este último depende negativamente do número de horas trabalhadas, ou seja, o trabalho tem a propriedade de desutilidade. A oferta de trabalho baseia-se no processo de escolha do quanto o indivíduo estará disposto a renunciar de lazer para auferir rendimentos que tornaria factível o seu plano de consumo, dada a estrutura de preços relativos da economia.

Por outro lado, a demanda por mão-de-obra é determinada pela maximização do lucro das empresas sujeitas a uma restrição de tecnologia, sendo esta dada por uma função de produção, operando em um mercado de competição perfeita. Desta forma, a curva de demanda por trabalho em um espaço gráfico número de trabalhadores versus salário real é idêntica à curva que relaciona um determinado nível de emprego à sua produtividade marginal. 
O Gráfico 1 ilustra o equilíbrio no mercado de trabalho, no qual $L^{S}$ e $L^{D}$ são, respectivamente, oferta e demanda por trabalho; $w_{e}$ é o salário real de equilíbrio; e $L_{o}$ é quantidade de trabalho empregada no equilíbrio.

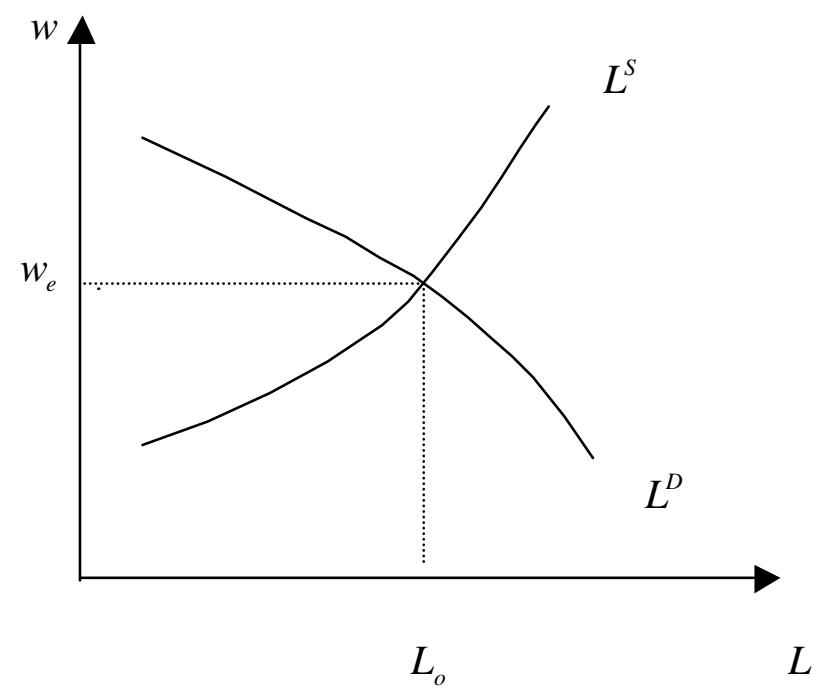

Gráfico 1 - Equilíbrio no mercado de trabalho em concorrência perfeita.

O equilíbrio no mercado de trabalho apresenta três propriedades fundamentais:

a) não existe desemprego involuntário, ou seja, todos os trabalhadores que se oferecem, ao salário vigente, encontram emprego;

b) os rabalhadores igualam seu salário real ao custo marginal do trabalho, ou seja, do lazer sacrificado. Portanto, eles maximizam a sua função utilidade; e

c) as empresas igualam o produto marginal do trabalho ao salário real, maximizando seus lucros. 
O salário real é o preço que equilibra o mercado de trabalho. As implicações de políticas nessa abordagem são no sentido de aperfeiçoar o funcionamento do mercado de trabalho, eliminando os fatores que interferem no mecanismo livre determinação dos salários reais, tais como: os impostos sobre a mão-de-obra, as leis de estabilidade do emprego, o salário desemprego, o salário mínimo e a ação sindical. Pode-se agrupar esses mecanismos de desajuste em fatores institucionais e sindicais. Se o mercado funcionar livremente, o pleno emprego será atingido. Mas, se houver barreiras para esse funcionamento, haverá desemprego.

Como a demanda por mão-de-obra depende da produtividade do trabalho, tem-se que o aumento de tal item (devido a uma melhoria tecnológica) desloca a curva de demanda de trabalho para a direita, implicando maior salário real de equilíbrio.

Nas próximas subseções (itens 2.1.2 e 2.1.3) são apresentados outros modelos neoclássicos de determinação de salários agrícolas onde se avaliam o papel do salário mínimo sobre o nível de emprego e salário de equilíbrio.

\subsubsection{Mercado de trabalho em concorrência perfeita com restrição}

O modelo de mercado de trabalho em concorrência perfeita torna-se mais realista quando se introduz as imperfeições de mercado como, por exemplo, a presença ativa dos sindicatos ou de restrições institucionais, como a imposição do salário mínimo. Esta última restrição implica, basicamente, em efeito negativo ou efeito nulo sobre o nível de emprego.

Gallasch (1975) propôs um modelo estrutural para o mercado de trabalho agrícola com quatro equações: oferta, demanda, excesso de oferta e oferta igual à demanda. $\mathrm{O}$ autor queria analisar os efeitos do salário mínimo sobre os níveis de salário e emprego. A equação de excesso de oferta introduz neste mercado de trabalho uma 
possibilidade de análise mais realista ${ }^{7}$, no qual o excesso de oferta, para o autor, ocorreria em função do salário mínimo encontrar-se acima do salário de equilíbrio do setor agropecuário.

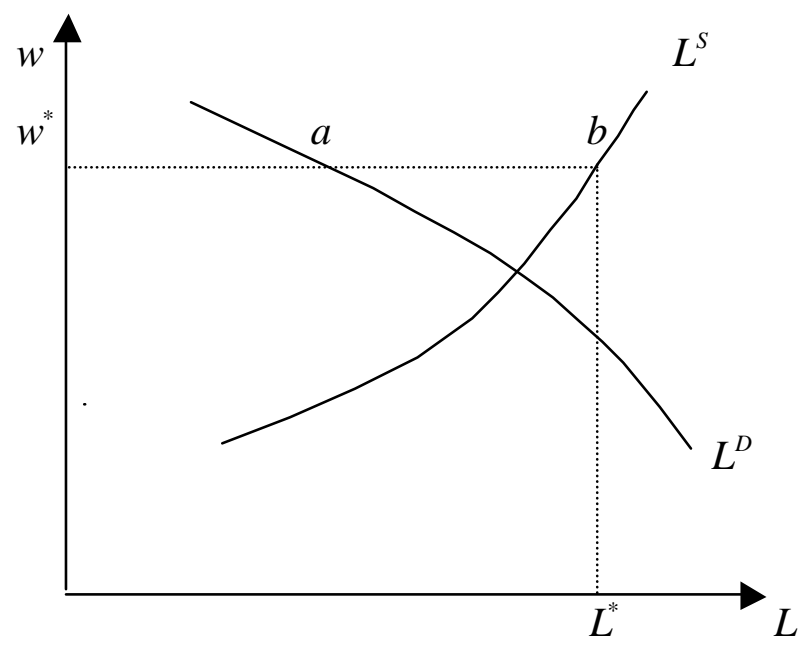

Gráfico 2 - Equilíbrio no mercado de trabalho em concorrência perfeita com restrição.

O Gráfico 2 ilustra a curva de oferta e demanda por trabalho em um espaço gráfico número de trabalhadores versus salário real. Esse gráfico mostra o salário mínimo $\left(w^{*}\right)$ acima do salário de equilíbrio do mercado, gerando, dessa forma, um excedente de oferta em relação à demanda dado pelo segmento $\overline{a b}$. Para que esta situação ocorra, todas as firmas estão pagando pelo menos um salário mínimo para os trabalhadores. Neste caso, o salário mínimo acarreta efeito negativo sobre o nível de emprego e positivo para os trabalhadores que estiverem empregados. Quando ocorre esta situação, o modelo estrutural de Gallasch (1975) é formado pelas quatro equações citadas. Já o efeito nulo do salário mínimo sobre o nível de salário agrícola e de

${ }^{7}$ O efeito do salário mínimo no nível de emprego e salários no mercado de trabalho agrícola é analisado com mais detalhes no capítulo 3 . 
emprego ocorreria quando o equilíbrio do mercado de trabalho está acima deste salário mínimo $\left(w^{*}\right)$. Conseqüentemente, o modelo estrutural de Gallasch (1975) estaria formado por apenas três equações, pois não haveria excedente de mão-de-obra.

Segundo Gallasch (1975), uma terceira situação ainda mais realista considera que nem todas as firmas remunerariam os trabalhadores com pelo menos um salário mínimo. Os salários estariam acima ou abaixo do mínimo. Conforme o autor, nesta situação, os níveis de salário e emprego dados pelo equilíbrio entre oferta e demanda resultam do nível de desequilíbrio que o salário mínimo provoca na demanda por mãode-obra.

No modelo estrutural, da forma que foi proposto por Gallasch (1975), conforme evidencia o próprio autor, há uma dificuldade em estimar a equação de excedente de oferta em razão da limitação de informações sobre a oferta de mão-de-obra no setor agropecuário. Poder-se-ia, alternativamente, obter uma estimativa por meio do nível de desemprego no setor agropecuário, que deve consistir em uma proxy para o excedente de oferta de mão-de-obra.

Neste caso, as estatísticas são normalmente precárias, principalmente, quando se trata da mão-de-obra que não se dedica integralmente ao setor agropecuário. Como exemplo, citam-se os trabalhadores temporários que alternam empregos agrícolas e urbanos.

Gallasch (1975) aplicou a abordagem da equação na forma reduzida nas três situações. Na ausência de informações sobre o excedente de oferta de mão-de-obra, não poderia ser estimado um modelo estrutural com as quatro equações, mais especificamente, no caso em que o salário mínimo encontra-se acima do salário de equilíbrio. Outros estudos também aplicaram a forma reduzida (Gardner, 1972; Gallasch et al, 1978; Gasques, 1981; Dickens et al., 1995). 


\subsubsection{Mercado de trabalho monopsônico}

Os modelos de mercados de trabalho monopsônicos são apresentados usualmente como exemplo de concorrência imperfeita nos manuais de microeconomia e de economia do trabalho. Os mercados monopsônicos de produto ou de insumo assumem os mesmos pressupostos descritos anteriormente para um mercado de concorrência perfeita (item 2.1.1). Entretanto, no mercado de fatores monopsônicos, há apenas um demandante de mão-de-obra, com poder de monopólio sobre a contratação da mão-de-obra. No caso de apenas um insumo variando, ou seja, o número de

trabalhadores ou horas trabalhadas na função de produção, o mercado alcança o equilíbrio quando a despesa marginal do trabalho se iguala à sua receita marginal. A partir desse equilíbrio, encontra-se a quantidade de trabalhadores que estarão dispostos a trabalhar a um dado nível salarial, considerando que esta firma monopolística não se defronta com uma curva de oferta perfeitamente elástica.

Dickens et al. (1995) aplicaram um modelo monopsônico para analisar os possíveis efeitos do salário mínimo sobre o mercado de trabalho. Segundo esses autores, é mais real pressupor que os trabalhadores agrícolas apresentam pouca mobilidade no espaço rural, em decorrência do grande vínculo que têm com o local de moradia. Portanto, não há perfeita mobilidade dos trabalhadores. Além disso, os autores acreditam que, na realidade, as informações sobre empregos alternativos devem ser imperfeitas. Considerando estes argumentos, compõe-se uma situação em que a oferta de mão-deobra para um empregador individual não deve ser perfeitamente elástica. Dessa forma, o mercado de trabalho deve ser considerado monopolístico.

Os modelos de mercado monopolístico admitem incorporar restrições sindicais ou institucionais, como o salário mínimo. Os efeitos dessas restrições sobre o nível de salário e emprego vigentes no mercado de trabalho podem ser positivo, negativo ou nulo. Cada uma dessas situações depende da posição do salário de equilíbrio em relação à restrição imposta a esse mercado. 
O Gráfico 3 ilustra o efeito do salário mínimo para uma firma monopsônica no mercado de fatores, neste caso, no mercado de trabalho ${ }^{8}$. Esse gráfico mostra a curva de oferta de trabalho $\left(L^{S}\right)$ em um espaço gráfico número de trabalhadores versus salário real. O efeito do salário mínimo dependerá da posição da curva da receita marginal do trabalho ( $R M g L)$ em relação ao nível do salário mínimo. Segundo Dickens et al. (1995), o efeito nulo do salário mínimo, assim como na concorrência perfeita, ocorre quando o salário de equilíbrio encontra-se acima do mínimo. Neste caso, esta firma tem a curva de receita marginal do trabalho representada por $R M g L_{1}$. Esta intercepta a curva de despesas marginal $(D M g L)$ no ponto A. Transpondo este ponto para curva $L^{S}$, encontrase o equilíbrio (ponto A') empregando $L_{1}$ trabalhadores ao nível salarial de $w_{1}$.

O efeito positivo do salário mínimo sobre os níveis de emprego e salário pode ser ilustrado partindo do equilíbrio inicial dado pela interseção entre a curva da receita marginal $R M g L_{2}$ e a curva $D M g L$ (pontoB), e transpondo este ponto para a curva $L^{S}$, encontra-se (ponto B') $L_{2}$ trabalhadores empregados ao nível salarial de $w_{2}$. Caso seja institucionalizado um salário mínimo $w^{*}$, a firma defrontaria com uma curva de oferta dada pelo segmento $\overline{w^{*} a L^{S}}$, e a correspondente curva de despesa marginal do trabalho $(D M g L)$ representada pelo segmento $\overline{w^{*} a b D M g L}$. Nesta situação o emprego expande de $L_{2}$ para $L^{*}$, e o salário aumenta de $w_{2}$ para $w^{*}$, reduzindo, desta forma, os ganhos monopolísticos do empregador. Dickens et al (1995) sugerem não pensar em ganhos monopolísticos. Esses ganhos deveriam de fato existir somente quando uma substancial proporção de trabalhadores estivesse estreitamente vinculada com o local de moradia, o que provocaria uma drástica redução da mobilidade desses trabalhadores.

O Gráfico 3 ilustra, também, o efeito negativo do salário mínimo sobre o nível de emprego. Considerando-se o equilíbrio inicial dado pela interseção entre a curva de receita marginal do trabalho $R M g L_{3}$ e a curva $D M g L$ (ponto C), e transpondo este

\footnotetext{
${ }^{8}$ Mais detalhes sobre o modelo monopsônico ver Ferguson (1991).
} 
ponto para a curva $L^{S}$, encontra-se (ponto C') $L_{3}$ trabalhadores empregados ao nível salarial $w_{3}$. Caso seja institucionalizado um salário mínimo $w^{*}$, a firma defrontar-se-ia com uma curva de oferta dada pelo segmento $\overline{w^{*} a L^{S}}$, e a correspondente curva de despesa marginal do trabalho $(D M g L)$, representada pelo segmento $\overline{w^{*} a b D M g L}$. A firma maximizaria os lucros no ponto $e$, onde a despesa marginal se iguala à receita marginal do trabalho. Nesta situação, o emprego reduz de $L_{3}$ para $L_{31}$, e o salário aumenta $w_{3}$ para $w^{*}$, reduzindo, desta forma, os ganhos monopolísticos do empregador.

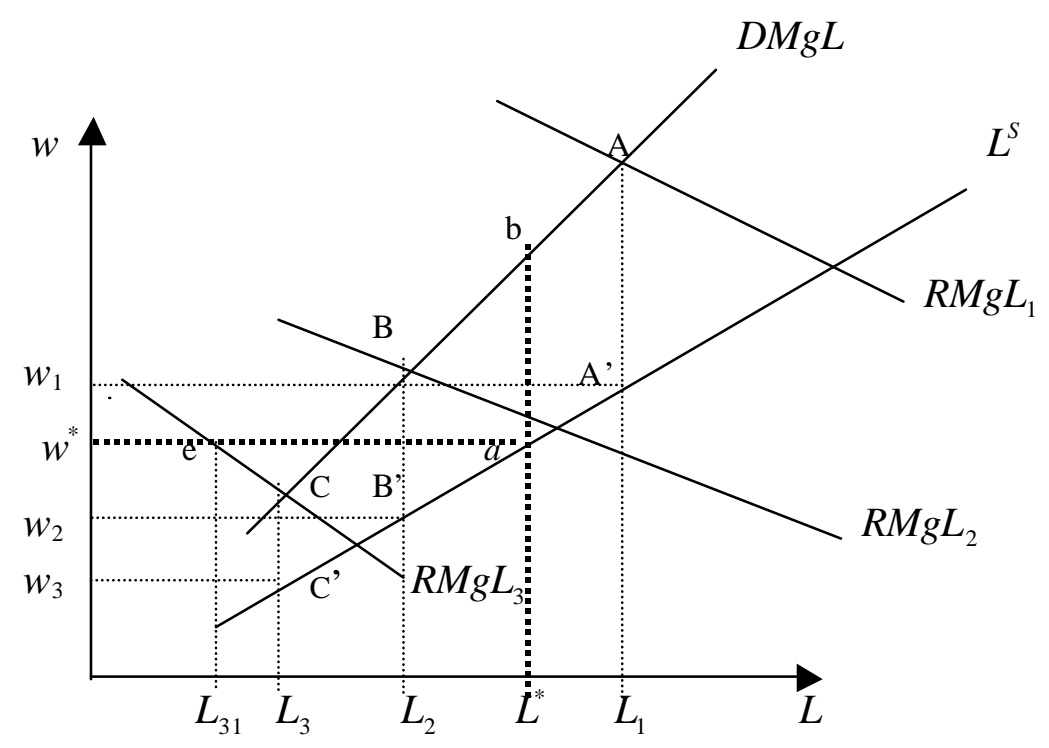

Gráfico 3 - Equilíbrio no mercado de trabalho monopsônico. 


\subsection{Mercado de trabalho segmentado}

A abordagem do mercado de trabalho segmentado é vastamente aplicada nas teorias de determinação de salário, bem como nas teorias que procuram explicar as diferenças salariais entre os ramos industriais. Já os estudos sobre o mercado de trabalho agrícola aplicando essa abordagem são menos freqüentes na literatura. No Apêndice 1 são apresentadas algumas das publicações com inspirações teóricas nos mercados segmentados.

Apesar dessa abordagem teórica aparentemente ser pouco adequada para analisar os mercados de mão-de-obra não-qualificada, ela torna-se relevante à medida que, neste estudo, são avaliados dois tipos de trabalhadores: os temporários e os permanentes. A abordagem do mercado de trabalho segmentado fornece elementos analíticos para considerar a formação de dois segmentos de trabalhadores dentro do mercado de trabalho agrícola.

Segundo Carneiro (1997), as teorias que adotam a abordagem do mercado de trabalho segmentado, de modo geral, diferenciam-se da teoria clássica e de alguns modelos da teoria neoclássica de mercado de trabalho, fundamentalmente, em razão de assumir que ocorre a institucionalização do mercado. Isto se traduz em um mercado de trabalho não-homogêneo e na existência de grupos não-competitivos, quando se pressupõe o relaxamento das hipóteses de perfeita mobilidade e substituição da força de trabalho.

Segundo Taubman \& Wachter (1986), os modelos neoclássicos também admitem a formação de segmentos nos mercados de trabalho. Há vários fatores que geram a segmentação do mercado, tais como os aspectos geográficos, biológicos, idade, união dos trabalhadores, leis e restrições à imigração, entre outros. Os autores afirmam que as teorias dos mercados segmentados são extremamente interessantes porque admitem causas mais abrangentes para a ocorrência de segmentação. 
$\mathrm{O}$ entendimento de segmento depende da abordagem teórica a ser considerada. Atualmente, há uma vasta literatura sobre o assunto, mas devem ser destacados os trabalhos pioneiros, como a publicação de Doeringer \& Piore (1971). Estes autores formularam um modelo teórico considerando a existência de um mercado interno de trabalho na firma. Eles estabeleceram a distinção entre os mercados internos e externos à firma. Os mercados internos - em contraposição aos mercados competitivos caracterizam-se por apresentar aspectos comportamentais relativamente independentes da situação do mercado de trabalho externo à empresa.

Os autores argumentam que os fatores mais importantes causadores dessas estruturas internas seriam as especificidades das qualificações dos empregados e da tecnologia adotada pela empresa, além do processo de treinamento recebido na firma e da formação de costumes internos. Dentre os costumes estabelecidos nos mercados internos, um dos mais importantes está relacionado com a estrutura de cargos e salários.

As firmas, com a intenção de formar uma força de trabalho estável, remuneram os seus trabalhadores em um nível superior ao custo de oportunidade. Desta forma, as firmas procuram restringir a mobilidade da mão-de-obra. A partir desse mecanismo, gera-se uma drástica redução da influência do mercado de trabalho na estrutura salarial interna da firma.

Doeringer \& Piore (1971) desenvolvem um modelo dual no qual o mercado de trabalho é dividido em primário e secundário. No mercado primário estariam concentrados os empregos do setor moderno da economia, com as ocupações que fornecem salários mais altos, estabilidade, melhores condições de trabalho e utilização de tecnologia avançada. Por outro lado, no mercado de trabalho secundário, concentramse os empregos com salários mais baixos, estagnação tecnológica e níveis elevados de desemprego.

Outro estudo importante sobre a segmentação do mercado de trabalho é o de Reich et al. (1973). Segundo estes autores, a segmentação do trabalho é um processo histórico pelo qual as forças políticas e econômicas estimulam a divisão interna do 
mercado de trabalho, dividindo-o em submercados ou segmentos que se diferenciam entre si pelas diferentes características do mercado de trabalho e por regras comportamentais de cada grupo de trabalhadores.

Portanto, a segmentação do mercado de trabalho é um processo histórico, não ocorrendo devido a uma determinação ad hoc dos patrões ou dos trabalhadores. Cada segmento do mercado de trabalho pode ser designado a partir do corte horizontal ao longo da hierarquia ocupacional, ou seja, pelas ocupações mais ou menos graduadas, bem como por um corte vertical, ou seja, pelas ocupações de um ramo industrial.

As abordagens mais recentes de segmentação são os modelos insidersoutsiders e salário eficiência. Ambas foram desenvolvidas em meados da década de $70 \mathrm{e}$ ao longo dos anos 80. A preocupação básica desses modelos foi a elucidação do fenômeno da rigidez dos salários reais nos países europeus, nos quais constatavam-se altas taxas de desemprego neste mesmo período. Tal situação era dificilmente explicada pelas teorias vigentes na época, motivando a formulação de novos pressupostos.

Os modelos insiders-outsiders têm como idéia básica a existência de conflito entre os trabalhadores empregados e os desempregados. Nestes modelos, as firmas maximizam lucros, sendo que o custo de rotatividade da mão-de-obra entra como argumento na função lucro.

Lindbeck \& Snower (1988) desenvolveram um modelo sobre o comportamento do mercado de trabalho que procura negar a existência de homogeneidade entre os trabalhadores empregados e desempregados, surgindo, desta forma, a idéia inicial dos modelos insiders-outsiders. Os trabalhadores insiders têm poder de barganha sobre o salário nominal, que é sustentado por três fontes: (a) os custos de empregar e demitir trabalhadores; (b) a cooperação entre os insiders e, por outro lado, a hostilidade destes em relação aos outsiders, que se candidatam para ocupar o posto de trabalho de um insiders; e (c) o efeito deletério que a rotatividade poderia causar sobre o grau de esforço dedicado à produção: os trabalhadores empregados esperam que o seu 
maior esforço seja recompensado no futuro. Caso a firma empregadora tenha aumento da taxa de rotatividade, isto pode desestimular o aumento desse esforço do trabalhador.

Os modelos do salário eficiência foram inicialmente formulados por Stiglitz (1974, 1976) e Bliss \& Stern (1978). Estes modelos têm como pressuposição básica a relação inversa à da abordagem neoclássica sobre a causalidade entre salário e produtividade. Na teoria do salário eficiência é a variação salarial que causa a alteração de produtividade 9 . Nos modelos de salário eficiência, a firma maximiza o lucro, sendo que o esforço do trabalhador no processo produtivo entra como argumento na função lucro da firma ${ }^{10}$.

O mecanismo de ajustamento dos modelos salário eficiência seria dado pela percepção do trabalhador de que um salário maior aumentaria os custos de oportunidade do seu emprego, dessa forma, reduzindo a negligência no trabalho, ou seja, aumentando a produtividade. Por outro lado, quando ocorre demissão de trabalhadores, as empresas têm custos associados à dispensa, recrutamento e treinamento. Nesse caso, quanto mais alta a especificidade da ocupação maior serão os custos incorridos pela empresa. Portanto, as firmas, com a finalidade de reduzir custos dessa natureza, pagam salários acima do equilíbrio.

As empresas podem também incorrer em custos quando oferecem baixos salários no caso de contratação de novos trabalhadores, pois podem sofrer problema de seleção adversa, isto é, as firmas, provavelmente, não estariam selecionando os melhores trabalhadores, pois estariam oferecendo salários abaixo do salário de reserva ${ }^{11}$ desses indivíduos.

Os modelos insiders-outsiders e salário eficiência apresentam muitos pontos em comum, no entanto, deve-se destacar que a grande diferença básica entre eles é o

\footnotetext{
${ }^{9}$ Leibenstein (1957) elaborou a hipótese básica dos modelos salário eficiência.

${ }^{10}$ Yellen (1984) faz a tipologia de quatro modelos com microfundamentos econômicos distintos para a teoria do salário eficiência. Katz (1986) acrescentou o quinto modelo: a ameaça sindical.

${ }^{11}$ Define-se salário de reserva como a remuneração mínima que um determinado trabalhador julga ser justa para aceitar um determinado posto de trabalho.
} 
poder de mercado que os trabalhadores insiders possuem, que é suficiente para elevar os custos associados à rotatividade da mão-de-obra. Desta forma, esses trabalhadores teriam condições de influenciar na decisão de emprego das firmas, assim como nas condições de determinar o seu nível salarial (Carneiro, 1997; Amadeo \& Estevão, 1994).

Não obstantes todas as abordagens existentes de mercado de trabalho segmentado, Taubman \& Wachter (1986) constatam que o mesmo pode ser segmentado segundo as estruturas de remuneração que existem dentro de um determinado setor. Isto significa, que se pode identificar os segmentos no mercado de trabalho à medida que se identificam diferentes mecanismos de determinação salarial. Ou ainda, em outras palavras é possível tirar uma ou mais linhas demarcatórias de segmentos de trabalho por meio da estrutura salarial de um ramo de atividade.

\subsection{Modelo de determinação dos salários considerando segmentação do mercado de trabalho e indexação via salário mínimo}

Os modelos discutidos no item 2.1 trataram o salário mínimo como uma variável $a d$ hoc às equações de demanda e oferta de trabalhadores. No entanto, se o salário mínimo for utilizado pelos trabalhadores nas suas decisões de oferta de trabalho, ele deve ser considerado como uma variável da curva de oferta de trabalho.

De outro lado, o mercado de trabalho agrícola apresenta a segmentação entre os trabalhadores temporários e permanentes. As empresas agropecuárias utilizam tecnologias que implicam em diferentes demandas por trabalhadores permanentes e temporários. Estes dois tipos de trabalhadores têm diferentes qualificações e oportunidades. Isto por sua vez, implica em diferentes curvas de ofertas de trabalho. Esses trabalhadores não são substitutos entre si. Uma unidade agropecuária tem rotinas diárias de atividades, as quais demandam trabalhadores permanentes. No entanto, o 
processo produtivo tem, também, picos de atividades, as quais demandam trabalhadores temporários. Estes são, de modo geral, menos qualificados do que os trabalhadores permanentes.

Considere uma formulação neoclássica onde a demanda de trabalho (DT) depende da tecnologia $(P m o)$, do preço do produto agrícola $(P e)$ e do salário do trabalhador agrícola $(W)$.

$$
D T^{i}=f^{i}\left(W^{i}, P e, P m o^{i}\right)
$$

onde: $i$ refere-se ao trabalhador temporário (vo) ou permanente (pe).

A oferta de trabalhadores agrícolas $(L T)$ depende do salário recebido $(W)$, do salário mínimo $(W M)$ e de outras variáveis que afetam as categorias de trabalhadores (Z).

$$
L T^{i}=g^{i}\left(W^{i}, W M, Z^{i}\right)
$$

onde: $i$ refere-se ao trabalhador temporário (vo) ou permanente (pe).

Observa-se que as funções $f^{i}$ e $g^{i}$ são diferentes para cada categoria de trabalhador (temporários e permanentes). Além disto, o vetor $Z^{i}$ contém diferentes variáveis para cada categoria de trabalhador.

Em condições de equilíbrio, ou seja, $D T^{i}=L T^{i}$, equação (3), defini-se o salário de equilíbrio $W^{i}$. Este equilíbrio é similar ao do Gráfico 1. No entanto, uma variação do salário mínimo implica em um novo desejo salarial por parte dos trabalhadores. Considere que o salário mínimo aumente. Os trabalhadores terão novas pretensões para seus salários desejados, deslocando a curva de oferta de trabalho para a esquerda (ver Gráfico 4). O equilíbrio passará do ponto E para o F. O salário de equilíbrio aumentará de $w_{0}^{i}$ para $w_{1}^{i}$. 


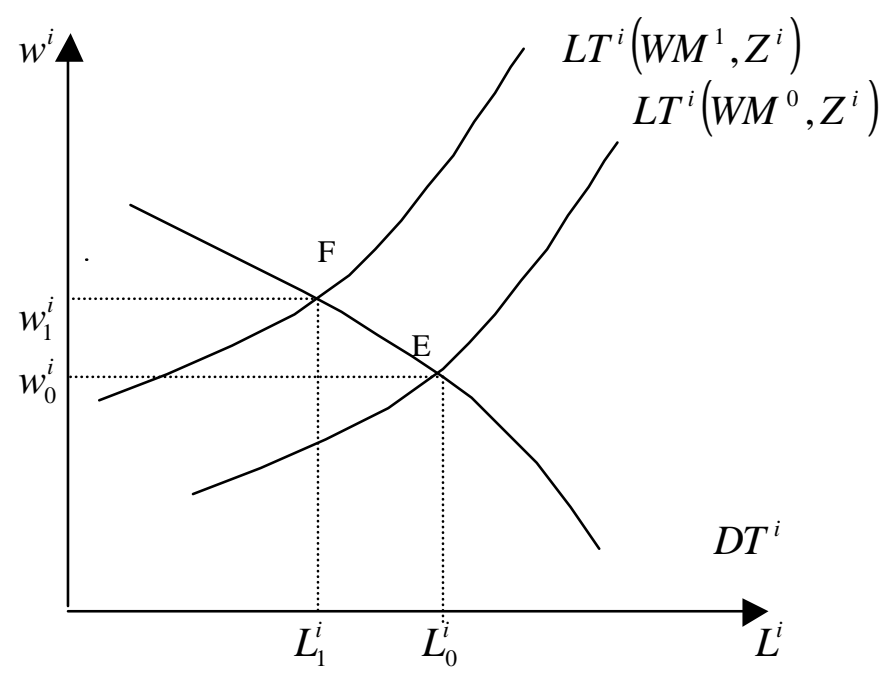

Gráfico 4 - Salário mínimo indexando o salário agrícola.

Os trabalhadores temporários e permanentes têm diferentes curvas $D T$ e $L T$, em outras palavras, eles se defrontam com diferentes funções $f^{i}$ e $g^{i}$. Assim, o salário mínimo pode ter diferentes intensidades de indexação sobre os salários agrícolas.

As equações (1), (2) e (3) inovam em relação aos modelos dos itens 2.1 e 2.2 por: (a) tratarem o salário mínimo como uma variável da oferta de trabalho; (b) adicionam a segmentação no mercado de trabalho agrícola, ou seja, reconhece a existência de pelo menos duas estruturas salariais, definidas por diferentes funções de oferta e demanda de trabalho. 


\section{EVOLUÇÃO DA LITERATURA SOBRE MERCADO DE TRABALHO E SALÁRIOS AGRÍCOLAS}

Este capítulo é composto por três seções. Na primeira (item 3.1), são apresentados alguns aspectos da formação do mercado de trabalho não-qualificado e das variáveis que influenciam o salário dessa mão-de-obra, enfatizando principalmente os efeitos do salário mínimo sobre o mercado de trabalho.

Na segunda seção (item 3.2), são apresentados alguns aspectos da evolução do mercado de trabalho no setor agropecuário brasileiro. Procura-se levantar os principais fatos e interpretações da evolução do mercado de trabalho agropecuário ao longo da formação econômica nacional, trazendo à tona as discussões mais importantes, no entanto, sem aprofundar pontos mais polêmicos.

A terceira seção (item 3.3) revê a literatura sobre salários agrícolas, a qual é dividida em duas partes. Na primeira (subitem 3.3.1), são apresentadas as principais pesquisas interpretativas encontradas na literatura sobre o salário agrícola no Brasil. Na segunda parte (subitem 3.3.2), são apresentados os trabalhos econométricos mais representativos sobre os salários agrícolas na literatura nacional e internacional.

Há um grande grupo de pesquisas econométricas sobre salários presente na literatura internacional (ver Apêndice 1), que se mostra mais interessada em analisar os mecanismos de oferta de trabalho da mão-de-obra oriunda das propriedades familiares. Esta literatura também demonstra a preocupação dos autores quanto às restrições de 
oferta de trabalho, mas no sentido de investigar e aplicar teorias que elucidem a resistência dos indivíduos em mudar de ocupação, ou seja, da ocupação no setor urbanoindustrial para o setor agropecuário.

$\mathrm{Na}$ realidade brasileira, de forma generalizada, não há evidências de restrições de oferta de mão-de-obra agrícola não-qualificada. No Brasil, é até mais provável que haja problemas de restrição de demanda por este tipo de mão-de-obra.

\subsection{Mercado de trabalho da mão-de-obra não-qualificada}

Os estudos sobre a determinação do salário da mão-de-obra não-qualificada no Brasil são fundamentais para compreender o funcionamento desse mercado de trabalho e a distribuição funcional da renda (participação relativa dos salários e lucros na renda). A literatura localiza esse tipo de mão-de-obra em vários ramos industriais, mas, em especial, na construção civil, na ocupação de servente de pedreiro. Já o setor agropecuário é tradicionalmente analisado como um mercado de trabalho formado por mão-de-obra não-qualificada, sendo normalmente enquadrada nas categorias de trabalhadores permanentes e temporários, empregada nas mais diversas ocupações possíveis no universo produtivo da agricultura e da pecuária brasileira.

Os mercados de trabalho de mão-de-obra não-qualificada, tanto urbana quanto agrícola, apresentam alguns pontos de interação que são analisados na seção seguinte. Não obstante as diferenças dos mercados de trabalho urbano e agrícola, há um conjunto de variáveis econômicas e institucionais, como o salário mínimo, que afetam ambos os mercados. O salário mínimo foi inicialmente introduzido no mercado de trabalho urbano em 1940, e no mercado agrícola em 1963. 
O objetivo da criação do salário mínimo no Brasil foi o combate à pobreza. Mas, segundo Neri (1997), este propósito do salário mínimo pode ser posto em dúvida por diversos argumentos. Para tal análise, deve-se tentar captar os efeitos da existência por si só do salário mínimo na economia, e também quando ele sofre algum tipo de reajuste. Neste contexto, o papel do salário mínimo em termos de combate à pobreza assume especial relevância no meio rural, conforme é demonstrado em vários trabalhos (Hoffmann, 1992; Corrêa, 1995). Os habitantes de áreas rurais têm grande contribuição na formação do extrato da população mais pobre do Brasil. Portanto, os efeitos do salário mínimo tendem a tornar-se mais abrangentes para o universo das famílias que têm seus membros empregados nas atividades agrícolas.

A literatura que analisa a influência do salário mínimo sobre o mercado de trabalho urbano é mais ampla que a relacionada à sua influência no mercado agrícola. Nesta seção, é apresentado como o salário mínimo afeta a determinação dos salários e o nível de emprego no mercado de trabalho urbano e, mais especificamente, da mão-deobra não-qualificada. Este tipo de literatura contribui para aprofundar a análise sobre as variáveis que estão determinando a formação dos salários agrícolas.

\subsubsection{O mercado de trabalho e o salário mínimo}

Constata-se, por meio da literatura, que os pesquisadores nas décadas de 70 e 80 levantaram grande polêmica sobre alguns pontos específicos da formação da taxa de salário da mão-de-obra não-qualificada. O papel do salário mínimo foi o centro desse grande debate. A idéia básica estava em torno do grau de influência do salário mínimo na determinação da taxa salarial da mão-de-obra não-qualificada urbana.

Havia dois argumentos sobre a polêmica levantada. O trabalho propulsor dessa discussão foi o de Macedo \& Garcia (1978). Esses autores julgavam que a 
relevância do salário mínimo vinha decrescendo em alguns segmentos do mercado de trabalho, perdendo, conseqüentemente, sua importância como referência na remuneração da força de trabalho não-qualificada. Portanto, a taxa salarial da economia como um todo tinha pouca influência de fatores institucionais, como o salário mínimo.

Por outro lado, Souza \& Baltar (1979) apresentam réplica ao trabalho de Macedo \& Garcia (1978), argumentando que o salário mínimo desempenhava um papel fundamental na determinação da taxa de salários da mão-de-obra não-qualificada e, além disso, gerava um efeito "farol" sobre as demais categorias ocupacionais ${ }^{12}$. A idéia básica que estava por trás desse efeito era de que o salário mínimo funcionaria como uma espécie de indexador dos salários da economia. Um aumento do salário mínimo elevaria tanto o salário de trabalhadores não-qualificados quanto dos trabalhadores que recebiam salário acima do mínimo. Os salários dos trabalhadores do setor informal também eram afetados pelo salário mínimo (Barros et al., 1997). Drobny \& Wells (1983) e Sabóia (1985) reforçam a hipótese institucionalista sobre o papel do salário mínimo na determinação dos salários da mão-de-obra não-qualificada na economia nacional.

A hipótese institucional foi empiricamente comprovada pelos autores citados, assim como por outros trabalhos publicados, conforme constata Campos (1992). No entanto, não se podem excluir da análise as forças de mercado, representadas empiricamente pelo hiato do produto e pela taxa de desemprego aberto. Desse modo, é mais sustentável uma análise que comporte os dois argumentos como fatores determinantes da taxa de salário: o salário mínimo e as forças de mercado. Campos (1992) evidencia a necessidade de inclusão de outras variáveis institucionais como o processo de negociações coletivas, e não somente o salário mínimo como determinante da taxa salarial.

As pesquisas sobre o papel do salário mínimo nos países desenvolvidos, como nos Estados Unidos, também não elucidaram o tema em definitivo. Por exemplo,

\footnotetext{
${ }^{12}$ A polêmica entre estes grupos de autores implicou em mais dois artigos, um de comentário de Macedo \& Garcia (1980) e outro de réplica de Souza \& Baltar (1980).
} 
os resultados da pesquisa de Card \& Krueger (1994) - sobre o efeito da elevação do salário no nível de emprego dos funcionários das redes de restaurantes do tipo fast food no estado de New Jersey - foram contrários ao que prediz a teoria econômica, pois aqueles autores não encontraram evidências de redução do número de trabalhadores empregados. Por outro lado, Neumark \& Wascher (2000) analisaram as mesmas redes de restaurantes da pesquisa de Card \& Krueger (1994), no entanto, utilizando outras fontes de dados. Neumark \& Wascher (2000) encontraram, entretanto, resultados opostos aos de Card \& Krueger, ou seja, o aumento do salário mínimo provocou a redução de demanda por trabalhadores de menor salário ${ }^{13}$.

Os efeitos do salário mínimo sobre o mercado de trabalho são vários. Além do efeito "farol", que já foi visto, há outros abordados na literatura. Barros et al. (1997) cita o efeito "enclausuramento" que está associado ao crescimento do setor não coberto ${ }^{14}$ da economia. Para melhor compreender este efeito, pode-se considerar o caso de um mercado de trabalho segmentado com mão-de-obra heterogênea e que tem um aumento do salário mínimo. Nesta situação, haveria dois efeitos sobre a distribuição de renda. Por um lado, elevaria os salários dos trabalhadores pouco qualificados no setor coberto sem o respectivo aumento de produtividade e, por outro lado, em razão da ineficiência que este aumento introduziria no processo produtivo, esta situação conduziria a uma redução no salário dos demais trabalhadores. Esse efeito negativo do salário mínimo é denominado de efeito "enclausuramento".

Neri (1997) refere-se ao efeito "pobreza" do salário mínimo, cuja idéia central estaria associada à influência do salário mínimo sobre a cauda inferior da distribuição da renda. Este autor aplicou em sua pesquisa o conceito de renda domiciliar per capita, encontrando uma relação inversa entre pobreza e salário mínimo. Com isto, o autor confirmou a sua hipótese de que o salário mínimo tem maior impacto sobre as populações mais pobres.

\footnotetext{
${ }^{13}$ O trabalho de Neumark \& Wascher (2000), motivou a réplica de Card \& Krueger (2000).

14 Refere-se ao setor informal da economia. Procurou-se ser fiel ao tipo de linguagem adotada pelos autores.
} 


\subsection{Evolução do mercado de trabalho agropecuário brasileiro}

A formação do mercado de trabalho agrícola brasileiro inicia-se com o surgimento do próprio setor agropecuário como uma atividade diferenciada na economia nacional. Durante o período colonial, no Brasil predominava "a grande lavoura", a qual formava um organismo social baseado na grande propriedade latifundiária, na monocultura de exportação e no trabalho escravo.

Segundo Furtado (1972), coube à escravidão importante papel no processo de estruturação da economia agrícola brasileira, pois forneceu à grande empresa agromercantil os meios de frustrar qualquer outra forma de organização agrícola em escala nacional ${ }^{15}$. O monopólio da propriedade da terra, por sua vez, permitiu consolidar as posições ganhas com base na escravidão.

No período colonial houve "acaparação" de terras, um processo pelo qual uma minoria conseguia submeter a seus interesses as comunidades camponesas, seja extraindo destas os excedentes, seja proletarizando-as. A comunidade camponesa no Brasil formou-se em diminutas proporções. No entanto, nas regiões onde se formou, pouca influência teve no processo de acumulação capitalista. Conforme Furtado (1972), isto trata-se de uma informação da maior significância, pois, praticamente por toda parte, as sociedades mais complexas se formaram a partir de comunidades rurais, que préexistem à penetração e generalização do trabalho assalariado. Nesta mesma interpretação, o autor observa que, na economia cafeeira, a evolução do trabalho escravo para o sistema de colonato ocorreu sem que surgisse previamente a agricultura baseada na exploração familiar.

A partir do momento em que a mão-de-obra escrava se torna escassa e a oferta de trabalho livre mais abundante, criam-se condições favoráveis ao 
desenvolvimento de pequenas explorações agrícolas. A partir desse momento, o controle da propriedade da terra por uma minoria passa a ser fator determinante da organização agrícola. O controle de terra foi o mecanismo de manutenção do sistema tradicional fundado na empresa agromercantil.

A promulgação da Lei de Terras foi um forte golpe para a expansão da agricultura baseada na exploração familiar, pois vetava o livre acesso à terra, a não ser por compra. Segundo Martins (1997), o intuito da Lei de Terras era essencialmente garantir a formação do mercado de trabalho, impedindo que o iniciado fluxo de imigrantes estrangeiros se diluísse na imensidão das terras brasileiras, o que dificultaria a criação do mercado de trabalho.

A Lei de Terras se incluiu no longo e seguro processo de libertação dos escravos, de tal maneira que o término da escravidão não provocaria a ruptura do sistema socioeconômico vigente. Com a Lei de Terras, a massa de libertos pela Lei Áurea, ou mesmo antes dela - por meios legais como alforrias, Lei do Sexagenário, Lei do Ventre Livre e outros - não teria acesso à terra. Desta forma, evitava-se o esvaziamento do mercado de trabalho. A Lei de terras conservou seu papel mesmo em um momento em que os escravos libertos não apareciam como a primeira opção de mãode-obra para os cafezais, pois já estava em curso a corrente imigratória com origem na Europa para trabalhar nas lavouras de café.

Com o fim da escravidão, vários esquemas de relações de trabalho assalariado surgiram na agropecuária brasileira. Na primeira metade do século XX, por exemplo, Goodman et al. (1985) citam os meeiros, arrendatários e trabalhadores residentes como sendo assalariados disfarçados. A proletarização desses indivíduos ocorreu a partir dos anos 60 , com o processo de capitalização do setor agropecuário, ou a chamada modernização da agricultura. Os cientistas sociais estudaram amplamente a

${ }^{15}$ Esta opinião de Furtado deve ser relativizada, pois no Sul do país formaram-se colônias de pequenas propriedades de imigrantes . 
proletarização do trabalhador agrícola e as transformações socioeconômicas ocorridas na agropecuária. Cita-se como exemplo os trabalhos de Mello (1975) e Brant (1979).

Cacciamali (1986) sintetiza em dois grupos a discussão na literatura e no meio acadêmico sobre as razões que provocaram o crescimento, em algumas regiões, ou até mesmo o surgimento, da utilização da mão-de-obra temporária na atividade agropecuária. O primeiro grupo compõe-se de autores que associam o crescimento da utilização da mão-de-obra temporária ao surgimento do Estatuto do Trabalhador Rural e seus desdobramentos (ETR, Lei 4.214 de 02.03.1963). Esses autores argumentam que os empregadores rurais, para se eximirem do pagamento dos direitos regulados pelo ETR, expulsaram, ou reduziram ao máximo, os trabalhadores agrícolas residentes em suas fazendas. Os fazendeiros acreditavam que os custos e as obrigações impostas pela legislação eram muito elevados, considerando a baixa qualidade da força de trabalho empregada. Além disto, o emprego de mão-de-obra temporária se justifica em razão da descontinuidade inerente ao processo produtivo nas atividades agropecuárias.

Portanto, após 1963, o trabalho permanente nas atividades agropecuárias e a reorganização das relações de trabalho existentes se traduziriam em ônus para os empregadores. A forma de burlar a legislação vigente foi a descaracterização dos vínculos empregatícios e do assalariamento dos trabalhadores residentes, por meio da utilização do trabalho intermitente.

O outro grupo de pesquisadores atribuía o crescimento do trabalho assalariado temporário na agropecuária, após os anos 60, a uma nova fase do desenvolvimento capitalista do país e do próprio setor agropecuário. Esses pesquisadores não acreditavam que a aplicação da legislação - o Estatuto do Trabalhador Rural - fosse o fator causador do fenômeno "trabalhador temporário". A persistência e o crescimento dessa modalidade de relação de trabalho deve-se, segundo os autores desse grupo, à especialização numa mesma atividade agrícola, nas diversas regiões do país, o que implica na intensificação do assalariamento temporário. 
Esse fato ocorreu independentemente da incidência ou não de encargos trabalhistas sobre os salários pagos aos trabalhadores agrícolas. Cacciamali (1986) reforça esses argumentos, pois, a sua opinião, não é correta a afirmação de que o surgimento de legislação específica, regulamentando as relações de trabalho no campo, fosse o responsável pelo aparecimento do assalariamento temporário, uma vez que legislação similar já existia desde a década de 30 .

Cacciamali (1986) e Brant (1979) têm a mesma opinião de Mello (1975, p.147): o bóia-fria é a afirmação "histórica do sistema". Conforme Mello (1975), o bóiafria, enquanto componente das fileiras dos ofertantes de força de trabalho e enquanto membro da superpopulação relativa, é a afirmação do sistema capitalista. "A forma que esse indivíduo realiza o seu trabalho no campo é uma decorrência da existência deste excedente da oferta de força de trabalho, em relação à demanda. A possibilidade de contar com um tipo de trabalhador que, recebendo por tarefa ou por dia, trabalhando num ritmo irregular, favorece os interesses do empregador existe, em última análise, como decorrência da superabundância de mão-de-obra.” Mello (1975, p.87).

Aguirre \& Bianchi (1989) formularam uma perspectiva diferenciada da questão do surgimento do trabalhador volante. As autoras analisaram este fenômeno a partir da constatação de que a necessidade de acumulação para a atividade capitalista, no caso brasileiro, poderia ter três possíveis opções para a acumulação de capital: extensão da jornada de trabalho, aumento da intensidade do trabalho e aumento de sua produtividade. A primeira opção não parecia ser uma alternativa factível, pois a jornada de trabalho é suficientemente exaustiva. Quanto ao aumento da intensidade do trabalho (segunda opção), só seria viável se houvesse um forte incentivo para o trabalhador. No entanto, quando se trata de trabalho manual, há dificuldades de controle rigoroso sobre o esforço dispendido. Já a terceira opção (o aumento da produtividade do trabalho) foi factível de ser implantada com o processo de modernização da agropecuária, viabilizando-se por meio de investimento em capital fixo. 
Segundo Aguirre \& Bianchi (1989), em condições de ampla disponibilidade de mão-de-obra, a alternativa para capitalização da agropecuária poderia ser a utilização do trabalho volante. Desta forma, esse tipo de trabalho seria útil no processo de transição de uma agricultura tradicional para outra tecnicamente mais adia ntada. Principalmente nas décadas de 70 e 80, o processo de tecnificação do setor agropecuário intensificourse, reduzindo a relação trabalho/capital e aumentando a relação trabalhador volante/permanente.

Primeiramente, o surgimento da Lei de Terra e, décadas depois, o Estatuto do Trabalhador Rural compõem dois importantes fenômenos de um conjunto de fatores que influenciaram a formação do mercado de trabalho agrícola. Entre esses fatores, inclui-se também o processo de modernização do setor agropecuário, que foi implementado por políticas setoriais. A mais notória delas foi a disponibilidade do crédito rural oficial com taxas de juros diferenciadas, a partir da década de 70. Neste período, as políticas de modernização do setor agropecuário foram amplamente favorecidas com os preços crescentes de alguns produtos no mercado externo, os quais eram produtos alvos do crédito "barato" (Barros, 1979; Melo, 1979; Fonseca \& Staduto, 1995). As regiões Centro-Oeste, Sudeste e Sul foram as mais favorecidas em relação ao Norte e Nordeste em termos de políticas setoriais para tecnificação do setor agropecuário, refletindo em crescimento das taxas de produtividade nessas regiões ao longo dos anos 70 e 80 (Staduto \& Freitas, 2001).

A tecnificação da agropecuária tende a se efletir no mercado de trabalho agrícola, pois como ressaltaram Aguirre \& Bianchi (1989), o trabalhador volante tenderia a ser uma forma de transição para a total mecanização do processo ${ }^{16}$. Nas regiões Centro-Oeste, Sudeste e Sul, os impactos da intensificação da mecanização e utilização de insumos modernos sobre o mercado de trabalho foram mais intensos em

\footnotetext{
16 Esta transição a que se referem os autores, provavelmente, nunca será concluída, ou seja, jamais o processo produtivo no setor agropecuário será totalmente mecanizado, mas deve atingir patamares muito elevados.
} 
relação às demais regiões, sendo que o processo de transição para mecanização total deve estar mais desenvolvido.

Müller (1989) faz algumas pressuposições apoiadas na inevitabilidade de desaparecimento de todos os produtores rurais brasileiros que não se inserirem nos complexos agroindustriais. Em razão do processo de intensificação da modernização da agropecuária, que privilegiou os grandes proprietários de terra, os pequenos produtores devem sofrer esse risco de forma mais eminente. $O$ autor discute a solução para a população excedente em decorrência da exclusão do processo produtivo, chegando à conclusão de que os setores a serviço dos complexos agroindustriais deverão ser os grandes absorvedores de mão-de-obra da população excluída.

Atualmente, vários setores da agropecuária brasileira estão sofrendo novamente rápidas alterações no mercado de trabalho, como é o caso do setor sucroalcooleiro paulista. Este sofre pressões dos ambientalistas e do avanço tecnológico, as quais podem resultar na extinção, em curto prazo, do cortador de cana-de-açúcar.

Constata-se na agropecuária brasileira o aumentando da disponibilidade de tecnologias poupadoras de mão-de-obra e, concomitante, ocorre o crescimento da oferta da mão-de-obra. Segundo Cacciamali (1986), as empresas agropecuárias têm optado pela adoção dessas tecnologias, pois seguem uma tendência histórica de, primordialmente, atender a duas finalidades: promover o amento de produtividade e aumentar o controle sobre o processo de trabalho e, portanto, sobre a produção.

Segundo Sorj (1980), a massa de trabalhadores expulsa das fazendas gerou o mercado de trabalho que, por sua vez, possibilitou novas expulsões de trabalhadores permanentes, já que estava assegurada a oferta de força de trabalho temporária. Sejam quais forem as causas do incremento do trabalho assalariado temporário (pois para o autor elas têm pesos distintos segundo as diferentes regiões), essa modalidade se transformou em uma forma importante de trabalho assalariado agrícola no Brasil.

Sorj (1980) distinguiu duas formas de trabalho do assalariado: 
a) o assalariado que se origina da pequena produção tradicional, na procura de rendas complementares. Para esses trabalhadores é possível fazer uma tipologia em termos da importância da renda relativa obtida do minifúndio e da venda da força de trabalho;

b) os trabalhadores temporários que dependem totalmente da venda da sua força de trabalho e que moram em vilas e cidades. Pode-se dividir esses trabalhadores assalariados temporários em duas modalidades: os indivíduos que se dedicam exclusivamente ao trabalho na agropecuária; e os indivíduos que eventualmente trabalham tanto no campo quanto na cidade.

Para Silva (1982), a categoria dos trabalhadores bóias-frias (temporários) é composta pelos seguintes indivíduos:

a) aqueles que são bóias-frias o ano inteiro: os bóias-frias permanentes. Por muitas vezes, são, na verdade, trabalhadores efetivos na propriedade agrícola, prestando serviços quase que ininterruptamente, mas não recebem os direitos trabalhistas;

b) os que trabalham apenas na época das safras: os bóias-frias eventuais. Trabalham em diversas propriedades agrícolas, em períodos descontínuos, totalizando, geralmente, menos de dois meses de trabalho por ano. A grande parte dos indivíduos dessa categoria não faz parte regularmente da força de trabalho, constituindo-se de menores em idade escolar (com menos de 14 anos), idosos e "donas-de-casa"; e

c) aqueles que se posicionam em um grupo intermediário entre os dois anteriores: os bóias-frias temporários. Empregam-se na agricultura principalmente na época das safras, caracterizando-se pela alternância em empregos agrícolas e não-agrícolas, gerando a integração do mercado de trabalho urbano-rural da mão-de-obra não-qualificada. 
Por outro lado, a categoria dos trabalhadores assalariados permanentes no setor agropecuário é a mais especializada e, geralmente, é composta pelos tratoristas e mecânicos, podendo ser residentes ou não na propriedade rural (Sorj, 1980). Nas regiões mais desenvolvidas do país há uma tendência de ampliação dos postos de trabalhos mais especializados e qualificados, desse modo, melhorando a qualidade das ocupações no setor. Istake (1999) faz este tipo de constatação para as atividades agropecuárias do estado do Paraná. A autora, no entanto, constata que o grau de especialização da mãode-obra agrícola ainda é pequena.

\subsection{Literatura sobre determinação dos salários agrícolas}

Segundo Bacha (1979, p.585): “O salário da mão-de-obra não qualificada é o mais importante indicador do padrão de vida da população brasileira”. A literatura sobre o salário agrícola no Brasil pode ser dividida em dois grupos: os trabalhos que desenvolvem modelos econométricos de determinação dos salários agrícolas e os que se dedicam à interpretação analítica de sua determinação e ao comportamento do mercado de trabalho agrícola. Desse modo, dividiu-se esta seção em duas partes, sendo que a primeira parte (subitem 3.3.1) é dedicada a analisar o conjunto de interpretações analíticas mais relevantes da literatura sobre o comportamento do salário agrícola. $\mathrm{Na}$ segunda parte (subitem 3.3.2), revisou-se a literatura nacional e internacional sobre o tratamento econométrico utilizado para estimar o salário agrícola. 


\subsubsection{Interpretações analíticas dos salários agrícolas}

Lewis (1969) fez importantes contribuições para o entendimento das economias não-desenvolvidas e, em especial, destaca-se a publicação do trabalho "O desenvolvimento econômico com oferta ilimitada de mão-de-obra". Um dos pontos mais polêmicos desse trabalho é a pressuposição de que o produto marginal do trabalho na agricultura nos países não-desenvolvidos é igual a zero ou, até mesmo, negativo. Desta forma, supõe-se que no setor agropecuário deve ocorrer desemprego disfarçado. Outros autores concordam com a mesma hipótese: Furtado (1972), Leibenstein (1957) e Bacha (1979).

Considerando-se válida a hipótese de que o produto marginal do trabalho na agricultura é igual a zero, segundo Lopez (1969), fica a seguinte indagação: como um trabalhador que não tem nenhuma contribuição para o produto marginal obtém salários positivos?

O modelo de Lewis providencia resposta plausível à indagação feita acima, partindo de algumas pressuposições básicas. No modelo de Lewis, o setor da agricultura que transfere mão-de-obra para a indústria é o composto pelos estabelecimentos familiares de subsistência. $\mathrm{O}$ modelo tem a rigidez de estabelecer ausência de mobilidade entre os segmentos agrícolas de subsistência, comercial e misto. Com isto, formam-se ilhas de produção. Nestas circunstâncias, não haveria alternativa para a mãode-obra familiar a não ser transferir-se para a indústria (Lopez, 1969). Portanto, para que os indivíduos tenham meios de sobrevivência, cada membro da família recebe uma parcela da produção, não se levando em consideração a contribuição de cada um no processo produtivo. Não havendo salário alternativo fora do estabelecimento agrícola e considerando a ausência de mobilidade, os salários se aproximam da produtividade média de cada membro da família. 
Para Lopez (1969), o argumento de Lewis sobre a remuneração dos membros das famílias dos pequenos proprietários rurais é um ponto alto na defesa da hipótese de que o produto marginal do trabalho agrícola é zero. Entretanto, segundo Lopez (1969), caso uma parcela considerável da mão-de-obra fosse retirada do setor agropecuário, o produto das propriedades familiares não decresceria; pois ocorria um esforço maior por parte dos trabalhadores remane scentes para manter o nível de produção. Desta forma, o fato de que os trabalhadores restantes tivessem que fazer esforço maior para manter a produção, configuraria uma prova de que a produtividade marginal não é zero.

Leibenstein (1957) formulou uma hipótese semelhante à de Lewis de que a produtividade marginal do trabalho é igual a zero. Entretanto, Leibenstein tinha objetivos diferentes. Conforme ressalta Lopez (1969), a preocupação de Leibenstein era justificar exatamente a indagação sobre a existência de salários positivos nas regiões, na situação em que o produto marginal do trabalho fosse igual a zero ou, até mesmo, negativo. Para tanto, o autor segue uma linha argumentativa, na qual essencialmente procura demonstrar que os salários determinam a produtividade do trabalho, desta forma, contrariando a pressuposição da teoria neoclássica, ou seja, os salários são determinados pela produtividade do trabalho.

A respeito disto, Leibenstein (1957) observou que no mercado de trabalho agrícola há certas circunstâncias em que os grandes proprietários tendem a absorver parcelas crescentes de mão-de-obra para evitar a redução dos salários. Caso ocorresse o declínio dos salários, haveria como conseqüência a redução na produtividade do trabalhador, uma vez que os salários guardam estreitas proporcionalidades com a produtividade da mão-de-obra empregada. A nutrição do trabalhador está relacionada com o salário, criando verdadeiros níveis de energia que, por sua vez, motivariam o trabalhador a empenhar-se mais ou menos no processo produtivo. Os salários determinam os níveis nutricionais da mão-de-obra, os quais atuam no sentido de determinar a maior ou menor produtividade do trabalhador. Esta argumentação tem 
pontos semelhantes com os pressupostos do salário eficiência discutidos no capítulo 2 (subitem 2.2).

Schultz (1965) apresentava posição contrária ao produto marginal do trabalho na agricultura ser igual a zero ou negativo. Este autor supunha que essa produtividade era positiva, aceitando até a possibilidade de ser próximo de zero, mas nunca zero.

Youmans \& Schuh (1968) realizaram uma pesquisa nos municípios em torno da cidade de Belo Horizonte, no período de expansão da capital mineira. Esse processo de crescimento de Belo Horizonte atraiu trabalhadores dos municípios vizinhos, inclusive trabalhadores agrícolas, para ocuparem os novos postos de trabalhos abertos no setor urbano-industrial. Na avaliação dos autores, ocorreu redução da produção agrícola nos municípios que tiveram maior fluxo migratório em direção à capital mineira, confirmando a pressuposição de Schultz de que o produto marginal na agropecuária não poderia ser negativo.

A controvérsia sobre o tema não deixa de ser interessante, motivando uma série de outras pesquisas. Outras discussões foram abertas também sobre o mercado de trabalho agrícola. Dentre elas se destaca a iniciada por Bacha (1979), que analisou o crescimento econômico e o comportamento dos salários urbanos e agrícolas no Brasil. Este trabalho desencadeou uma série de debates e interpretações sobre o tema salário e mercado de trabalho agropecuário na literatura nacional.

Bacha (1979) analisou mais especificamente os salários urbanos e agrícolas do antigo Estado da Guanabara e Estado de São Paulo, respectivamente. O autor constatou que os salários agrícolas corrigidos pelos "preços recebidos pelos produtores" (salário-produto) mantiveram-se constantes ao longo do período de 1948 a 1978, ocorrendo apenas mudanças de patamares nos anos 1963/64 com a mudança da legislação do trabalhador rural. Por outro lado, os salários agrícolas corrigidos pelos índices de inflação aumentaram espetacularmente a partir de 1968, acompanhando o aumento da relação de troca agricultura/indústria no mesmo período. 
O aumento da relação de troca foi responsável pela redução da diferença entre salários agrícolas e urbanos. A suposição do autor para explicar o comportamento dessa diferença salarial se apóia no fato de que a oferta do trabalho na agropecuária encontrava-se basicamente acomodada dentro das pequenas propriedades, criando um mecanismo que reage à relação de troca da agricultura/indústria. Quando aumenta essa relação, a oferta de trabalho é reduzida, pois os indivíduos intensificam o trabalho em suas próprias propriedades, para aproveitar a elevação dos preços agrícolas. Outros fatores de ordem institucional concorreram para influenciar o comportamento dos salários urbanos e agrícolas, tais como: o Estatuto do Trabalhador, o salário mínimo, o arrocho do salário urbano, o desmonte do sindicados urbanos e os ciclos econômicos, por exemplo.

O ponto de partida da análise de Bacha (1979) foi o modelo dual proposto por Lewis. No entanto, Bacha fez algumas restrições quanto à aplicação deste modelo “...a constância a longo prazo do salário urbano foi resultado de um ciclo político, e não conseqüência de ajustamentos no mercado de trabalho do tipo considerado na literatura do modelo dual de crescimento" (Bacha, 1979, p.597). Por outro lado, Bacha (1979) utilizou algumas pressuposições do modelo de Lewis: a agricultura formada por um setor de subsistência e a remuneração dos membros das famílias pelo produto médio.

Bacha (1979) apresentou uma pesquisa extremamente consistente, principalmente em termos de dados empíricos. A partir desse trabalho foram publicados vários outros artigos contestando as pressuposições do autor e reacendendo essa temática no âmbito acadêmico.

Gasques (1980) iniciou a série de debates em torno das suposições formuladas por Bacha (1979). A crítica de Gasques ficou centrada basicamente sobre a afirmativa de que "O salário monetário no setor rural é determinado pelo valor da produtividade média da mão-de-obra na pequena agricultura...” (Bacha, 1979, p.600). Segundo Gasques (1980), essa hipótese ocorreria basicamente em duas situações: a) se houvesse excesso de mão-de-obra no meio rural, mas Bacha deixa explícito que na 
agricultura perdurou escassez de mão-de-obra. No entanto, somente em uma situação em que houvesse excedente de mão-de-obra, os salários recebidos pelos trabalhadores seriam de acordo com o produto médio; e b) a maioria da população agrícola é formada por mão-de-obra que trabalha no próprio estabelecimento.

Na agropecuária brasileira essas duas hipóteses perdem sentido, visto que a maior parte da mão-de-obra assalariada na agropecuária não tem relação alguma com a posse da terra. Portanto, os salários seriam pagos segundo a contribuição da força de trabalho para a produção, ou seja, a produtividade do fator.

Bacha (1980) fez a réplica a Gasques, confirmando a sua suposição, apoiando-se em contundentes dados empíricos. No entanto, após alguns anos, o trabalho de Bacha (1979) voltava a ser contestado, agora por Resende (1985), que criticou a forma de obtenção do índice salário-produto. Resende baseou as suas críticas na constatação de que os produtos cultivados pelos pequenos agricultores, ofertantes de trabalho agrícola, são diferentes dos produtos cultivados pelos grandes produtores rurais, demandantes de trabalho agrícola.

Dessa forma, o mais correto seria obter dois índices distintos de salárioproduto para os pequenos e os grandes produtores. Os pequenos produtores teriam o índice salário-produto corrigido pelos preços dos produtos domésticos e os grandes produtores teriam o índice salário-produto corrigido pelos produtos de exportação. $\mathrm{O}$ índice da relação de troca agricultura/indústria deveria também ser construído em separado para os produtos domésticos e para os produtos de exportação

Resende (1985) aplicou estes procedimentos e encontrou resultados que divergiam com os de Bacha (1979), concluindo que esse foi o grande erro do trabalho de Bacha. Resende também encontrou explicação alternativa para a elevação dos salários agrícolas em relação aos urbanos após 1968. Bacha apontava a relação de troca agricultura/indústria e os fatores institucionais como sendo os grandes responsáveis por aquela elevação. Já para Resende, essa elevação ocorreu em razão do ciclo de 
crescimento econômico, que estava em fase de rápida expansão, propiciando o aumento progressivo das oportunidades alternativas ao trabalho assalariado agrícola, “... de tal modo que o equilíbrio simultâneo nos vários mercados requereu uma elevação diferencial do salário rural" (Resende, 1985, p.54). Dessa forma, a explicação encontrase no próprio mercado de trabalho agrícola.

Os determinantes do mercado de trabalho agrícola têm várias versões e interpretações. Na literatura mais recente, este debate não teve a mesma repercussão que nos anos anteriores, talvez porque o setor agropecuário ao longo dos anos tenha perdido sua importância na composição da renda nacional ou mesmo em razão da ausência de alguma publicação na literatura nacional que tenha tido impacto semelhante à publicação de Bacha (1979).

$\mathrm{Na}$ parte seguinte dessa seção são revisadas as literaturas nacionais e internacionais sobre os trabalhos de cunho mais econométrico, os quais colaboram para elucidar a formação dos salários agrícolas no Brasil.

\subsubsection{Pesquisas econométricas sobre os salários agrícolas}

Uma das primeiras investigações econométricas sobre os salários agrícolas encontradas na literatura foi realizada por Schuh (1962). O autor estimou equações simultâneas de oferta e demanda de mão-de-obra de trabalhadores assalariados agrícolas nos Estados Unidos, entre os anos de 1927 a 1957, e obteve os resultados esperados segundo o modelo de concorrência perfeita. Os coeficientes das variáveis da oferta salários agrícolas, tendência e força de trabalho agrícola - e das variáveis da demanda salários agrícolas, preços agrícolas e tecnologia - foram significativos estatisticamente. 
Já as primeiras pesquisas econométricas no Brasil sobre o produto marginal do trabalho e os salários no setor agropecuário foram realizadas por Nicholls \& Paiva (1966, 1967), intitulada "Ninety-Nine fazendas: The Structure and Productivity of Brazilian Agriculture, 1963". Os autores, para realizar a pesquisa, visitaram noventa e nove fazendas no Brasil, agrupadas em várias regiões, com a finalidade de diagnosticar aspectos econômicos das propriedades. As fazendas representaram uma amostra da situação da agropecuária brasileira, sendo os dados publicados em relatórios preliminares para cada região. A seguir são comentados os resultados para duas regiões: o Cariri e o Agreste.

No município de Crato, no estado do Ceará, região do Cariri, por meio da estimação de uma função de produção do tipo Cobb-Douglas, os autores encontraram que o salário da mão-de-obra empregada nas fazendas era superior ao produto marginal. Além disso, no município de Crato, os pesquisadores constataram que havia excesso de oferta de trabalho. Uma explicação plausível para essa situação seria o fato do salário mínimo vigente ter sido superior ao salário pago aos trabalhadores, o qual restringiria o pleno ajuste dos salários, impondo valores significativamente maiores que a contribuição marginal do trabalho. Contudo, conforme os autores, não era o caso desta situação.

No Agreste pernambucano, mais especificamente no município de Caruaru, os resultados obtidos pelos pesquisadores indicaram que a taxa de salário da mão-deobra era estatisticamente igual ao produto marginal do trabalho empregado nas propriedades. Dessa forma, os salários ajustavam-se de acordo com a teoria microeconômica neoclássica. Os resultados da pesquisa nessa região divergiriam dos obtidos para Crato, evidenciando heterogeneidade do mercado de trabalho agrícola na região do Nordeste.

Os trabalhos apresentados acima não estimaram equações de determinação do salário agrícola, mas se tratam de uns dos primeiros estudos que analisaram o mercado trabalho agrícola no Brasil. 
A seguir, são apresentados os trabalhos que estimaram as equações de oferta e demanda de trabalho ou equações de determinação do salário na agropecuária brasileira, além de outros trabalhos relevantes sobre o tema.

Os modelos de oferta e demanda de trabalho agrícola estimados por Saylor (1974) para o Estado de São Paulo são uma das primeiras pesquisas encontradas na literatura que analisa o mercado de trabalho no Brasil. O autor aplicou o método dos Mínimos Quadrados de Dois Estágios para o período de 1948 a 1970, utilizando-se dados anuais. $\mathrm{O}$ autor não teve a preocupação de fazer um modelo de equilíbrio para determinar a quantidade de trabalho empregado na agricultura ou propor um modelo de salário de equilíbrio.

Bacha (1991) aponta algumas limitações no trabalho de Saylor (1974) centradas principalmente no agrupamento equivocado das categorias de trabalhadores permanentes, temporários e membros não-remunerados da família para estimar as equações propostas. Mas, deve-se destacar, como foi analisado na seção anterior, que a categoria do trabalhador volante surgiu principalmente ao longo dos anos 60. Desta forma, o estudo de Saylor (1974) abrange apenas alguns anos no qual poderia ser identificado o seu efeito na determinação das equações de oferta e demanda.

Gasques (1975) estimou um modelo de oferta e demanda de trabalho agrícola temporária (denominada pelo autor como trabalhador volante não-qualificado) para o Estado de São Paulo. O autor procurou identificar variáveis que explicavam o comportamento desse mercado de trabalho, aplicando o método dos Mínimos Quadrados de Dois Estágios para dados mensais. O modelo captou, por meio de variáveis binárias, a estacionalidade do salário e a utilização da de mão-de-obra volante no ano inteiro.

Bacha (1991) novamente apresenta limitações no modelo do Gasques (1975) pelo fato de considerar a mão-de-obra volante como uma categoria de trabalhadores homogênea. Segundo Bacha, nessa categoria poderia se distinguir até quatro tipos de trabalhadores. 
Levando-se em conta as críticas apontadas por Bacha (1991) às pesquisas de Saylor (1974) e Gasques (1975), ao considerar em seus modelos de mercado de trabalho agrícola que os trabalhadores são homogêneos, pode-se inferir que é mais preciso distinguir pelos menos dois segmentos: os trabalhadores temporários, estando aglutinados em pequenos produtores assalariados e trabalhadores bóias-frias (permanentes, esporádicos e temporários); e os trabalhadores permanentes.

Os trabalhadores temporários apresentam uma relação trabalhista diferente da verificada com os trabalhadores permanentes. Do ponto de vista legal, os contratos de trabalho desses dois segmentos também são distintos. Além disso, os trabalhadores permanentes recebem salários indiretos, tais como moradia, água, luz, parte da produção, área para produção própria, por exemplo.

Do ponto de vista analítico, a segmentação do mercado de trabalho pode ser definida segundo a abordagem levantada por Taubman \& Waschter (1985), conforme análise já apresentada no capítulo anterior (item 2.2). Esses autores afirmam que as fronteiras entre os segmentos poderiam ser estabelecidas à medida que são encontradas diferentes estruturas salariais dentro de um setor. O trabalho de Reich et al. (1973) fortalece a possibilidade de distinguir os segmentos dentro do mercado de trabalho agrícola de acordo com o processo histórico de desenvolvimento do capitalismo. De fato, os trabalhadores temporários surgem com o desenvolvimento do capitalismo no setor agropecuário, como discutido na seção anterior (item 3.2).

Não se deve omitir a contribuição de Saylor (1974) e Gasques (1975) ao incluírem nos seus modelos a produtividade da agricultura do Estado de São Paulo. No entanto, esses autores seriam mais precisos caso considerassem a produtividade do fator trabalho, pois a remuneração dos fatores é feita segundo a sua contribuição para o produto. Entretanto, o procedimento adotado por aqueles autores não deixa de ser uma primeira aproximação para tentar captar o fator tecnologia afetando os salários. Provavelmente, esses autores não teriam utilizado a variável mais apropriada em razão de limitação de dados. 
Gallasch (1975), com o objetivo de analisar o efeito do salário mínimo sobre o salário e o nível de emprego agrícola, formulou um modelo estrutural de equilíbrio do mercado de trabalho considerando a existência de um excedente de oferta causado pelo salário mínimo (discutido no subitem 2.1.2). O autor, mesmo mediante as dificuldades de obter dados adequados para estimar o modelo estrutural proposto, adotou a abordagem de equações na forma reduzida para estimar equações simultâneas de salário e emprego, incluindo o salário mínimo nos modelos para captar a sua influência sobre estas duas variáveis.

Gardner (1972) e Lianos (1972) - também com a finalidade de analisar a influência do salário mínimo sobre o mercado de trabalho agrícola - estimaram para os Estados Unidos equações na forma reduzida de salário e emprego e apenas equações de demanda de trabalho, respectivamente. Mais recentemente, as pesquisas de Dickens et al. (1995) evidenciaram a importância do salário mínimo para o mercado de trabalho agrícola da Inglaterra.

Gasques (1981) propôs um modelo estrutural de equilíbrio do mercado de trabalho a partir da formulação proposta por Gallasch (1975) para a determinação do salário agrícola, no qual é acrescentada uma equação que expressa o excedente de oferta de trabalho gerado por um valor de salário mínimo acima do salário de equilíbrio, como demonstrado no capítulo anterior (subitem 2.1.2). Gasques (1981) teve a mesma dificuldade de Gallasch (1975) quanto à existência de uma fonte de dados que fornecesse a quantidade de trabalho ofertado. Gasques (1981), tal como Gallasch (1975), adotou a abordagem de equações reduzidas para estimar as equações de emprego e salários agrícolas com os dados em pooling (cross section e séries temporais).

Bacha (1991) apontava pelo menos uma limitação no modelo de Gasques (1981). Este último considera que os trabalhadores permanentes e temporários são substitutos entre si, ou seja, uma categoria homogênea. Gasques (1981) admite que os trabalhadores são homogêneos ao assumir que os salários agrícolas são determinados pelas mesmas variáveis. Segundo Bacha (1991), as tarefas dos trabalhadores temporários 
e permanentes são suplementares entre si, ou seja, um deles pode suprir a ausência do outro, mas não são substitutos entre si, ou mesmo complementares. Além disso, no modelo de demanda de trabalho de Gasques (1981) não aparece a produtividade do trabalho como variável independente.

A inclusão da variável salário mínimo não é uma regra nas equações de determinação do salário, pois depende do mercado analisado e das hipóteses levantadas na equação estimada. Por exemplo, Palmer-Jones \& Parikh (1998) analisaram os determinantes do salário na agricultura em Bangladesh aplicando a metodologia de cointegração e correção de erro de Johansen-Juselins, sem usar salário mínimo como variável explicativa.

Cunha \& Maia (1984) também estimaram equações de salário agrícola para o Brasil sem considerar o salário mínimo. Esses autores propuseram um modelo considerando a existência de dois submercados de trabalho agrícola: dos trabalhadores permanentes e temporários. Os autores reconheceram a qualificação distinta entre as categorias consideradas e, portanto, geraram curvas distintas de oferta e demanda para esses dois tipos de trabalhadores. Os autores tinham como hipótese que os trabalhadores permanentes substituem os temporários, mas não ocorre o inverso. Os autores introduziram de fato a idéia de que o mercado de trabalho agrícola não é tão homogêneo, havendo pelo menos duas categorias relativamente bem definidas, os trabalhadores temporários e os permanentes.

Bacha (1991) teceu críticas sobre a hipótese de complementaridade entre os trabalhadores permanentes e temporários. Para Bacha (1991), essas duas categorias de trabalhadores são suplementares, mas não substitutas ou complementares entre si. E, mais uma vez, cabe constatar que Cunha \& Maia (1984) não consideraram a produtividade do trabalho na equação proposta, podendo haver problemas de especificação no modelo estimado. 
Bacha (1991) propôs um modelo de equilíbrio do mercado de trabalho para determinar os salários agrícolas para a cafeicultura do Estado de Minas Gerais, incorporando as críticas feitas aos outros autores. Bacha segmentou o mercado de trabalho agrícola em trabalhadores temporários e permanentes e identificou quatro tipos distintos de trabalhadores temporários, gerando quatro curvas de oferta de trabalho para essa categoria: uma para o pequeno produtor não-tecnificado e três curvas distintas para o bóia-fria - temporário, permanente e esporádico. Outro aspecto importante ressaltado pelo autor é a suplementariedade entre os trabalhadores temporários e permanentes.

Bacha (1991) usou a média móvel bianual da produtividade em sacas de café beneficiado por hectare produtivo como proxy para a produtividade do trabalho. Como o próprio autor reconhece, esta não é a medida ideal, mas pela ausência de dados para a construção de uma série temporal para a produtividade do trabalho para a cafeicultura mineira, fez-se o uso dessa proxy.

Istake (1999) analisou o mercado de trabalho agrícola do Estado do Paraná a partir dos modelos propostos por Bacha (1991), incorporando algumas alterações que contribuíram para aperfeiçoar o modelo originalmente proposto. Além disso, o trabalho do Istake (1999) apresentou avanço sobre os demais, pois incluiu a produtividade do trabalho agrícola. Apesar do avanço apresentado pela autora, ela utilizou-se da produtividade do trabalho do setor agropecuário do Brasil, sendo mais apropriado utilizar a produtividade do trabalho para o setor agropecuário do Estado do Paraná. A autora ajustou uma poligonal tentando captar a quebra de tendência detectada para os salários agrícolas.

O estudo de Gonçalves (1996) não é de caráter econométrico, mas revela um comportamento não esperado dos salários agrícolas no Estado de São Paulo, isto é, os salários decresceram entre os anos de 1987 e 1994, período esse em que foram apontados seguidos recordes de produção na agropecuária paulista e brasileira. $\mathrm{O}$ autor coloca interrogações sobre o comportamento dos salários e, de forma mais ampla, sugere que há grandes distorções na distribuição funcional da renda. Bacha (1979), analisando 
os salários agrícolas nas décadas de 50 e 60, já apontava na mesma direção, afirmando: “O aumento a longo prazo observado nos salários rurais não parece estar ligado à tendência ascendente da produtividade da mão-de-obra na agricultura de São Paulo" (Bacha, 1979, p.591).

De modo geral, os modelos que incorporam a produtividade do trabalho consideram, de forma implícita ou explícita, que a demanda de trabalho cresce até o limite em que o preço do produto multiplicado pela produtividade física do trabalho é igual ao seu salário, de acordo com os pressupostos da teoria neoclássica. Desta forma, os salários são pagos segundo a produtividade marginal do trabalho. Contudo, os trabalhos de Nicholls \& Paiva $(1966,1967)$ demonstraram que essa situação pode não ser verificada na agropecuária brasileira, em razão das falhas de mercados oriundas de problemas no próprio funcionamento do mercado ou de características regionais.

A maior parte das pesquisas econométricas sobre salários agrícolas no Brasil foram realizadas em períodos anteriores ou nas fases iniciais da modernização do setor agropecuário (Nicholls \& Paiva, 1966, 1967; Saylor, 1974; Gasques, 1975, 1981; Cunha \& Maia, 1984). Poucas pesquisas foram realizadas abrangendo o período onde o setor agropecuário já estava se modernizando (Bacha, 1988; Istake, 1999). No entanto, essas pesquisas mais recentes têm abrangência restrita às zonas produtoras de café em Minas Gerais e ao Estado do Paraná, respectivamente.

Desta forma, nota-se uma lacuna na literatura sobre a formação e o comportamento dos salários agrícolas no Brasil como um todo. Para tanto, o presente trabalho estima equações de determinação salarial dos trabalhadores agrícolas temporários e permanentes no Brasil e nas regiões menos e mais tecnificadas. Procurase, com isto, contribuir para a elucidação dos mecanismos de funcionamento do mercado de trabalho agrícola no Brasil. 


\section{MODELOS ECONOMÉTRICOS DE DETERMINAÇÃO DO SALÁRIO AGRÍCOLA NO BRASIL}

Este capítulo é dividido em três seções, sendo que a primeira (item 4.1) subdivide-se em três partes. Inicialmente, são apresentadas as características dos modelos adotados para estimar os salários de equilíbrio (subitem 4.1.1). Em seguida, são elaborados os modelos empíricos de determinação dos salários de equilíbrio para os trabalhadores temporários (subitem 4.1.2) e permanentes (subitem 4.1.3). Na segunda seção (item 4.2), são discutidos os procedimentos econométricos adotados na estimação do modelo empírico descrito anteriormente. Na última seção (item 4.3), são apresentadas as definições e as fontes dos dados utilizados.

\subsection{Modelos empíricos de determinação de salário agrícola}

\subsubsection{Considerações gerais}

Os modelos econométricos de determinação dos salários agrícolas dos trabalhadores permanentes e temporários, a serem apresentados nos próximos subitens, foram formulados a partir da construção teórica elaborada no item 2.3. Apesar deste 
modelo não ter sido anteriormente considerado na literatura, ele justifica, também, as equações usadas por Bacha (1988) e Istake (1999). Os modelos desses autores são reformulados de modo a adaptar-se aos objetivos da presente tese. Bacha (1988) incorpora algumas críticas tecidas aos trabalhos econométricos anteriormente realizados e Istake (1999) introduz algumas alterações que aperfeiçoaram os modelos propostos por Bacha (1988).

As equações de determinação dos salários dos trabalhadores temporários e permanentes são desenvolvidas a partir de um modelo de equilíbrio em concorrência perfeita. As equações foram estimadas com os dados em pooling (cross section e série temporal).

Os pontos fundamentais que foram considerados nos modelos empíricos de determinação dos salários agrícolas dos trabalhadores permanentes e temporários, de acordo com as análises efetuadas no capítulo anterior, são os seguintes:

a) distingue os trabalhadores agrícolas em duas categorias: temporários e permanentes. Esses trabalhadores compõem dois submercados, ou seja, dois segmentos dentro do mercado de trabalho agrícola. Segundo Bacha (1988), essas duas categorias de trabalhadores são suplementares entre si, ou seja, uma delas pode suprir a insuficiência de disponibilidade da outra, mas não são substitutas entre si ou, mesmo, complementares. As variáveis que deslocam as curvas de oferta dos trabalhadores temporários e permanentes não são necessariamente as mesmas. Mas, quando as variáveis que provocam esse deslocamento são as mesmas em ambas as curvas de oferta, espera-se que a intensidade do deslocamento seja diferente.

b) a oferta de mão-de-obra temporária tem dois grandes componentes: a) o pequeno proprietário não-tecnificado; e b) o bóia-fria. Este último, por sua vez, subdividese em três outros grupos de trabalhadores: o bóia-fria permanente, o esporádico e o temporário. O primeiro componente foi discutido no trabalho de Bacha (1979) 
e o segundo foi proposto por Silva (1982). O somatório desses componentes forma a curva de oferta da mão-de-obra temporária;

c) nos modelos de determinação dos salários agrícolas foi considerado como fator institucional o salário mínimo. Outros fatores institucionais neste mercado de trabalho são praticamente ausentes, tais como sindicatos e associações. Nos segmentos menos qualificados do mercado de trabalho, como visto no capítulo 3 (subitem 3.1.1), o salário mínimo tende a ter grande influência na formação salarial, servindo como um indexador.

d) segundo os modelos de concorrência perfeita, a produtividade do trabalho é uma variável influente na determinação dos salários. Desta forma, ela foi incluída nos modelos de determinação dos salários dos trabalhadores temporários e permanentes.

\subsubsection{Modelo de determinação do salário agrícola dos trabalhadores temporários}

A oferta de mão-de-obra temporária é formada pelos pequenos produtores rurais não-tecnificados e pelos bóias-frias. A seguir são apresentadas as variáveis que influenciam a oferta de trabalho de cada um desses componentes.

A oferta da mão-de-obra dos pequenos produtores não-tecnificados está relacionada com os salários dos trabalhadores temporários, com os preços recebidos pelos produtos gerados nas atividades dos pequenos produtores $(P p)$ e com os custos dos insumos aplicados em suas atividades agropecuárias $(P i)$. Estas últimas duas variáveis podem ser melhor expressas em termos de preços relativos, isto é, $P a=P p / P i$. 
A alocação da força de trabalho dos pequenos produtores rurais depende, em parte, dos preços relativos $(\mathrm{Pa})$. Caso os preços relativos sejam favoráveis aos produtos agrícolas, a força de trabalho familiar dos pequenos produtores alocada no mercado de trabalho será reduzida, já que os indivíduos dessas famílias dedicarão a maior parte do tempo em suas propriedades. Portanto, para uma dada variação de $P a$, haverá uma variação no sentido oposto na oferta da mão-de-obra, considerando a mesma taxa salarial. Na prática, esses produtores entram no mercado de trabalho como mão-de-obra temporária para completar a renda. Por exemplo, quando $P a$ for decrescente, em um espaço gráfico número de trabalhadores versus salário real, a curva de oferta se deslocaria para a direita.

A oferta de mão-de-obra do bóia-fria é composta por três tipos de trabalhadores, como foi apresentado no capítulo anterior (item 3.2):

a) mão-de-obra do bóia-fria permanente. Os indivíduos que compõem essa força de trabalho dedicam-se somente às atividades agropecuárias. Nesta situação, a oferta de trabalho é função dos salários pagos ao trabalhador temporário e é, também, influenciada pelo salário mínimo. Como este tipo de mão-de-obra é um empregado permanente disfarçado, ele se pauta pelo valor do salário mínimo quando decide qual é o salário demandado ${ }^{17}$.

b) mão-de-obra do bóia-fria esporádico. Neste caso, a oferta de trabalho é função somente do próprio salário vigente para essa ocupação, ou seja, da remuneração ao trabalhador agrícola temporário. Esses trabalhadores não pertencem ao mercado de trabalho urbano. Eles entram no mercado de trabalho agrícola quando os custos de oportunidade da sua mão-de-obra crescem, ou seja, a oferta de trabalho desta categoria cresce quando há o crescimento do salário do trabalhador temporário;

\footnotetext{
${ }^{17}$ É importante ressaltar que uma equação de oferta de trabalho é, também, uma equação de demanda de salário. Em outras palavras, em uma equação de oferta de trabalho se mede o salário desejado pelo trabalhador para cada quantidade de trabalho ofertado. No caso do bóia-fria permanente, o salário mínimo é tomado como referência para definir o salário demandado.
} 
c) a oferta de trabalho do bóia-fria temporário dependerá da possibilidade desse trabalhador obter ocupação não-qualificada e não-agrícola fora da área agrícola. A atividade mais ocorrente neste caso é a de servente de pedreiro, dentro do meio rural ${ }^{18}$ ou nos centros urbanos. Portanto, a oferta de trabalho do bóia-fria temporário será função do salário alternativo urbano (salário do servente de pedreiro), além dos salários pagos aos trabalhadores temporários.

De acordo com o exposto acima, a função de oferta de trabalho temporário tem a seguinte configuração:

$L T T=L p p+L b p+L b e+L b t$

onde:

$L T T=$ oferta de trabalho temporário;

$L p p=$ oferta de trabalho do pequeno produtor não-tecnificado;

$L b p=$ oferta de trabalho do bóia-fria permanente;

Lbe = oferta de trabalho do bóia-fria esporádico;

$L b t=$ oferta de trabalho do bóia-fria temporário.

As ofertas de trabalho por parte dos trabalhadores temporários citados acima têm o comportamento dado pelas seguintes funções na forma reduzida:

$$
\begin{aligned}
& L p p=f_{1}(W T, P a) \\
& L b p=f_{2}(W T, W M) \\
& L b e=f_{3}(W T)
\end{aligned}
$$

\footnotetext{
${ }^{18}$ Segundo Silva (1999), no meio rural, depois da atividade de serviços domésticos, é a atividade da construção civil que ocupa mais pessoas.
} 
$L b t=f_{4}(W T, W U)$

onde:

$W T$ = salário real do trabalhador temporário;

$P a=$ relação entre preços recebidos e preços pagos pelos produtores agrícolas;

$W U$ = salário real do emprego alternativo;

$W M$ = salário mínimo real.

Supondo-se que as equações (5), (6), (7) e (8) tenham formas lineares, obtêm-se as seguintes equações, com os respectivos sinais esperados dos coeficientes:

$$
\begin{array}{ll}
L p p=a_{0}+a_{1} \cdot W T+a_{2} \cdot P a & \text { onde: } a_{1}>0 \text { e } a_{2}<0 \\
L b p=b_{0}+b_{1} \cdot W T+b_{2} \cdot W M & \text { onde: } b_{1}>0 \text { e } b_{2}<0 \\
L b e=c_{0}+c_{1} \cdot W T & \text { onde: } c_{1}>0 \\
L b t=d_{0}+d_{1} \cdot W T+d_{2} \cdot W U & \text { onde: } d_{1}>0 \text { e } d_{2}<0
\end{array}
$$

A oferta total de trabalho temporário é dada pela equação (4). Fazendo a substituição das equações (9), (10), (11) e (12) na equação (4):

$L T T=A_{0}+A_{1} \cdot W T+A_{2} \cdot P a+A_{3} \cdot W U+A_{4} \cdot W M$

onde:

$$
\begin{array}{ll}
A_{0}=a_{0}+b_{0}+c_{0}+d_{0} ; & A_{1}=a_{1}+b_{1}+c_{1}+d_{1} ; \\
A_{2}=a_{2} ; & A_{3}=d_{2} ; \\
A_{4}=b_{2} &
\end{array}
$$


sendo: $A_{1}>0, A_{2}<0, A_{3}<0$ e $A_{4}<0$

A demanda de trabalho temporário, além de ser função do salário real do trabalhador temporário $(W T)$ é, também, influenciada pelos preços dos produtos comerciais $(P c)$, pelos custos dos insumos $(P i)$ e pelo nível tecnológico $(Y e)$. Istake (1999) modificou o modelo originalmente proposto por Bacha (1988) adotando a produtividade do trabalho agropecuário (Pmo) como medida de nível tecnológico e substituiu as variáveis $(P i)$ e $(P c)$ pela relação de preços recebidos e pagos pelos produtores rurais, ou seja, o índice de paridade da agropecuária, isto é, $P a=P c / P i$.

Nota-se que foi adotada a mesma variável $(P a)$ para expressar a relação de preços recebidos e pagos pelos pequenos produtores para a demanda de trabalho e oferta de trabalho dos pequenos produtores rurais [equação (5)]. Neste caso, está sendo considerada a abordagem analítica sob o ponto de vista dos sistemas agroindustriais, onde se torna pouco relevante distinguir o que é produção de grandes produtores (comerciais) e de pequenos, o que corresponderia preponderantemente à produção de produtos de exportação e domésticos, respectivamente. Atualmente, a abordagem analítica dos sistemas agroindustriais é amplamente aceita na literatura econômica. Por outro lado, a abordagem analítica que distingue a produção oriunda dos produtores grandes ou pequenos foi muito importante em um determinado recorte temporal.

Istake (1999) também considerou como argumento na equação de demanda por trabalho a variável volume físico da produção agrícola. Entretanto, no modelo aqui proposto não foi considerada essa variável, a qual teria uma interpretação mais precisa caso o modelo estimado se restringisse à análise dos salários relativos à produção de um único produto, como foi o estudo de Bacha (1988). Considerando-se que a análise do presente estudo é voltada para os salários pagos no setor agropecuário como um todo, o aumento do volume físico de produção agrícola pode ser originado da expansão de área, da mudança de composição das culturas ou aumento de produtividade. A soma desses três fatores, contudo, pode resultar em uma relação pouco precisa entre o volume da 
produção agrícola e a demanda por trabalho. $\mathrm{Na}$ literatura há vários modelos de demanda de trabalho agrícola para o setor agropecuário como um todo, os quais não têm como argumento o volume de produção (Schuh, 1962; Saylor, 1974; Gallasch, 1975; Lianos, 1972; Palmer-Jones \& Parikh, 1998). Portanto, diante destas considerações, optou-se em propor um modelo de demanda da mão-de-obra temporária que tenha a seguinte forma reduzida:

$D T T=m(W T, P a, P m o)$

onde:

$D T T=$ demanda de trabalhadores temporários;

$P a=$ relação de preços recebidos e preços pagos pelos produtores rurais;

$P m o=$ produtividade do trabalho.

Considerando a expressão (14) na forma linear, tem-se a seguinte equação:

$D T T=B_{0}+B_{1} \cdot W T+B_{2} \cdot P a+B_{3} \cdot P m o$

onde: $B_{1}<0, B_{2}>0$ e $B_{3}>0$.

A seguinte condição de equilíbrio pode ser estabelecida:

$D T T=L T T$

As equações (13), (15) e (16) formam um sistema simultâneo, no qual WT, LTT e DTT são variáveis endógenas e $W U, W M, P a$ e $P m o$ são variáveis exógenas.

Substituindo-se as expressões (13) e (15) na equação (16), tem-se:

$B_{0}+B_{1} \cdot W T+B_{2} \cdot P a+B_{3} \cdot P m o=A_{0}+A_{1} \cdot W T+A_{2} \cdot P a+A_{3} \cdot W U+A_{4} \cdot W M$

Reorganizando a expressão acima: 


$$
\begin{aligned}
& \left(B_{1}-A_{1}\right) \cdot W T=A_{0}+A_{2} \cdot P a+A_{3} \cdot W U+A_{4} \cdot W M-B_{0}-B_{2} \cdot P a-B_{3} \cdot P m o \\
& W T=\left[\left(A_{0}-B_{0}\right) /\left(B_{1}-A_{1}\right)\right]+\left[\left(A_{2}-B_{2}\right) /\left(B_{1}-A_{1}\right)\right] \cdot P a+\left[A_{3} /\left(B_{1}-A_{1}\right)\right] \cdot W U+ \\
& {\left[-B_{3} /\left(B_{1}-A_{1}\right)\right] \cdot P m o+\left[A_{4} /\left(B_{1}-A_{1}\right)\right] \cdot W M}
\end{aligned}
$$

$\mathrm{Ou}$

$$
W T=C_{0}+C_{1} \cdot P a+C_{2} \cdot W U+C_{3} \cdot P m o+C_{4} \cdot W M
$$

sendo:

$$
\begin{array}{ll}
C_{0}=\left[\left(A_{0}-B_{0}\right) /\left(B_{1}-A_{1}\right)\right] ; & C_{1}=\left[\left(A_{2}-B_{2}\right) /\left(B_{1}-A_{1}\right)\right] ; \\
C_{2}=\left[A_{3} /\left(B_{1}-A_{1}\right)\right] ; & C_{3}=\left[-B_{3} /\left(B_{1}-A_{1}\right)\right] ; \\
C_{4}=\left[A_{4} /\left(B_{1}-A_{1}\right)\right] . &
\end{array}
$$

Espera-se: $C_{1}>0, C_{2}>0, C_{3}>0$ e $C_{4}>0$.

\subsubsection{Modelo de determinação do salário agrícola dos trabalhadores permanentes}

Segundo o modelo proposto por Bacha (1988), a oferta de mão-de-obra permanente é influenciada pelo salário agrícola do trabalhador permanente e pelo salário mínimo. Além disso, esta categoria de trabalhadores normalmente recebe salário indireto, sendo este um grande incentivo para a oferta. No entanto, captar o salário indireto é extremamente difícil. O salário indireto também tem um papel importante em termos de reduzir a mobilidade deste tipo de trabalhador para outros setores da

economia. Conseqüentemente, quanto maior é o salário agrícola indireto menor é a integração entre os mercados de trabalho urbano e agrícola. A equação de oferta de mãode-obra permanente tem a seguinte forma: 
$L T P=h(W P, W M)$

onde:

$L T P=$ oferta de trabalhadores permanentes;

$W P=$ salário real dos trabalhadores permanentes;

$W M=$ salário mínimo real.

Considerando a expressão (19) na forma linear, tem-se a seguinte equação:

$L T P=c_{0}+c_{1} \cdot W P+c_{2} \cdot W M$

onde: $c_{1}>0$ e $c_{2}<0$

A equação de demanda de trabalhadores permanentes basicamente diferencia-se do modelo adotado por Istake (1999) pela exclusão da variável volume da produção agrícola, em razão das mesmas motivações apresentadas na subseção anterior (item 4.1.2). Desta forma, a equação de demanda de trabalhadores permanentes tem a seguinte forma reduzida:

$D T P=l(W P, P a, P m o)$

onde:

$D T P=$ demanda por trabalhadores permanentes;

$P a=$ relação entre preços recebidos e preços pagos pelos produtores rurais;

Pmo $=$ produtividade do trabalho.

Considerando a expressão (21) na forma linear:

$D T P=e_{0}+e_{1} \cdot W P+e_{2} \cdot P a+e_{3} \cdot P m o$ 
onde: $e_{1}<0, e_{2}>0$ e $e_{3}>0$.

Tem-se a seguinte condição de equilíbrio:

$L T P=D T P$

As equações (20), (22) e (23) formam um sistema simultâneo, onde LTP, $D T P$ e $W P$ são as variáveis endógenas; e $W M, P a$ e $P m o$ são as variáveis exógenas.

Substituindo-se as expressões (20) e (22) na equação (23), tem-se:

$c_{0}+c_{1} \cdot W P+c_{2} \cdot W M=e_{0}+e_{1} W P+e_{2} P a+e_{3} P m o$

Isolando-se WP do lado esquerdo da igualdade, têm-se:

$\left(c_{1}-e_{1}\right) \cdot W P=e_{0}+e_{2} \cdot P a+e_{3} \cdot P m o-c_{2} \cdot W M-c_{0}$

$W P=\left[\left(e_{0}-c_{0}\right) /\left(c_{1}-e_{1}\right)\right]+\left[e_{2} /\left(c_{1}-e_{1}\right)\right] \cdot P a+\left[e_{3} /\left(c_{1}-e_{1}\right)\right] \cdot P m o+\left[-c_{2} /\left(c_{1}-e_{1}\right)\right] \cdot W M(24)$

ou

$W P=G_{0}+G_{1} \cdot P a+G_{2} \cdot P m o+G_{3} \cdot W M$

onde:
$G_{0}=\left[\left(e_{0}-c_{0}\right) /\left(c_{1}-e_{1}\right)\right]$
$G_{1}=\left[e_{2} /\left(c_{1}-e_{1}\right)\right]$
$G_{2}=\left[e_{3} /\left(c_{1}-e_{1}\right)\right]$
$G_{3}=\left[-c_{2} /\left(c_{1}-e_{1}\right)\right]$

Espera-se: $G_{1}>0, G_{2}>0$ e $G_{3}>0$.

Os modelos de determinação dos salários dos trabalhadores agrícolas temporários e permanentes são representados pelas equações (18) e (25), respectivamente. 
$W T=C_{0}+C_{1} \cdot P a+C_{2} \cdot W U+C_{3} \cdot P m o+C_{4} \cdot W M$

$W P=G_{0}+G_{1} \cdot P a+G_{2} \cdot P m o+G_{3} \cdot W M$

\subsection{Procedimentos econométricos para estimar as equações (18) e (25)}

Uma das grandes dificuldades na estimação de regressões com dados temporais é a limitação do número de observações, sem contar os problemas de qualidade dos dados (o que será discutido na próxima seção, item 4.3). Para suprir esta deficiência de número limitado de dados, as equações (18) e (25) de determinação dos salários dos trabalhadores temporários e permanentes, respectivamente, foram estimadas em pooling.

As equações (18) e (25) foram estimadas para o Brasil considerando-se 18 unidades da Federação. As demais unidades da Federação não foram consideradas em razão da ausência de informações para o período total da análise (1971 a 1996). As equações (18) e (25) também foram estimadas para as regiões com o setor agropecuário menos e mais tecnificado. A região menos tecnificada é formada por nove unidades da Federação: Acre e os estados da região Nordeste, exceto Piauí (Maranhão, Ceará, Rio Grande do Norte, Paraíba, Pernambuco, Alagoas, Sergipe e Bahia). A região mais tecnificada é formada por nove unidades da Federação: os estados das regiões CentroOeste, Sudeste e Sul (Minas Gerais, Espírito Santo, Rio de Janeiro, São Paulo, Paraná, Santa Catarina, Rio Grande do Sul, Mato Grosso e Goiás) ${ }^{19}$.

\footnotetext{
${ }^{19}$ No Estado de Goiás está agregado o Estado de Tocantins, e o Estado de Mato Grosso e Mato Grosso Sul estão agregados. Esses ajustes foram necessários para se ter o número de observações iguais para todas as unidades da Federação. Portanto, trata-se de um pooling equilibrado, ou seja, a quantidade e os anos das observações são os mesmos para todas as unidades da Federação.
} 
As 18 unidades da Federação consideradas no estudo têm 25 observações anuais correspondendo ao período de 1971 a $1996^{20}$. Os dados disponíveis para a estimação dos modelos de determinação dos salários agrícolas dos trabalhadores temporários e permanentes para o Brasil e para as regiões menos e mais tecnificadas permitem montar poolings balanceados, ou seja, todas as unidades de cross section têm o mesmo número de observações para os mesmos anos.

Segundo Baltagi (1995), há algumas vantagens em estimar equações com dados em pooling. Para as estimações dos modelos definidos, equações (18) e (25), podem-se destacar os seguintes benefícios:

a) controle das heterogeneidades individuais. Os dados em pooling sugerem que as unidades de cross section (indivíduos, firmas, países ou estados) são heterogêneas. Os estudos com dados em séries temporais ou cross section em separados não controlam estas heterogeneidade, ocorrendo o risco de obter resultados viesados.

b) Os dados em pooling fornecem maior número de observações, mais variabilidade, menos problema de multicolineariedade, maior grau de liberdade e mais eficiência.

O modelo econométrico com dados em pooling tem a seguinte formulação geral:

$$
\begin{aligned}
& y_{i t}=\sum_{k=1}^{p} X_{i t k} \beta_{k}+u_{i t} \\
& i=1, \ldots, N \\
& t=1, \ldots, T
\end{aligned}
$$

\footnotetext{
${ }^{20}$ O último ano de análise corresponde ao período de coleta de dados do Censo Agropecuário de 1995/96, ou seja, agosto de 1995 a julho de 1996. Nesta situação, há apenas 25 observações anuais (1971 a 1995/96).
} 
onde:

$N=$ número de unidades de cross section;

$T$ = número de observações de cada cross section;

$k=$ número de variáveis exógenas;

$y$ = variável endógena;

$X=$ variável exógena;

$\beta=$ parâmetro;

$u=$ termo de erro.

O modelo econométrico mais adequado a ser adotado quando se tem dados em pooling deve considerar a estrutura do termo de erro $\left(u_{i t}\right)$ da equação (26).

Segundo Greene (1997), Judge et al. (1985) e Kmenta (1990), dados de painel ou pooling tendem a apresentar algumas violações dos pressupostos básicos dos Mínimos Quadrados Ordinários (MQO). Conforme estes autores e a literatura em geral, dados dessa natureza podem apresentar problemas de heterocedasticia e autocorrelação serial dos resíduos. Estes problemas estão associados, principalmente, aos dados cross section e séries temporais, respectivamente. Nos dados em pooling, normalmente estão presente problemas de correlação dos termos de erro entre as unidades de cross section, ou seja, entre as unidades da Federação, o que é denominado de correlação contemporânea.

No presente estudo assume-se que a estrutura do termo de erro pode apresentar duas formas. A primeira pressupõe que o termo de erro apresenta problema de autocorrelação serial de primeira ordem. A segunda forma pressupõe que o termo de erro apresenta três componentes. 
A primeira estrutura tem as seguintes características:

$E\left(u_{i t}^{2}\right)=\sigma_{i i}$

$E\left(u_{i t} u_{j t}\right)=\sigma_{i t}$

$u_{i t}=\rho_{i} u_{i, t-1}+\varepsilon_{i t}$. (heterocedástico)

(correlação contemporânea)

(autocorrelação serial de primeira ordem)

e os componentes $u_{i t}$ e $\varepsilon_{i t}$ satisfazem às seguintes condições:

$E\left(u_{i, t-1} \varepsilon_{j t}\right)=0$

$E\left(\varepsilon_{i t} \varepsilon_{j t}\right)=\phi_{i j}$

$E\left(\varepsilon_{i t} \varepsilon_{j s}\right)=0 \quad(s \neq t)$

$E\left(u_{i t}\right)=0$

$E\left(\varepsilon_{i t}\right)=0$

Na segunda estrutura, conforme Baltagi (1995), o termo de erro da equação (26) pode apresentar três componentes, fazendo com que a variância de $u_{i t}$, consequentemente, seja composta por três componentes. Tal característica diferencia-se da estrutura anterior que tem apenas uma variância. Na segunda estrutura, o termo de erro é denominado de "componentes" do erro do tipo two-way ${ }^{21}$, tendo a seguinte forma:

$u_{i t}=\mu_{i}+\lambda_{t}+v_{i t} \quad(i=1, \ldots, N ; t=1, \ldots, T)$

na qual:

$\mu_{i}=$ características específicas não-observáveis de cada unidade de cross section;

${ }^{21} \mathrm{O}$ termo de erro do tipo one-way é composto por apenas dois componentes: $u_{i t}=\mu_{i}+\mathrm{v}_{i t}$ 
$\lambda_{t}=$ eventos ocorridos em qualquer unidade de tempo que afetam todas as unidades de cross section;

$\mathbf{V}_{i t}=$ resultante do erro estocástico.

$\mu_{i} \sim N\left(0, \sigma_{\mu}^{2}\right)$

$\lambda_{t} \sim N\left(0, \sigma_{\lambda}^{2}\right)$

$v_{i t} \sim N\left(0, \sigma_{v}^{2}\right)$

O termo de erro $\left(u_{i t}\right)$ é homocedástico com variância dada por:

$\operatorname{Var}\left(u_{i t}\right)=\sigma^{2}=\sigma_{\mu}^{2}+\sigma_{\lambda}^{2}+\sigma_{v}^{2}$.

Esta estrutura do termo de erro torna-se particularmente importante em função de considerar o componente tempo $\left(\lambda_{t}\right)$. Segundo Baltagi (1995), o componente do termo de erro $\lambda_{t}$ não varia individualmente. Ele capta efeitos específicos no tempo que não são incluídos como parâmetro na equação de regressão. No caso da economia brasileira, os planos de estabilização monetária produziram efeitos sobre os níveis salariais da economia como um todo em determinados anos, ou seja, em determinadas unidades do tempo.

No capítulo seguinte (item 5.1) são apresentados os resultados dos testes estatísticos realizados para verificar se o termo de erro apresenta a estrutura de "componentes" ou problema de autocorrelação serial. Caso o termo de erro apresente problemas de autocorrelação serial, conforme prediz Greene (1997) e Judge (1988), as equações serão estimadas pelo método desenvolvido por Parks (1967). Caso o problema de autocorrelação serial não seja detectado, as equações serão estimadas pelo método desenvolvido por Fuller \& Battese (1974), no qual pressupõe-se que a estrutura do termo de erro é de "componentes". 
A aplicação do método de Parks é adequada quando os dados apresentam autocorrelação serial de primeira ordem. Além disto, este método corrige problema de correlação contemporânea e admite ser aplicado na presença de heterocedasticia.

Guilkey \& Schimdt (1973) e Guilkey (1974) aplicaram e verificaram que o método proposto por Parks (1967) produz estimadores assintoticamente eficientes. O método de Parks (1967) apresenta três etapas para a obtenção do estimador desejado:

a) cada unidade de cross section é estimada pelo método dos MQO para obter um estimador consistente do $\rho$ (coeficiente de autocorrelação). Este estimador é obtido para que os dados da equação sejam transformados pelo procedimento Prais-Winstern, com a finalidade de remover a autocorrelação serial do termo de erro.

b) estima-se novamente a equação pelo MQO com os dados transformados, ou seja, com o problema de autocorrelação corrigido. Por meio desta estimação, calcula-se a matriz de covariância do termo de erro;

c) usando da matriz de covariância do termo de erro estimada no item (b), estimam-se os parâmetros do modelo pelo método dos Mínimos Quadrados Generalizados, corrigindo o problema de correlação contemporânea.

Segundo Greene (1997), assumir que exista um $\rho$ comum para todas as unidades de cross section é uma restrição. Entretanto, segundo o autor, isto não é tão grave quanto assumir que o conjunto dos dados é homocedástico. Por outro lado, este tipo de restrição é facilmente aceita se o número de observações de cada cross section ( $T$ ) for pequeno. No caso deste estudo, $T$ não pode ser considerado como reduzido, conseqüentemente, é mais adequado estimar um $\rho$ para cada unidade de cross section, como prevê o método de Parks (1967).

Segundo Parks (1967), os procedimentos dos itens (b) e (c) equivalem ao método de Dois Estágios de Zellner (1962). Cabe ressaltar que o $\rho$ estimado é 
calculado para cada unidade de cross section, e não para o conjunto dos dados. Portanto, deve-se verificar a existência de autocorrelação serial para cada unidade de cross section.

Supondo que esteja ausente o problema de autocorrelação serial no conjunto das unidades de cross section, o modelo de "componente" torna-se o mais adequado. Como visto anteriormente, este modelo econométrico considera que o temo de erro é homocedástico. No entanto, conforme afirma Baltagi (1995), o modelo de Fuller \& Battese (1974) admite que o componente $\mu_{i}$ do termo de erro possa apresentar heterocedasticia de grupo, relaxando a pressuposição apresentada inicialmente. O componente do termo de erro dos efeitos específicos não-observáveis de cada unidade de cross section $\left(\mu_{i}\right)$ deve apresentar a seguinte característica: $\mu_{i} \sim\left(0, w_{i}^{2}\right)$.

Esta situação demonstrada por Baltagi (1995) é fundamental, pois remove uma restrição severa do modelo econométrico de Fuller \& Battese (1974). Segundo Greene (1997), os modelos de "componentes" de erro apresentam heterocedasticia de grupo. Isto significa que cada unidade de cross section tem uma variância do termo de erro distinta, podendo-se, por meio da aplicação do método de estimação dos Mínimos Quadrados Generalizados, estimar parâmetros assintoticamente eficientes.

Portanto, $\mu_{i}$ na forma de vetor, tem as seguintes características:

$$
\mu_{i} \sim\left(0, \Sigma_{\mu}\right)
$$

onde:

$\Sigma_{\mu}=\operatorname{diag}\left[w_{i}^{2}\right]$, sendo uma matriz diagonal com as dimensões de $N$ x $N$.

O método de Fuller \& Battese (1974) apresenta basicamente três etapas para a obtenção do estimador desejado (SAS, 1993b): 
a) calculam-se estimadores das variâncias de cada componente do termo de $\operatorname{erro}\left(\sigma_{\mu}^{2}, \sigma_{\lambda}^{2}, \sigma_{v}^{2}\right)$;

b) os estimadores são calculados por método dos Mínimos Quadrados Generalizados seguindo as seguintes etapas:

$b_{1}$ ) são obtidas constantes usando os estimadores das variâncias dos componentes do termo de erro;

$\mathrm{b}_{2}$ ) as constantes obtidas são usadas para transformar os dados que serão utilizados para estimar as equações;

$\mathrm{b}_{3}$ ) faz-se a regressão dos dados estimados aplicando o método dos Mínimos Quadrados Ordinários.

\subsection{Definição das variáveis e fontes de dados}

As variáveis das equações (18) e (25) foram definidas e obtidas da seguinte forma:

$W T=$ salário real dos trabalhadores agrícolas temporários. Os dados foram obtidos na Fundação Getúlio Vargas - RJ e correspondem à remuneração diária dos trabalhadores diaristas. Os valores foram corrigidos pelo IGP-DI, data-base agosto de 1994, e transformados em médias anuais;

$W P=$ salário real dos trabalhadores agrícolas permanentes. Os dados foram obtidos na FGV - RJ e correspondem à remuneração mensal da categoria dos trabalhadores permanentes. Os valores foram corrigidos pelo IGP-DI, data-base agosto de 1994, e transformados em médias anuais; 
$W U$ = salário real do emprego urbano alternativo. Consideroutse como "proxy" a média anual do salário do servente de pedreiro da construção civil para as respectivas capitais das unidades da Federação. Os dados foram coletados no Anuário Estatístico do Brasil publicado pelo IBGE. Em seguida, esses valores foram corrigidos pelo IGP-DI, data-base agosto de 1994, e transformados em médias anuais, conforme a sua disponibilidade. Os diversos números do Anuário Estatístico do Brasil não seguem um padrão uniforme, ao longo dos anos, de publicação dos salários de servente de pedreiro. A disponibilidade dos dados é mensal, no entanto, não se repete para os mesmos meses durante os anos considerados na análise, tendo as seguintes variações: a) os dados são disponíveis somente para os meses de março, junho, setembro e dezembro para alguns anos; b) para outros anos os dados somente são disponíveis para os meses junho e dezembro, exceto em algumas capitais (para as quais são publicados dados mensais para todos os meses do ano). Nesta última situação (b), os dados foram coletados somente para os meses de junho e dezembro, inclusive para estas capitais que apresentam dados mensais para o ano todo. Na primeira situação (a), fez-se as médias anuais, pois era possível uniformizar a série de dados;

$W M=$ salário mínimo real. Os dados foram coletados no Anuário Estatístico do Brasil publicado pelo IBGE, para as respectivas regiões das unidades da Federação. Somente a partir 1984, o salário mínimo foi unificado para todas as regiões. Os valores nominais foram corrigidos pelo IGP-DI, data-base agosto de 1994, e transformados em médias anuais;

$P a=$ índice de relação de preços recebidos e pagos pelos produtores rurais das unidades da Federação. Consideroutse como "proxy" a relação média anual entre os Índices de Preços Recebidos e os Índices de Preços Pagos pelos Produtores Rurais, construídos pela FGV-RJ. Os dados foram coletados na Revista Conjuntura Econômica. Esses Índices não estão disponíveis para todas as unidades da Federação. Essa situação foi solucionada utilizando-se o Índice do estado mais próximo; 
$P m o=$ índice da produtividade do trabalho agropecuário. Foi calculado a partir dos dados da pesquisa de Gasques \& Conceição (2000). Os autores calcularam o índice de Tornqvist para todas as unidades da Federação, utilizando os dados dos Censos Agropecuários dos anos de 1970, 1975, 1980, 1985 e 1995/96. Entre os anos Censitários, o índice de produtividade do trabalho foi calculado pela taxa geométrica de crescimento.

O cálculo da produtividade do trabalho agrícola por meio do índice Tornqvist, realizado por Gasques \& Conceição (2000), tende a minimizar o problema de subestimação dos dados do Censo Agropecuário de 1995/96, conforme constatação do próprio IBGE (Censo Agropecuário, 1998) ${ }^{22}$. O índice Tornqvist é aplicado para calcular a produtividade total dos fatores, assim como de cada fator de produção. A idéia básica na construção desse índice refere-se à identidade que há entre o valor total da produção e o valor total do custo de produção. Para atingir tal identidade, o fundamental é o valor gasto com cada fator que, por sua vez, será um fator de ponderação para o total dos custos. Portanto, quando se realiza esta ponderação, reduz-se a subestimação do fator trabalho, pois outros fatores de produção também tendem a estar subestimados.

A produtividade do trabalho, utilizando os dados censitários, poderia ser calculada pela metodologia aplicada por Hoffmann et al. (1985). Entretanto, os dados subestimados do Censo Agropecuário 1995/96 acarretariam a subestimação da produtividade do trabalho em relação aos demais anos censitários.

Os dados utilizados nas estimativas das equações (18) e (25) estão no Apêndice 2 .

\footnotetext{
22 Os trabalhos de Hoffmann \& Silva (1999) e Vicente (1998) discutem o problema de subestimação dos dados do Censo Agropecuário de 1995/96 em relação aos Censos anteriores.
} 


\section{APLICAÇÃO EMPÍRICA DOS MODELOS DE DETERMINAÇÃO DE SALÁRIOS AGRÍCOLAS}

Este capítulo está dividido em duas seções. Na primeira (item 5.1) são realizados os testes estatísticos com a finalidade de verificar o melhor procedimento econométrico para estimar as equações (18) e (25) de determinação dos salários dos trabalhadores temporários e permanentes, respectivamente. Por meio desses testes podese inferir sobre a estrutura do termo de erro, o qual indica o procedimento econométrico mais adequado a ser utilizado. Na segunda seção (item 5.2) são apresentados os resultados estimados dos modelos de determinação dos salários agrícolas. Esta seção é composta em duas partes. Na primeira (item 5.2.1) são apresentados e analisados os resultados da estimação dos modelos de determinação dos salários dos trabalhadores temporários. Na segunda parte (item 5.2.2) são apresentados e analisados os resultados da estimação dos modelos de determinação dos salários dos trabalhadores permanentes.

\subsection{Análise da estrutura do termo de erro}

No capítulo 4 (item 4.3) foram apresentados dois métodos econométricos: método de Parks e de Fuller \& Battese. A análise da estrutura do termo de erro apontará qual será o procedimento mais adequado para estimar as equações (18) e (25) de 
determinação dos salários dos trabalhadores temporários e permanentes, respectivamente. O ponto básico a ser verificado é a presença ou não de autocorrelação serial de primeira ordem nos resíduos. O método de Parks estima o coeficiente de autocorrelação $\left(\rho_{i}\right)$ para cada unidade de cross section (que no presente estudo corresponde a cada unidade da Federação). A autocorrelação serial é corrigida individualmente para cada unidade de cross section por meio da aplicação dos seus respectivos $\rho_{i}, i=1, \ldots, N$, para transformar os dados, conforme discutido no capítulo anterior (item 4.3).

Segundo Greene (1997) e SAS (1993a), o procedimento estatístico para verificar a existência de autocorrelação serial para cada unidade de cross section consiste em estimar os modelos de determinação dos salários dos trabalhadores temporários e permanentes, equações (18) e (25), para cada unidade de cross section (ou seja, para cada unidade da Federação) pelo método MQO, com os dados em logaritmo neperiano, e verificar a significância estatística do teste Durbin-Watson.

A Tabela 1 mostra os resultados dos testes Durbin-Watson para as estimativas das equações (18) e (25) para as 18 unidades de cross section. Nenhuma das unidades, nas estimativas de ambas equações, apresentaram problemas de autrocorrelação serial do resíduo a $1 \%$ de significância estatística. Na estimação da equação (18), das 18 unidades de cross section, 8 não apresentaram autocorrelação serial e 10 apresentaram resultados inconclusivos. Na estimação da equação (25), das 18 unidades de cross section, 15 não apresentaram autocorrelação serial e três unidades de cross section apresentaram resultados inconclusivos. Estes resultados, portanto, não evidenciam a presença de autocorrelação serial nos resíduos no conjunto das equações estimadas.

Considerando-se os resultados dos testes realizados, pressupõe-se que as equações a serem estimadas tenham uma estrutura de "componentes" do termo de erro. Desta forma, acredita-se que o procedimento econométrico de Fuller \& Battese é o mais 
adequado como discutido no capítulo anterior (item 4.3). No Apêndice 3 é descrito com mais detalhes o método de Fuller \& Battese.

Tabela 1. Teste Durbin-Watson das equações de determinação dos salários dos trabalhadores temporários e permanentes, respectivamente, equações (18) e (25).

\begin{tabular}{lcc}
\hline \multirow{2}{*}{ Unidade da Federação } & \multicolumn{2}{c}{ DW calculado } \\
\cline { 2 - 3 } & Equação de Salário Temporário & Equação de Salário Permanente \\
\hline Acre & $1,43^{\mathrm{b}}$ & $1,35^{\mathrm{b}}$ \\
Maranhão & $1,82^{\mathrm{a}}$ & $2,31^{\mathrm{a}}$ \\
Ceará & $1,74^{\mathrm{a}}$ & $1,50^{\mathrm{a}}$ \\
Rio Grande do Norte & $1,48^{\mathrm{b}}$ & $1,42^{\mathrm{a}}$ \\
Paraíba & $1,40^{\mathrm{b}}$ & $1,55^{\mathrm{a}}$ \\
Pernambuco & $1,63^{\mathrm{a}}$ & $1,16^{\mathrm{b}}$ \\
Alagoas & $1,63^{\mathrm{a}}$ & $2,29^{\mathrm{a}}$ \\
Sergipe & $1,53^{\mathrm{a}}$ & $2,25^{\mathrm{a}}$ \\
Bahia & $1,50^{\mathrm{b}}$ & $1,94^{\mathrm{a}}$ \\
Minas Gerais & $1,36^{\mathrm{b}}$ & $0,89^{\mathrm{b}}$ \\
Espírito Santo & $1,18^{\mathrm{b}}$ & $1,64^{\mathrm{a}}$ \\
Rio de Janeiro & $1,75^{\mathrm{a}}$ & $1,77^{\mathrm{a}}$ \\
São Paulo & $1,29^{\mathrm{b}}$ & $2,28^{\mathrm{a}}$ \\
Paraná & $1,53^{\mathrm{a}}$ & $1,42^{\mathrm{a}}$ \\
Santa Catarina & $1,27^{\mathrm{b}}$ & $1,53^{\mathrm{a}}$ \\
Rio Grande do Sul & $1,32^{\mathrm{b}}$ & $1,38^{\mathrm{a}}$ \\
Mato Grosso & $1,16^{\mathrm{b}}$ & $1,48^{\mathrm{a}}$ \\
Goiás & $1,62^{\mathrm{a}}$ & $1,76^{\mathrm{a}}$ \\
\hline
\end{tabular}

Fonte: Dados da pesquisa.

a não há autocorrelação ao nível de significância de $1 \%$; $^{\text {b }}$ inconclusivo ao nível de significância de $1 \%$.

O método de Fuller \& Battese admite que os dados apresentam heterocedasticia de grupo. Para certificar-se que os dados aplicados nas estimações apresentam problemas dessa natureza, foram realizados testes estatísticos sugeridos por Greene (1997). Segundo este autor, o teste do multiplicador de Lagrange (LM) é o mais indicado para detectar heterocedasticia de grupo.

Conforme Greene (1997), o multiplicador de Lagrange (LM) apresenta a seguinte expressão: 
$\mathrm{LM}=\sum_{i=1}^{N}\left[\frac{T}{2 s^{2}}\left(\frac{s_{i}^{2}}{s^{2}}-1\right)\right]^{2}\left(\frac{2 s^{4}}{T}\right)$

$\mathrm{Ou}$

$\mathrm{LM}=\frac{T}{2} \sum_{i=1}^{N}\left[\frac{s_{i}^{2}}{s^{2}}-1\right]^{2}$

Os estimadores da variância $\left(s^{2}\right)$ do LM podem ser calculados a partir do MQO. O teste LM tem $N-1$ graus de liberdade e distribuição Qui-Quadrado.

Aplicando a expressão (29) aos dados que são utilizados nas estimativas das equações (18) e (25), obtêm-se os resultados do teste de heterocedasticia de grupo apresentados m Tabela 2. Pode-se verificar, por meio dessa tabela, que os dados das equações de determinação dos salários dos trabalhadores temporários e permanentes no Brasil e nas regiões menos e mais tecnificadas são significativos ao nível de 1\%, exceto para a equação dos salários dos trabalhadores temporários para a região mais tecnificada, que teve nível de significância de 5\%. Desta forma, segundo Greene (1997), confirma-se a existência de heterocedasticia de grupo.

Os resultados das tabelas 1 e 2 indicam que a estrutura de "componentes" do termo de erro é a que melhor se ajusta aos dados utilizados nas estimativas das equações (18) e (25), em razão das evidências de ausência de autocorrelação serial e a existência de heterocedasticia de grupo. Desta forma, o método de Fuller \& Battese apresenta-se mais adequado em relação ao método de Parks para efetuar as estimativas das equações de determinação dos salários dos trabalhadores temporários e permanentes no Brasil e nas regiões menos e mais tecnificadas. 
Tabela 2. Teste de heterocedasticia de grupo (teste LM) dos dados das equações de determinação dos salários dos trabalhadores temporários e permanentes no Brasil e nas regiões menos e mais tecnificadas.

\begin{tabular}{lcc}
\hline & Trabalhadores Temporários & Trabalhadores Permanentes \\
\hline Brasil & $69,18^{\mathrm{a}}$ & $108,97^{\mathrm{a}}$ \\
Região menos tecnificada & $23,54^{\mathrm{a}}$ & $31,27^{\mathrm{a}}$ \\
Região mais tecnificada & $16,90^{\mathrm{b}}$ & $41,31^{\mathrm{a}}$ \\
\hline
\end{tabular}

Fonte: Dados da pesquisa.

${ }^{a}$ significativo ao nível de $1 \% ;{ }^{\text {b }}$ significativo ao nível de $5 \%$.

\subsection{Equações de determinação dos salários agrícolas}

Esta seção é composta por duas partes. Na primeira (item 5.2.1), são analisados os resultados da estimação da equação dos salários dos trabalhadores temporários e, a segunda parte (item 5.2.2), os resultados da estimação da equação dos salários dos trabalhadores permanentes.

Três conjuntos de regressões foram estimados. $\mathrm{O}$ primeiro conjunto considera o período de 1971 a 1996 como um todo. Esses resultados são apresentados nos itens a seguir. $\mathrm{O}$ segundo conjunto considera dois subperíodos na série de tempo. Isto foi feito devido a diferentes comportamentos dos salários durante os 26 anos em análise. As regressões por subperíodos estão no Apêndice 4. O terceiro conjunto foi estimado com a variável tendência e os resultados obtidos (Apêndice 5) foram semelhantes às estimativas com o modelo original (o primeiro conjunto de equações), ou seja, sem a variável tendência, ocorrendo apenas um pequeno aumento do coeficiente $\mathrm{R}^{2}$. Comparando o primeiro e o segundo conjuntos de regressões, constata-se que os melhores resultados em termos econométricos foram obtidos quando se analisa o período de 1971 a 1996 como um todo. 
Analisando os resultados das tabelas 3 e 4, constata-se, de modo geral, que as regressões por regiões apresentaram melhores resultados econométricos do que para todo o Brasil. Isto justifica a análise se focar nas regressões por regiões.

Os valores de $\mathrm{R}^{2}$ das regressões apresentadas nas tabelas 3 e 4 são pequenos. No entanto, valores similares foram encontrados nos trabalhos de Kruger \& Summers (1988), Neumark \& Wascher (2000) e Card \& Krueger (2000) que utilizaram os mesmos tipos de dados (cross section e séries temporais) adotados na presente tese. Além disso, de acordo com Draper \& Smith (1981), em regressões que procuram avaliar a influência das variáveis explicativas na determinação da variável dependente, a estatística $\mathrm{F}$ deve ser priorizada em relação ao $\mathrm{R}^{2}$. Observando-se, novamente, as tabelas 3 e 4 , constata-se que as estatísticas $\mathrm{F}$ foram significativas a $1 \%$.

As regressões foram calculadas com os dados transformados em logaritmo neperiano. Desta forma, obtêm-se os coeficientes de elasticidade das variáveis explicativas.

Para todas as regressões estimadas nas tabelas 3 e 4, os componentes da variância $\sigma_{\mu}^{2}, \sigma_{\lambda}^{2}$ e $\sigma_{v}^{2}$ são pequenos. Desta forma, eles não evidenciam problemas de ajustamento $^{23}$

\footnotetext{
${ }^{23}$ No Apêndice 3 é discutido este aspecto dos modelos com estrutura de "componentes" do termo de erro.
} 
Tabela 3. Resultados das estimativas das equações de determinação dos salários dos trabalhadores temporários pelo método de Fuller \& Battese no período de 1971 a $1996^{*}$.

\begin{tabular}{cccc}
\hline & Brasil & Região menos tecnificada & Região mais tecnificada \\
\hline Intercepto & $1,3267^{\mathrm{a}}$ & $-1,6439^{\mathrm{c}}$ & $0,1593^{\mathrm{ns}}$ \\
& $(3,18)$ & $(-1,88)$ & $(0,34)^{\mathrm{n}}$ \\
$W M$ & $0,0086^{\mathrm{ns}}$ & $0,5580^{\mathrm{a}}$ & $0,4470^{\mathrm{a}}$ \\
$W U$ & $(0,13)$ & $(3,44)$ & $(5,24)$ \\
& $0,1699^{\mathrm{a}}$ & $0,1372^{\mathrm{a}}$ & $0,0925^{\mathrm{d}}$ \\
$P a$ & $(4,13)$ & $(2,35)$ & $(1,53)^{\mathrm{a}}$ \\
& $-0,0005^{\mathrm{ns}}$ & $0,0231^{\mathrm{ns}}$ & $0,0379^{\mathrm{ns}}$ \\
$P m o$ & $(0,0181)$ & $(0,63)$ & $(1,06)$ \\
& $0,0668^{\mathrm{d}}$ & $0,1090^{\mathrm{d}}$ & $-0,0935^{\mathrm{b}}$ \\
$\sigma_{\mu}^{2}$ & $(1.91)$ & $(1,51)$ & $(-2,34)$ \\
$\sigma_{\lambda}^{2}$ & 0,0317 & 0,0114 & 0,0142 \\
$\sigma_{v}^{2}$ & 0,0238 & 0,0261 & 0,0184 \\
$\mathrm{R}^{2}$ & 0,0079 & 0,0058 & 0,0065 \\
$\mathrm{~F}$ & & & \\
Média $W T^{* *}$ & 0,0472 & 0,1439 & 0,1784 \\
DP $W T$ & $5,24^{\mathrm{a}}$ & $9,24^{\mathrm{a}}$ & $11,94^{\mathrm{a}}$ \\
\hline
\end{tabular}

Fonte: dados da pesquisa.

* os valores entre parênteses são ost-student calculados.

** corrigido pelo IGP-DI agosto de 1994.

$W T=$ salários dos trabalhadores temporários $W M=$ salário mínimo; $W U=$ salário do trabalho alternativo (servente de pedreiro); $P a=$ relação de preços recebidos e pagos pelos produtores rurais; $P m o=$ produtividade do trabalho; $\sigma_{\mu}^{2}=$ variância de $\mu_{i} ; \sigma_{\lambda}^{2}=$ variância de $\lambda_{t} ; \sigma_{v}^{2}=$ variância de $v_{i t} ; \mathrm{DP}=$ desvio padrão.

a significativo ao nível de $1 \%$; ${ }^{\mathrm{b}}$ significativo ao nível de $5 \%$; ${ }^{\mathrm{c}}$ significativo ao nível de $10 \%$; ${ }^{\text {d }}$ significativo ao nível de $20 \%$; ns não-significativo. 
Tabela 4. Resultados das estimativas das equações de determinação dos salários dos trabalhadores permanentes pelo método de Fuller \& Battese no período de 1971 a $1996 *$.

\begin{tabular}{cccc}
\hline & Brasil & Região menos tecnificada & Região mais tecnificada \\
\hline Intercepto & $0,6849^{\mathrm{c}}$ & $0,3083^{\mathrm{ns}}$ & $-0,0329^{\mathrm{ns}}$ \\
& $(1,80)$ & $(0,41)$ & $(-0,09)$ \\
$W M$ & $0,6718^{\mathrm{a}}$ & $0,7525^{\mathrm{a}}$ & $0,8830^{\mathrm{a}}$ \\
& $(11,36)$ & $(5,87)$ & $(15,15)$ \\
& $-0,0340^{\mathrm{ns}}$ & $-0,0361^{\mathrm{ns}}$ & $0,0156^{\mathrm{ns}}$ \\
$P m o$ & $(-1,25)$ & $(-0,85)$ & $(0,48)$ \\
& $0,1699^{\mathrm{a}}$ & $0,1544^{\mathrm{b}}$ & $0,1289^{\mathrm{a}}$ \\
$\sigma_{\mu}^{2}$ & $(4,87)$ & $(1,99)$ & $(3,64)$ \\
$\sigma_{\lambda}^{2}$ & 0,0218 & 0,0180 & 0,0035 \\
$\boldsymbol{\sigma}_{v}^{2}$ & 0,0080 & 0,0122 & 0,0051 \\
$\mathrm{R}^{2}$ & 0,0086 & 0,0071 & 0,0074 \\
$\mathrm{~F}$ & & & 0,5538 \\
Média $W P^{* *}$ & 0,2602 & 0,1645 & $91,43^{\mathrm{a}}$ \\
DP $W P$ & $52,29^{\mathrm{a}}$ & $14,05^{\mathrm{a}}$ & 139,91 \\
\hline
\end{tabular}

Fonte: Dados da pesquisa.

* os valores entre parênteses são ost-student calculados.

** corrigido pelo IGP-DI agosto de 1994.

$W P=$ salários dos trabalhadores permanentes $W M=$ salário mínimo; $P a=$ relação de preços recebidos e pagos pelos produtores rurais; $P m o=$ produtividade do trabalho; $\sigma_{\mu}=$ variância de $\mu_{i} ; \sigma_{\lambda}=$ variância de $\lambda_{t} ; \sigma_{v}=$ variância de $v_{i t} ; \mathrm{DP}=$ desvio padrão.

a significativo ao nível de $1 \%$; ${ }^{\text {b }}$ significativo ao nível de $5 \%$; $^{\mathrm{c}}$ significativo ao nível de $10 \%$; ${ }^{\mathrm{d}}$ significativo ao nível de $20 \%$; ${ }^{\text {ns }}$ não-significativo.

\subsubsection{Equação de determinação dos salários dos trabalhadores temporários}

Na Tabela 3 são apresentados os resultados das estimativas do modelo de determinação dos salários dos trabalhadores temporários, equação (18), aplicados para o Brasil e para as regiões menos e mais tecnificadas. ${ }^{24}$ Verifica-se na Tabela 3 que o

${ }^{24} W T=C_{0}+C_{1} \cdot P a+C_{2} \cdot W U+C_{3} \cdot P m o+C_{4} \cdot W M$ 
salário médio diário dos trabalhadores temporários nas regiões menos e mais tecnificadas são $\mathrm{R}$ \$ 4,49 e R \$ 6,25, respectivamente. Ou seja, o salário dos trabalhadores na região mais tecnificada é 39\% maior em relação à região menos tecnificada. Verificase, também, que o desvio padrão dos salários dos trabalhadores temporários no Brasil é superior aos demais conjuntos dos dados. A seguir, são efetuadas as análises de cada equação.

\subsubsection{Determinação dos salários dos trabalhadores temporários no Brasil}

Os resultados das estimativas dos salários temporários no Brasil mostram que o salário mínimo $(W M)$ e a relação de preços recebidos e pagos pelos produtores rurais $(P a)$ não são estatisticamente significativos.

O coeficiente do salário mínimo $(0,0086)$ não foi estatisticamente significativo para a estimativa no Brasil. Neste caso, pelo que foi discutido no capítulo 3 (item 3.1) sobre a importância do salário mínimo na formação dos salários dos trabalhadores urbanos não-qualificados, o coeficiente do salário mínimo deveria ser significativo e provavelmente com uma grande magnitude. Entretanto, os resultados apresentados na Tabela 3 não confirmam o esperado. Pode-se inferir que a agregação das regiões menos e mais tecnificadas deve ter contribuído para a não-significância estatística desse coeficiente.

O coeficiente do salário alternativo $(0,1699)$, em termos estatísticos, foi altamente significativo e com sinal esperado, conforme o modelo teórico. O salário alternativo influenciou na determinação dos salários dos trabalhadores temporários positivamente, isto é, o salário do trabalho alternativo desloca a força de trabalho de um setor da economia para outro. O deslocamento da força de trabalho agrícola para o setor 
urbano é incentivado pelos salários mais altos e pela possibilidade de usufruir dos serviços públicos disponíveis nas zonas urbanas.

O coeficiente da relação de preços recebidos e pagos pelos produtores rurais $(-0,0005)$ também não foi estatisticamente significativo. De fato, esperava-se que quanto maior fosse a relação de preços recebidos e pagos pelos produtores rurais $(\mathrm{Pa})$ maior fossem os salários dos trabalhadores temporários. A variável $P a$, dentre as variáveis explicativas, é a que apresenta uma interpretação menos precisa. Para exemplificar essa imprecisão, suponha que a $\mathrm{Pa}$ aumente em razão da queda dos preços pagos pelos produtores rurais (denominador dessa relação). De fato, esta situação não deixa claro o quanto foi a contribuição do fator trabalho em relação aos demais fatores de produção para a redução dos preços pagos pelos produtores rurais.

Dois mecanismos de ajustamento da $P a$ devem ser considerados, conforme discutido no capítulo 4 (item 4.2): pelo lado da oferta e pelo lado da demanda. Pode-se argumentar que $P a$ não foi importante para reduzir a oferta e/ou aumentar a demanda por mão-de-obra. Alternativamente, pode-se inferir que a redução da oferta não foi suficientemente influenciada por $P a$, ou o aume nto da demanda não foi suficientemente influenciado por $P a$.

Do ponto de vista da demanda, caso ocorresse um crescimento da $P a$ e os salários dos trabalhadores não aumentassem, os produtores rurais estariam auferindo ganhos com a $P a$ favorável e não estariam repassando para os salários; com isto, $P a$ não estaria influenciando na determinação dos salários dos trabalhadores temporários.

Do ponto de vista da oferta, é possível que um crescimento da $P a$ leve os pequenos produtores rurais a reduzir a oferta de mão-de-obra. No entanto, esta situação pode não estar sendo refletida no mercado de trabalho em razão de problemas estruturais do setor agropecuário. Entre os vários problemas estruturais ${ }^{25}$, observa-se a formação de um excedente de força de trabalho agrícola que minimiza o efeito de variações de $P a$

${ }^{25}$ Ver mais detalhes em Castro (1986). 
sobre a curva de oferta. Isto corre em razão de vários fatores, no entanto, há dois movimentos que estão em curso no setor agropecuário que contribuem para este problema estrutural: a adoção de tecnologias que reduz o emprego e o crescimento da concentração da propriedade da terra.

O coeficiente da variável produtividade do trabalho é estatisticamente significativo e apresenta sinal positivo. Deve-se notar que o valor não é alto $(0,0668)$ quando se compara com o coeficiente do salário alternativo. Nota-se que o período analisado foi de grande crescimento da produtividade de todos os fatores de produção, mas, na equação estimada, o coeficiente da produtividade do trabalho foi de magnitude reduzida.

A estimação da equação de determinação dos salários agrícolas dos trabalhadores temporários no Brasil pode ter apresentado resultados menos precisos em termos da significância dos coeficientes (como foram os casos dos coeficientes do salário mínimo e da relação de preços recebidos e pagos pelos produtores rurais) em razão da agregação das regiões menos e mais tecnificadas. A seguir são analisados os resultados das equações estimadas para as regiões menos e mais tecnificadas.

\subsubsection{Determinação dos salários dos trabalhadores temporários na região menos tecnificada}

Os resultados da equação do modelo de determinação dos salários dos trabalhadores temporários na região menos tecnificada (Acre e os estados da região Nordeste, exceto Piauí), apresentados na Tabela 3, mostram o coeficiente de determinação da regressão de 0,1439 e a estatística F significativa ao nível de $1 \%$.

O coeficiente do salário mínimo $(W M)$ é positivo e altamente significativo estatisticamente. O coeficiente do $W M(0,5580)$ é o de maior magnitude na equação, 
portanto, o efeito desse coeficiente na determinação dos salários dos trabalhadores temporários foi bastante significativo no período analisado (1971 a 1996). O WM deve estar funcionando como uma espécie de indexador, conforme discutido no capítulo 3 (item 3.1). Nesta circunstância, fatores institucionais, mais especificamente o salário mínimo, tiveram grande peso na determinação dos salários dos trabalhadores agrícolas e, provavelmente, introduzindo mecanismos de imperfeições de mercado.

A importância do salário mínimo na determinação dos salários dos trabalhadores temporários, expressa nos resultados da estimação do modelo, não deixa claro a magnitude dessa remuneração em relação ao salário mínimo (WM). Para tanto, foi plotada no Gráfico 5 a relação média entre os salários dos trabalhadores temporários (equivalente a 25 dias trabalhados) e o WM. Observa-se que os salários dos trabalhadores temporários (WT), em grande parte do período analisado, foram inferiores ao $W M$, ou muito próximos. Os $W T$ foram superiores ao $W M$ em boa parte dos anos 70 . Neste período ocorreram taxas positivas de crescimento do Produto Interno Bruto (PIB) brasileiro e o processo de convergência dos $W M$ regionais. $\mathrm{O} W M$ foi unificado em maio de 1984. Para cumprir tal meta, o governo federal implantou uma política de crescimento do $W M$ em termos reais nas regiões Norte e Nordeste, onde os valores eram menores em relação às demais regiões. Por outro lado, tal política reduziu o $W M$ em termos reais nas regiões Sudeste e Sul, com a finalidade de convergir e unificar os $W M$ adotados no país. Novamente, no início dos Planos Cruzado e Real, com a estabilização do valor de compra da moeda, os salários da economia como um todo tiveram abruptos crescimentos do poder de compra e a relação $W T / W M$ foi superior a 1.

Na região menos tecnificada, o salário mínimo até 1984 era menor que na região mais tecnificada. Portanto, comparativamente, a relação $W T / W M$ na região menos tecnificada em relação à região mais tecnificada está superestimada até esta data.

A institucionalização do salário mínimo, em 1963, para o mercado de trabalho agrícola não foi suficiente para garantir que o salário médio fosse igual ou superior ao mínimo. Os $W T$ em torno do $W M$ (como foram constatados no Gráfico 5) 
representam uma situação hipotética. De fito, em todo o período da análise, os WT tendem a ser superestimados, pois, nesta situação hipotética, considerou-se a renda de um indivíduo que dedica 25 dias do mês na atividade agropecuária. Tratando-se de atividade temporária, com caráter sazonal, dificilmente se encontra trabalho o ano todo para garantir uma renda mensal equivalente a 25 dias de trabalho.

Além disto, alguns direitos trabalhistas para o trabalhador temporário não são resguardados ou são freqüentemente violados. Com efeito, a renda média anual de um trabalhador que ganha salário mínimo na economia formal é muito maior do que um trabalhador temporário, pois este último não tem direitos trabalhistas resguardados por Lei, como férias remuneradas e décimo terceiro salário. Quando esse trabalhador temporário está na informalidade, o problema é muito mais grave. Também ficam ausentes outros direitos, como o previdenciário por tempo de serviço.

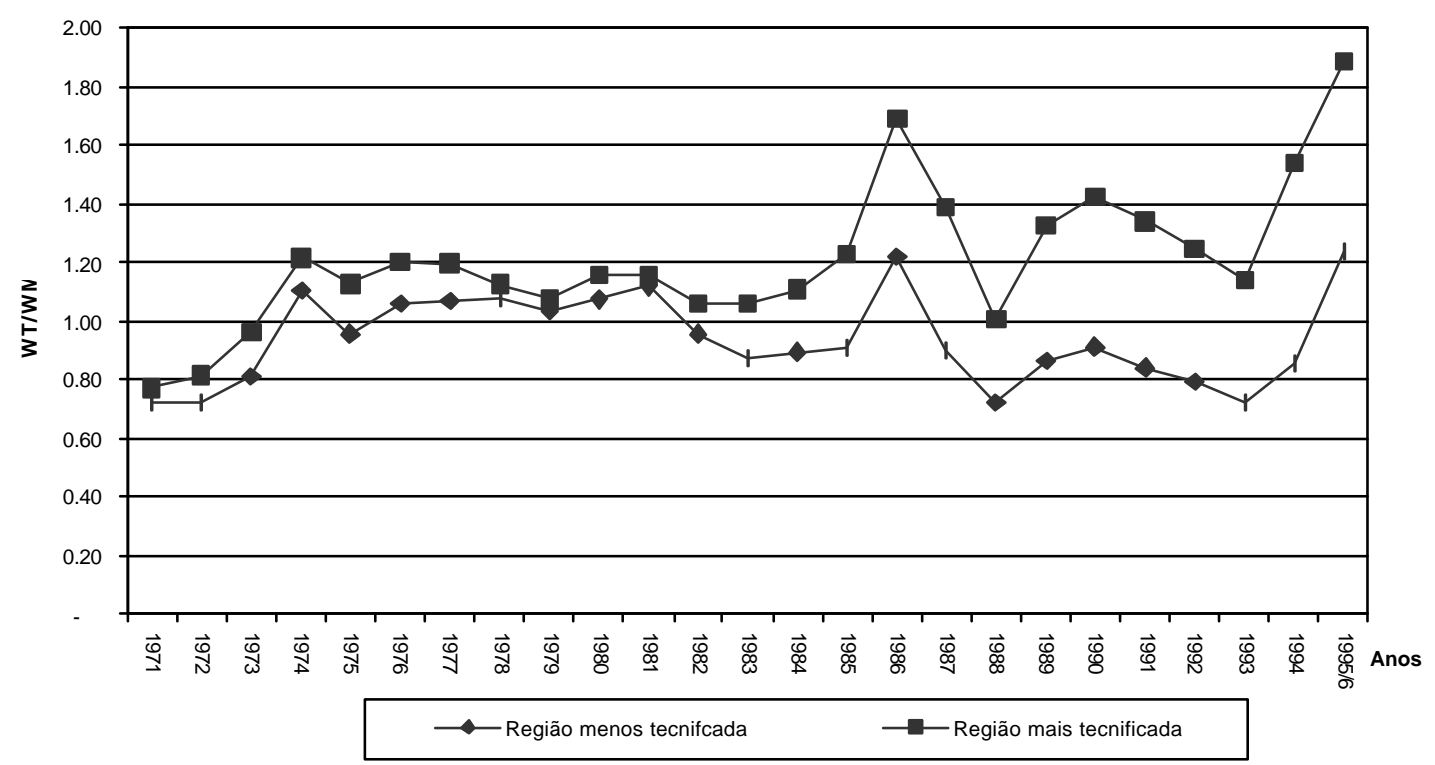

Gráfico 5 - Relação média entre os salários dos trabalhadores temporários equivalente a 25 dias de trabalho e o salário mínimo das regiões menos e mais tecnificadas no período de 1971 a 1996.

Fonte: Dados da pesquisa. 
O salário mínimo, mesmo colocado no contexto descrito acima, ainda é uma variável bastante influente na determinação dos salários dos trabalhadores temporários na região menos tecnificada. O salário mínimo foi um balizador dos salários dos trabalhadores não-qualificados da economia formal e informal tanto no setor urbano quanto no agropecuário no período analisado (1971 a 1996).

Os estudos de Hoffmann (1998), Corrêa \& Hoffmann (1997) e Neri (1997) apontam para uma correlação negativa entre salário mínimo e pobreza. Hoffmann (1998) e Corrêa \& Hoffmann (1997) analisaram particularmente esta relação para a PEA agrícola e encontram os mesmos resultados. A correlação negativa entre essas variáveis para o meio rural é fundamental, considerando que dentro da população rural estão os maiores índices de pobreza. Neste sentido, políticas econômicas de deterioração do salário mínimo adotadas no período em análise tiveram efeitos diretos nos salários desses trabalhadores e com desdobramentos na pobreza rural.

No setor agropecuário, além dos baixos salários dos trabalhadores temporários, constata-se que a informalidade tem grande peso na composição das relações trabalhistas, contribuindo para tornar ainda mais precários os postos de trabalho nesse segmento do mercado de trabalho agrícola ${ }^{26}$. Nas regiões mais isoladas do país, tais como as zonas rurais dos estados que compõem a região menos tecnificada, as instituições jurídicas provavelmente são menos presentes, dificultando que sejam resguardados minimamente os direitos dos trabalhadores ${ }^{27}$. No trabalho temporário, há muitas formas de relações contratuais, sendo que várias delas são bastante burocráticas, o que contribui para a informalidade. As intervenções das instituições jurídicas, contudo, algumas vezes conseguem inibir certos tipos de contratos dúbios, como é caso da contratação através das cooperativas de trabalhadores rurais (Staduto, 2001).

${ }^{26} \mathrm{O}$ trabalho temporário pela sua própria característica de alta rotatividade é considerado como precário e, normalmente, é agravado pela informalidade. Os empregadores não têm o costume de fazer contratos formais de trabalho temporário, os quais contêm alguns itens que melhoram a qualidade desses postos.

${ }^{27}$ Ver mais detalhes em Staduto (2001). 
O coeficiente do salário alternativo $(0,1372)$ é positivo e estatisticamente significativo. Nesta região estão os estados com menor grau de industrialização e urbanização, onde, conseqüentemente, as oportunidades de emprego alternativo são menores. Desta forma, poderia se esperar que a influência do salário alternativo fosse menos intensa. De fato, o coeficiente dessa variável não pode ser considerado alto.

O coeficiente da relação de preços recebidos e pagos pelos produtores rurais $(0,0231)$ não é estatisticamente significativo. Este resultado provavelmente deve ter as mesmas explicações dadas no caso da estimativa realizada para o Brasil. Na região menos tecnificada, verificam-se graves problemas estruturais de excedente de força de trabalho. Esta região foi origem de intensa migração de trabalhadores rurais para os grandes centros urbanos das regiões Centro-Oeste e Sudeste nos anos 60 e 70. Nos anos 80, o excedente de força de trabalho persistiu, predominando a migração inter-regional, ou seja, a migração ocorreu da zona rural para os centros urbanos da própria região (Silva, 1995).

O coeficiente da produtividade do trabalho (Pmo) é estatisticamente significativo e positivo. O coeficiente da Pmo é o de menor magnitude $(0,1090)$. Esperava-se que no segmento do mercado de trabalho agrícola temporário haja uma maior influência da variável produtividade do trabalho sobre o salário agrícola. $\mathrm{O}$ período em análise (1971 a 1996) foi de crescimento da produtividade do trabalho em todos estados. 


\subsubsection{Determinação dos salários dos trabalhadores temporários na região mais tecnificada}

Os resultados da estimativa da equação dos salários dos trabalhadores temporários na região mais tecnificada (estados das regiões Centro-Oeste, Sudeste e Sul), apresentados na Tabela 3 , mostram-se melhores em termos das estatísticas $\mathrm{R}^{2}$ $(0,1784)$ e $\mathrm{F}$ que as regressões para o Brasil e para a região menos tecnificada.

O coeficiente da variável salário mínimo $(0,4470)$ é altamente significativo estatisticamente e tem sinal positivo. O coeficiente do $W M$ é o de maior magnitude, portanto, é uma variável bastante influente na determinação dos salários dos trabalhadores temporários $(W T)$. Este resultado converge com a estimativa da região menos tecnificada.

A grande influência do $W M$ na determinação dos $W T$ na região mais tecnificada parece estar, aparentemente, em desacordo com o grau de desenvolvimento do setor agropecuário dos estados que compõem essa região. Seria menos provável que fatores institucionais tivessem papel tão predominante na determinação dos $W T$, por outro lado, os fatores inerentes às forças do mercado de trabalho deveriam ter mais peso, tais como o salário alternativo, a relação de preços recebidos e pagos pelos produtores rurais e a produtividade do trabalho. Mas, não foi isto que se constatou nos resultados das estimativas. Neste sentido, o resultado acima endossa a literatura sobre o papel do $W M$ na determinação dos salários da mão-de-obra não-qualificada.

O Gráfico 5 mostra que a relação $W T / W M$, em média, foi superior a 1 em praticamente todo o período em análise (1971 a 1996), com exceção dos anos de 1971 e 1972. Novamente, aqui cabe toda a análise feita na seção anterior sobre as restrições da relação $W T / W M$, ou seja, o indivíduo inserido neste segmento do mercado de trabalho agrícola dificilmente obtém trabalho o ano inteiro e os direitos trabalhistas são menores em relação aos contratos de trabalho permanente. Considerando estas restrições, 
constata-se que a renda média desses indivíduos tende a ser inferior em relação aos trabalhadores inseridos no mercado formal ou com contratos de trabalho permanentes.

O coeficiente do salário alternativo $(0,0925)$ é estatisticamente significativo e positivo. Esperava-se que ele fosse altamente significativo estatisticamente e de magnitude maior em relação à regressão da região menos tecnificada, em razão de que a região mais tecnificada tem maior industrialização e seu setor urbano-industrial é bastante dinâmico. Com efeito, os mecanismos de integração dos mercados agrícola e não-agrícola que são viabilizados por meio do salário alternativo deveriam, nesta região, ter maior influência na determinação dos salários temporários.

O coeficiente da relação de preços recebidos e pagos pelos produtores rurais $(0,0379)$ não é estatisticamente significativo. Este resultado provavelmente deve ter as mesmas explicações discutidas nos resultados das estimativas realizadas para o Brasil e para a região menos tecnificada. No caso especifico da região mais tecnificada, o processo de modernização do setor agropecuário foi mais intenso, no qual foram difundidas tecnologias poupadoras de mão-de-obra, contribuindo para formação de um excedente de força de trabalho. Isto, por sua vez, reduziu o efeito da relação de preços recebidos e pagos pelos produtores rurais sobre os salários agrícolas.

O coeficiente da produtividade do trabalho (-0,0935) é estatisticamente significativo e com sinal contrário ao esperado pelo modelo teórico. Este sinal negativo do coeficiente da produtividade do trabalho (Pmo) implica que o seu crescimento reduziria o salário dos trabalhadores. Mas o modelo teórico do capítulo 3 sugeria outra relação. Para explicar esta incoerência, deve-se fazer inicialmente algumas pressuposições. Primeiramente, considera-se que a produção do setor agropecuário possa ser representada por uma função de produção do tipo Cobb-Douglas ${ }^{28}$ e o expoente dessa função, que determina a parcela da renda que cabe ao trabalho ou capital, é fixo. Desta forma, pode-se inferir que a variação da produtividade média do trabalho é igual à

\footnotetext{
${ }^{28}$ Barros (1999) e Freitas (2001) ajustaram uma função de produção do tipo Cobb-Douglas para o setor agropecuário brasileiro.
} 
variação da produtividade marginal do trabalho. Assumindo estas pressuposições, e visto que a variável Pmo representa a produtividade média do trabalho no setor agropecuário, pode-se inferir (que no período da análise dessa pesquisa, de 1971 a 1996) que a mãode-obra temporária foi remunerada em intensidade muito inferior aos aumentos de sua produtividade.

O coeficiente negativo da Pmo indica que, no período analisado (1971 a 1996), deve ter ocorrido aumento da desigualdade na distribuição funcional da renda na região mais tecnificada. Examinando a literatura sobre a distribuição de renda das pessoas ocupadas no setor agrícola, verifica-se um grande contraste no comportamento da distribuição de renda entre as regiões menos e mais tecnificadas (ou seja, entre as regiões Nordeste e as regiões Centro-Oeste, Sudeste e Sul), o qual contribui para esclarecer porque o coeficiente Pmo apresentou sinal negativo.

Corrêa (1995) constatou que, no período de 1981 a 1990, a região Nordeste (que compreende praticamente a totalidade da região menos tecnificada) apresentou os maiores índices de pobreza entre as regiões brasileiras e, simultaneamente, os piores indicadores de miséria absoluta, menor renda média e, por outro lado, os menores índices de desigualdade da renda. No outro extremo, na região Centro-Oeste e no Estado de São Paulo (que correspondem à parte da região mais tecnificada), a autora observou os menores níveis de pobreza e o maior patamar de renda média e, por outro lado, constatou o maior patamar de desigualdade da renda e de crescimento percentual da desigualdade de renda do país. Já em uma posição intermediária em termos de indicadores de desigualdade de renda, pobreza e rendimento estão as regiões Sul e Sudeste (exceto São Paulo). Esses contrastes regionais sobre a distribuição de renda podem ser sintetizados, na constatação já realizada por Langoni (1973) apud Corrêa (1995) para o setor primário brasileiro: quanto maior o nível de rendimento, maior a desigualdade da distribuição de renda.

Estes resultados obtidos por Corrêa (1995) foram os mesmos alcançados por Hoffmann (1990) para o período de 1970 a 1980. Desta forma, Corrêa (1995) concluiu 
que os contrastes regionais relativos à desigualdade da renda, à pobreza e renda média, das pessoas ocupadas no setor agrícola, foram mantidos e ampliados na década de 80 em relação à década de 70. Diante desses resultados, pode-se inferir, de forma agregada ${ }^{29}$, que há um desequilíbrio na distribuição funcional da renda no setor agropecuário maior na região mais tecnificada do que na região menos tecnificada em praticamente todo o período em análise. Considerando que o salário é uma importante fonte de renda dos trabalhadores, o sinal negativo do coeficiente da produtividade do trabalho é coerente com a realidade brasileira e reforça o que foi constatado pelos autores sobre o crescimento da desigualdade da distribuição de renda na região mais tecnificada.

Corrêa (1995) ainda constatou que a "posição na ocupação ${ }^{30 "}$ no setor agropecuário foi o fator que mais contribuiu para aumentar a desigualdade de rendimento em todas as regiões do país. Esse fator é uma proxy para captar as diferenças no processo de formação dos rendimentos individuais do trabalho associadas às diferenças de distribuição prévia da propriedade ou da acumulação de capital físico no setor agropecuário brasileiro. Admite-se, para tanto, a hipótese de que as diferenças de acesso à propriedade são fortemente correlacionadas com a discriminação ocupacional, expressa no binômio empregado versus empregador.

Em termos regionais, no Centro-Oeste e o Sudeste, o fator "posição na ocupação" apresentou contribuição mais significativa para ampliar a desigualdade de rendimentos em relação às regiões Nordeste e Sul. Considerando que as regiões CentroOeste e Sudeste representam dois terços dos estados da região mais tecnificada, elas devem contribuir para expressar e fundamentar o crescimento da desigualdade na distribuição de renda associada à posse do capital na região mais tecnificada. Por sua vez, esta situação está em consonância com os péssimos índices da distribuição funcional da renda, que são expressos no coeficiente negativo da variável produtividade

${ }^{29}$ Refere-se de forma agregada em razão de que as regiões Sul e Sudeste, exceto São Paulo, estavam em uma posição intermediária em termos de distribuição de renda; já a região Centro-Oeste e São Paulo apresentaram o maior crescimento da desigualdade da distribuição de renda. Em outro extremo, a região Nordeste, que perfaz quase a totalidade da região menos tecnificada, apresentou a menor distribuição de renda no período de 1970 a 1990. 
do trabalho na equação de salário estimada. A renda gerada pelo trabalho no período analisado (1971 a 1996), em parte, foi transferida para o capital.

Além disso, como já discutido, segundo Gonçalves (1996), os salários agrícolas decresceram entre os anos de 1987 e 1994, e neste período foram apontados seguidos recordes de produção na agropecuária paulista, sugerindo que há grandes distorções na distribuição funcional da renda. Bacha (1979) analisou os salários agrícolas nas décadas de 50 e 60 e apontou na mesma direção: os salários ao longo prazo aparentemente não estavam acompanhando a tendência ascendente da produtividade. Considerando as pesquisas de Bacha (1979) e os resultados encontrados na presente pesquisa, pode-se afirmar que a disparidade entre os salários e produtividade do trabalho já é uma tendência persistente que ocorre por quase meio século.

Diante das análises realizadas acima, constata-se que a produtividade do trabalho aparentemente é uma variável pouco importante na determinação dos salários dos trabalhadores temporários. Nestas circunstâncias, o salário mínimo surgiu, no período da análise (1971 a 1996), como um forte referencial na determinação dos salários dos trabalhadores temporários, funcionado como um indexador dos salários. Portanto, o fator institucional foi fundamental na determinação dos salários agrícolas dos trabalhadores temporários.

\subsubsection{Equação de determinação dos salários dos trabalhadores permanentes}

Na Tabela 4 são apresentados os resultados das estimativas do modelo de determinação dos salários dos trabalhadores permanentes, equação $(25)^{31}$, aplicados para o Brasil e para as regiões menos e mais tecnificadas. Observa-se que o salário médio da

\footnotetext{
${ }^{30}$ Outros fatores analisados são educação, idade, sexo e região geográfica.

${ }^{31} W P=G_{0}+G_{1} \cdot P a+G_{2} \cdot P m o+G_{3} \cdot W M$
} 
região mais tecnificada $(\mathrm{R} \$ 139,91)$ foi $26 \%$ maior em relação à menos tecnificada $(\mathrm{R} \$$ 110,71) e o desvio padrão dos salários dos trabalhadores permanentes para o Brasil é superior aos demais conjuntos de dados. Nota-se que a diferença da média salarial dos trabalhadores permanentes entre regiões (26\%) é menor que a diferença entre as médias dos salários dos trabalhadores temporários (39\%).

Esta maior diferença salarial entre os trabalhadores temporários em relação aos trabalhadores permanentes pode estar relacionada à produtividade do trabalho, entre outros fatores. Contudo, esta diferença também indica a maior precariedade dos postos de trabalho temporários na região menos tecnificada. Balsadi \& Silva (2001) constataram que, na década de 90, o trabalho temporário, dentre as ocupações no meio rural (considerando o trabalho agrícola e não-agrícola), apresentou o menor índice de qualidade de trabalho no Estado de São Paulo e, provavelmente, esta situação seja muito mais grave nos estados da região Nordeste (região menos tecnificada).

Os valores das estatísticas $\mathrm{R}^{2}$ e $\mathrm{F}$ nas equações apresentadas na Tabela 4 são maiores do que os da Tabela 3, evidenciando melhor ajustamento econométrico nas equações de salários de trabalhadores permanentes.

\subsubsection{Determinação dos salários dos trabalhadores permanentes no Brasil}

O coeficiente do salário mínimo $(W M)$ é positivo e altamente significativo estatisticamente. O coeficiente do $W M(0,6718)$ é o de maior magnitude na equação estimada, portanto, tendo grande influência na determinação dos salários dos trabalhadores permanentes. No segmento do mercado de trabalho permanente, a remuneração é mensal, tornando-se mais previsível a influência do WM. A grande magnitude do coeficiente do $W M$ em relação às demais variáveis indica que esta variável provavelmente funcionou como um indexador dos salários dos trabalhadores 
permanentes $(W P)$. Tal situação é constatada pela literatura para os salários da mão-deobra não-qualificada na construção civil. Este comportamento em relação ao salário mínimo também foi constatado para os salários dos trabalhadores temporários. Novamente, fatores institucionais influenciaram significativamente na determinação dos salários dos trabalhadores agrícolas.

Deve-se considerar que não são todos os empregadores que pagam pelo menos um salário mínimo aos empregados. Desta forma, o salário de equilíbrio pode até estar abaixo do salário mínimo, devido ao descumprimento da lei que instituiu o salário mínimo. No entanto, esta situação não reduziu a influência do salário mínimo na formação dos salários agrícolas.

As mesmas inferências feitas na análise dos determinantes dos salários dos trabalhadores temporários para a região menos e para a mais tecnificadas podem ser tecidas para os trabalhadores permanentes, principalmente em relação à pobreza, à distribuição de renda e aos salários. Considerando que os trabalhadores permanentes recebem salário indireto (que não é contabilizado no salário monetário), os efeitos dessas variáveis (pobreza e distribuição de renda) devem ser menores. Além disso, os salários indiretos também tendem a melhorar a qualidade dos postos de trabalho dos trabalhadores permanentes em relação aos trabalhadores temporários.

O coeficiente da relação de preços recebidos e pagos pelos produtores rurais (-0,0340) não é estatisticamente significativo. A variável relação de preços recebidos e pagos pelos produtores rurais $(\mathrm{Pa})$, dentre as variáveis explicativas, é a que apresenta uma interpretação menos precisa, tal como constatado anteriormente (subitem 5.2.1.1). Assim, caso os produtores estivessem auferido ganhos com $P a$, estes não estariam sendo repassados aos salários. Esta imperfeição pode estar sendo causada pela forte indexação dos salários dos trabalhadores permanentes ao salário mínimo.

O coeficiente de produtividade do trabalho (Pmo) é altamente significativo estatisticamente e apresenta sinal positivo. Deve-se notar que o valor não é alto $(0,1699)$ quando comparado com o coeficiente do salário mínimo. O período analisado foi de 
grande crescimento da produtividade total dos fatores de produção na agropecuária brasileira, mas, na equação estimada, a variável Pmo foi de pequena magnitude.

\subsubsection{Determinação dos salários dos trabalhadores permanentes na região menos tecnificada}

O coeficiente do salário mínimo $(0,7525)$ é altamente significativo estatisticamente e positivo. O coeficiente do salário mínimo $(W M)$ foi o de maior magnitude na equação estimada, portanto, sendo uma variável bastante influente na determinação dos salários dos trabalhadores. De fato, como foi verificado nas outras equações, os empregadores adotaram uma política salarial implícita de indexação salarial com o WM.

No Gráfico 6 foi plotada a relação média entre os salários dos trabalhadores permanentes $(W P)$ e o $W M$, com a mesma finalidade descrita anteriormente (subitem 5.2.1.2), ou seja, apresentar uma melhor dimensão da remuneração dos salários médios recebidos pelos trabalhadores permanentes em relação ao WM. No Gráfico 6, observa-se (por meio do comportamento da relação $W T / W M$ ) que, em grande parte do período analisado, os $W P$ foram inferiores ao $W M$, ou muito próximos. Os $W P$ foram superiores ao $W M$ em alguns anos da década de 70, período em que ocorreram persistentes taxas positivas de crescimento do PIB e o processo de convergência dos $W M$ regionais, até sua unificação em 1984. No início dos Planos Cruzado e Real, com a estabilização da moeda, os salários da economia como um todo tiveram abruptos crescimentos do poder de compra e a relação $W P / W M$ foi superior a 1. 


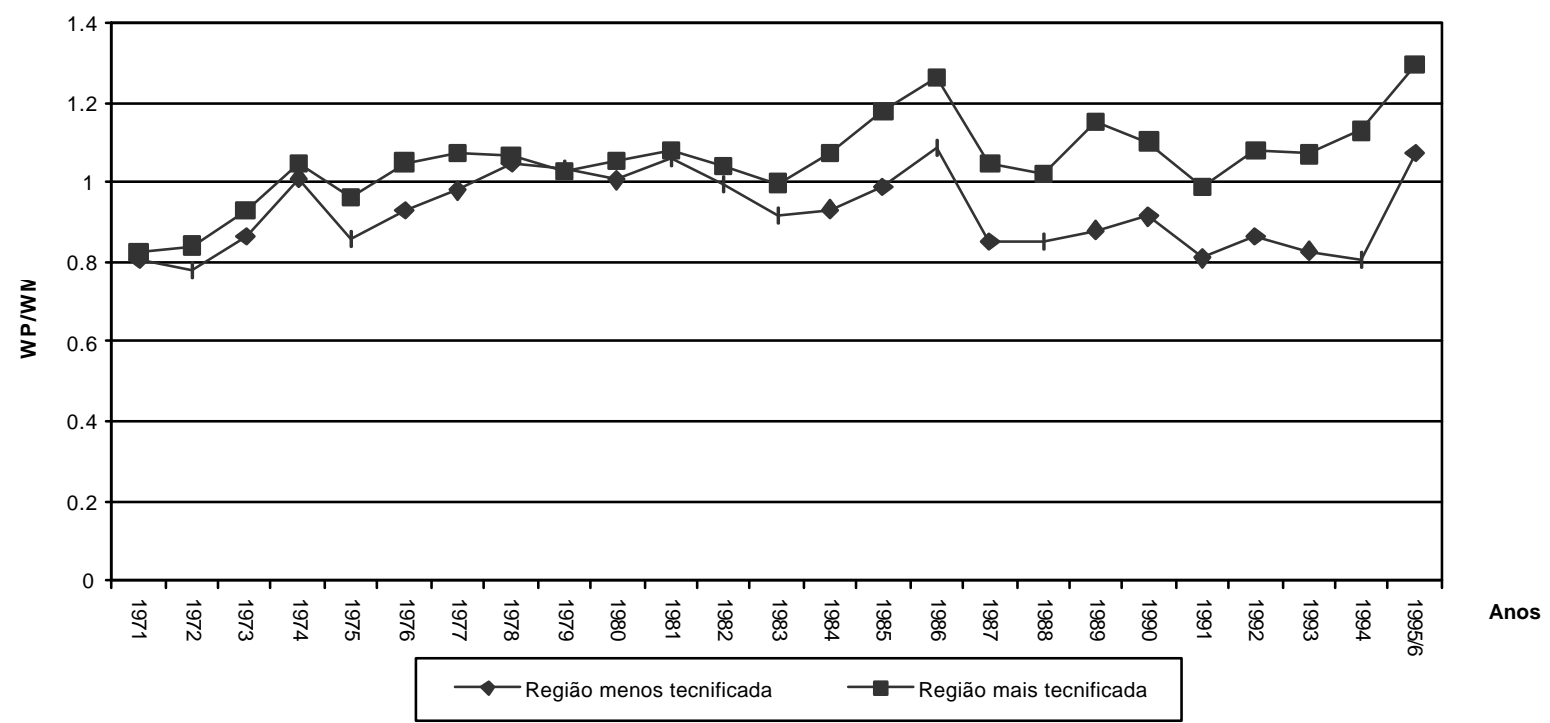

Gráfico 6 - Relação média entre os salários dos trabalhadores permanentes e o salário mínimo das regiões menos e mais tecnificadas no período de 1971 a 1996.

Fonte: Dados da pesquisa.

Na região menos tecnificada, o $W M$ até 1984 era menor do que na região mais tecnificada. Portanto, a relação $W P / W M$ na região menos tecnificada em relação à mais tecnificada está superestimada até este ano ${ }^{32}$.

A institucionalização do salário mínimo para o mercado de trabalho agrícola não foi suficiente para garantir que os salários médios fossem iguais ou superiores ao salário mínimo. De modo geral, a legislação vigente sobre o $W M$ para os trabalhadores agrícolas não foi completamente respeitada no período analisado (1971 a 1996). De fato, a efetivação de qualquer dispositivo legal depende, em grande parte, da eficiência das instituições jurídicas e das reivindicações dos interessados, por meio de sindicatos e associações. Provavelmente, nenhum desses dois comportamentos ocorreu com muita efetividade.

\footnotetext{
${ }^{32}$ Ver mais detalhes sobre o comportamento dos salários mínimos regionais no subitem 5.2.1.2.
} 
Mesmo considerando a grande informalidade no segmento do mercado de trabalho agrícola como um todo, políticas econômicas de deterioração do $W M$ têm efeitos diretos nos salários dos trabalhadores temporários, bem como sobre os trabalhadores permanentes em razão da política salarial implícita de indexação dos salários agrícolas ao WM. Os desdobramentos da pobreza rural tendem a ser menores nos trabalhadores permanentes em relação aos temporários em razão do recebimento de salário indireto.

O coeficiente da relação de preços recebidos e pagos pelos produtores rurais (-0,0361) não é estatisticamente significativo. A razão para este comportamento são as mesmas descritas na estimativa para o Brasil (subitem 5.2.2.1), ou seja, as possíveis imperfeições de mercado introduzido pelo $W M$.

O coeficiente da produtividade do trabalho $(0,1544)$ é estatisticamente significativo e positivo. Tal como analisado para os trabalhadores temporários na região menos tecnificada (subitem 5.2.1.2), esperava-se uma maior magnitude do coeficiente da produtividade do trabalho.

\subsubsection{Determinação dos salários dos trabalhadores permanentes na região mais tecnificada}

O coeficiente do salário mínimo $(0,8830)$ é altamente significativo estatisticamente e positivo. A grande magnitude desse coeficiente novamente mostra que esta variável tem grande efeito sobre a determinação dos salários dos trabalhadores permanentes. Provavelmente, os empregadores no período analisado seguiram uma forte política salarial implícita de indexação com o salário mínimo.

A relação média entre os salários dos trabalhadores permanentes $(W P)$ e o salário mínimo $(W M)$ está plotada no Gráfico 6. Observando o comportamento dessa 
relação, constata-se que, na maior parte do período analisado, os WP foram superiores ao $W M$, ou muito próximos. Neste segmento do mercado de trabalho agrícola, em média, pagaram-se salários superiores a um salário mínimo. Dentre os fatores que contribuíram para esta situação, deve-se mencionar a maior efetividade das ações das instituiçõos jurídicas na região mais tecnificada, o que motiva um razoável cumprimento da legislação, garantindo pelo menos que a remuneração fosse igual ou superior ao WM.

O coeficiente de relação de preços recebidos e pagos pelos produtores rurais $(0,0156)$ não é estatisticamente significativo. Desta forma, não há influência da relação de preços recebidos e pagos pelos produtores rurais $(\mathrm{Pa})$ na determinação desses salários agrícolas. Este resultado converge com as demais estimativas realizadas para os trabalhadores permanentes (Brasil e região menos tecnificada), sendo que a interpretação para o comportamento da $P a$ também é a mesma, a qual se baseia em possíveis imperfeições de mercado introduzidas pelo salário mínimo.

O coeficiente da produtividade do trabalho $(0,1289)$ é estatisticamente significativo e positivo. No entanto, a sua magnitude é muito pequena. Constata-se que o sinal do coeficiente da produtividade do trabalho (Pmo) foi divergente do verificado para os salários dos trabalhadores temporários na região mais tecnificada (nesse caso o sinal foi negativo). Pode-se inferir que no segmento dos trabalhadores permanentes não está ocorrendo o processo de transferência de renda, pelo menos, não na intensidade que ocorreu para os trabalhadores temporários.

Os postos de trabalho permanentes são menos precários, o que se expressa na relação positiva entre a produtividade do trabalho e os salários dos trabalhadores permanentes. $\mathrm{O}$ número de trabalhadores sem carteira assinada no mercado de trabalho agrícola é muito grande, mas tende a diminuir ao longo dos anos. Por exemplo, segundo Balsadi (1996), no Estado de São Paulo, em 1980, 26,40\% dos trabalhadores agrícolas tinham carteira assinada, já em 1990 passou para 46,80\%, desta forma, reduzindo a precariedade dos postos de trabalho. O universo dos trabalhadores com carteira assinada, em sua quase totalidade, é formado pela categoria dos trabalhadores permanentes 
(devem ser incluídos os tratoristas e o pessoal administrativo), visto que os trabalhadores temporários têm outras formatações de contratos de trabalhos e, normalmente, não assinam carteira de trabalho.

Já os postos de trabalho temporários agrícolas são extremamente precários. Esta situação facilitou o estabelecimento de relações trabalhistas nas quais os salários e a produtividade do trabalho apresentassem comportamentos divergentes ao longo dos anos analisados (1971 a 1996). 


\section{CONCLUSÕES}

Este trabalho analisou o comportamento dos salários agrícolas e estimou modelos de determinação de salário de equilíbrio para os trabalhadores temporários e permanentes no Brasil e nas regiões com o setor agropecuário menos tecnificado e mais tecnificado. Para efeito de análise, tomou-se em consideração o período de 1971 a 1996, para o qual havia informações sistemáticas.

Neste trabalho, os modelos empíricos de determinação de salários foram desenvolvidos a partir da pressuposição de que o mercado de trabalho agrícola pode ter dois segmentos, formados por duas categorias de trabalhadores (temporários e permanentes). Considera-se também que no mercado de trabalho agrícola haja duas estruturas salariais distintas (para trabalhadores temporários e permanentes) formadas através de processos históricos com características peculiares.

As maiores contribuições deste trabalho estão na elaboração de modelo teórico considerando a segmentação do mercado de trabalho e a indexação do salário agrícola, no procedimento econométrico utilizado, no tipo de dados considerados e na abrangência temporal e regional da análise. O presente trabalho reformulou os modelos de determinação dos salários de Bacha (1988) e Istake (1999), simplificando-os. A partir destas equações, o presente trabalho adotou procedimentos econométricos mais sofisticados do que os adotados pelos mencionados autores, considerando os dados em pooling. Isto permitiu aumentar o grau de liberdade das equações estimadas e incorporar 
correções de problemas típicos de dados dessa natureza. Além disso, o presente trabalho sintetiza um modelo teórico que fundamenta as equações econométricas estimadas.

A partir do processo de modernização do setor agropecuário, iniciado em meados dos anos 60 no Brasil, criaram-se condições para os estados brasileiros se tecnificarem, mas em diferentes intensidades. Esta situação teve impacto igualmente distinto sobre o mercado de trabalho agrícola. Para analisar a determinação dos salários agrícolas no Brasil, as unidades da Federação foram agrupadas em duas regiões: uma menos tecnificada (composta pelo Acre e pelos estados da região Nordeste, exceto o estado do Piauí) e outra mais tecnificada (composta pelos estados das regiões CentroOeste, Sudeste e Sul).

Nos modelos econométricos desenvolvidos foram considerados aspectos inerentes ao mercado de trabalho agrícola e um aspecto institucional (representado pelo salário mínimo). De um lado, nos modelos de concorrência perfeita, a variável produtividade do trabalho tem papel fundamental na determinação do salário, da mesma forma que o salário alternativo e a relação de preços recebidos e pagos pelos produtores rurais. De outro lado, a literatura explicita a importância do salário mínimo na determinação dos salários da mão-de-obra não-qualificada, sendo constatado sua função como um indexador dos salários dessa mão-de-obra.

As equações de determinação dos salários foram estimadas com os dados em pooling e adotado procedimento econométrico com base na análise da estrutura do termo de erro das equações estimadas. Constatourse que a estrutura de "componentes" (two way) do termo do erro foi a mais adequada. Para tanto, aplicou-se o procedimento econométrico de Fuller \& Battese.

A equação estimada de determinação dos salários dos trabalhadores temporários no Brasil não apresentou bons resultados, sendo que os coeficientes do salário mínimo e o da relação de preços recebidos e pagos pelos produtores rurais não foram estatisticamente significativos. Esta situação pode ser atribuída à agregação das regiões menos e mais tecnificadas em uma única grande região. 
Nas equações estimadas para as regiões menos e mais tecnificadas, o salário mínimo $(W M)$ foi altamente significativo estatisticamente. Já a variável relação de preços recebidos e pagos pelos produtores rurais $(\mathrm{Pa})$ não foi significativa estatisticamente para as demais equações. Dentre as várias causas possíveis foram destacados os mecanismos de ajustamento do ponto de vista da oferta de trabalho por parte dos pequenos produtores. Neste caso, as variações da $P a$ não afetariam o deslocamento da curva de oferta em razão de problemas estruturais de excedente de força de trabalho, provocados pela adoção de tecnologias poupadoras de mão-de-obra, e pela concentração de terra. Do ponto de vista da demanda, os empregadores não estariam repassando aos salários as variações da $P a$.

O coeficiente estimado do salário alternativo $(W U)$ tem sinal positivo e foi significativo estatisticamente em todas as equações estimadas para o segmento do mercado de trabalho temporário. Por outro lado, o coeficiente estimado da produtividade do trabalho $(\mathrm{Pmo})$ também foi significativo estatisticamente e com sinal positivo, exceto para a equação da região mais tecnificada, na qual o sinal foi negativo, isto é, contrário ao esperado. $\mathrm{O}$ comportamento dessa variável está em consonância com a literatura que analisa a distribuição da renda no setor agropecuário. Constatou-se, também através da literatura, que nas regiões mais desenvolvidas a desigualdade na distribuição de renda é mais acentuada. Considerando que o salário agrícola dos trabalhadores temporários é um importante componente da renda do setor agropecuário, o sinal negativo coeficiente da Pmo fica coerente com essa literatura. Mesmo nas equações em que o coeficiente estimado da Pmo foi de sinal positivo (Brasil e região menos tecnificada), a sua magnitude foi muito pequena em relação às demais variáveis, o que evidencia um certo grau de transferência de renda do trabalho para o fator de produção capital.

As estimativas das equações de salário dos trabalhadores permanentes no Brasil e nas regiões menos e mais tecnificadas apresentaram comportamentos semelhantes. Das três variáveis explicativas ( $W M, P a, P m o$ ) consideradas no modelo, apenas a $P a$ não foi significativa estatisticamente. Neste caso, dentre as várias explicações possíveis está o mecanismo de ajustamento do ponto de vista da demanda, 
no qual as variações de $P a$ não estão afetando a curva de demanda por trabalho. $\mathrm{O} W M$ nas três equações estimadas para esta categoria de trabalhador foi a variável de maior magnitude. Por outro lado, a Pmo teve coeficiente positivo e estatisticamente significante, mas bem inferior ao coeficiente do WM.

Os salários dos trabalhadores permanentes foram preponderantemente determinados pelo salário mínimo. A produtividade do trabalho teve influência positiva, mas, devido à pequena magnitude do coeficiente, pode-se inferir que deve estar ocorrendo transferência de renda do trabalho para o fator capital, naturalmente, em intensidade muito menor do que constatado para os trabalhadores temporários da região mais tecnificada, para a qual o sinal do coeficiente estimado foi negativo.

O salário mínimo foi a variável que mais se destacou na determinação dos salários agrícolas nas equações estimadas, com exceção da equação do Brasil para os trabalhadores temporários. Portanto, o salário mínimo tem funcionado como um indexador dos salários agrícolas, tal como demonstra a literatura para a mão-de-obra não-qualificada do setor urbano. No entanto, a institucionalização do salário mínimo no mercado de trabalho agrícola, em 1963, não foi suficiente para garantir que os salários dos trabalhadores temporários e permanentes na região menos tecnificada fossem igual ou superior ao mínimo em todo o período analisado nesta tese. Ainda em relação ao salário mínimo, deve-se destacar que as políticas de redução do mínimo têm efeito direto sobre os salários agrícolas brasileiros.

A produtividade do trabalho cresceu ao longo dos anos, principalmente na região mais tecnificada. No entanto, ela não foi a variável mais importante na determinação dos salários agrícolas. Nessa região deve estar ocorrendo grande transferência de renda do trabalho para o capital, tal como foi claramente constatado para os trabalhadores temporários (em que o coeficiente foi negativo). A determinação dos salários agrícolas, de modo geral, tem um forte componente institucional e os fatores de mercado têm papel secundário.

Uma vez constatado que o salário mínimo é o principal determinante dos salários na agropecuária brasileira e que isto tem, em alguns casos, impedido que o 
grande aumento da produtividade do trabalho se reflita em aumentos de salários, novas políticas econômicas e formas de atuação dos trabalhadores poderiam ser visualizadas para a agropecuária. Em regiões onde é persistente o pagamento de salários abaixo do mínimo, a maior fiscalização e a punição deveriam ser intensificadas de modo a garantir o pagamento do salário mínimo ao trabalhador agrícola. Em outras regiões, onde o crescimento da produtividade é muito grande e o salário mínimo é forte indexador dos salários agrícolas, os trabalhadores deveriam aprimorar sua organização para reivindicar melhores salários.

Uma das maiores limitações deste trabalho se refere aos dados de salários utilizados. A agregação desses dados (em nível de estado) e sua periodicidade de coleta (duas vezes por ano) não os tornam perfeitos. Ainda assim, eles são os melhores disponíveis para diversos estados. À medida que outras séries de dados de salários sejam disponíveis, outras pesquisas devem ser realizadas - principalmente em níveis regionais ou de propriedades rurais -, visando aprofundar a interpretação sobre os mecanismos de determinação salarial na agropecuária brasileira. 


\section{REFERÊNCIAS BIBLIOGRÁFICAS}

AGUIRRE, B.M.B.; BIANCHI, A.M. Reflexões sobre a organização do mercado de trabalho agrícola. Revista de Economia Política, v.9, n.1, p.31-46, 1989.

AMADEO, E.J.; ESTEVÃO. M. A teoria econômica do desemprego. São Paulo: Hucitec, 1994. 254p.

ÁVILA, A.F.D.; EVENSON, R.E. Total factor productivity growth in the brazilian agriculture and the role of agricultural research. In: CONGRESSO BRASILIERO DE ECONOMIA E SOCIOLOGIA RURAL, 33., Curitiba, 1995. Anais. Brasília: SOBER, 1995. p.631-657.

BACHA, C.J.C. Evolução recente da cafeicultura mineira: determinantes e impactos. São Paulo, 1988. 536p. Tese (Doutorado) - Instituto de Pesquisa Econômica, Universidade de São Paulo.

BACHA, C.J.C. Determinação dos salários na agricultura. Revista Brasileira de Economia, v.45, n.3, p.441-471, 1991.

BACHA, E. Crescimento econômico, salários urbanos e rurais: o caso do Brasil. Pesquisa e Planejamento Econômico, v.9, n.3, p.585-628, 1979.

BACHA, E. Crescimento econômico, salários urbanos e rurais: o caso do Brasil réplica. Pesquisa e Planejamento Econômico, v.10, n.2, p.645-646, 1980. 
BALSADI, O.V. Condicionantes da renda das pessoas ocupadas na agricultura paulista, 1981-1990. Informações Econômicas, v.26, n.8, p.41-47, 1996.

BALSADI, O.V.; SILVA, J.G. Qualidade do emprego no meio rural paulista no anos 90. Revista de Economia e Sociologia Rural, v.39, n.4, p.47-67, dez. 2001.

BALTAGI, B.H. Econometric analysis of panel data. Chichester: John Wiley, 1995. $256 \mathrm{p}$.

BARROS, P.B.; FOGEL, M.; MENDONÇA, R. Salário mínimo I: nível do salário mínimo no Brasil. In: ENCONTRO BRASILEIRO DE ECONOMETRIA, 11., Recife, 1997. Anais. Recife: SBE, 1997. v.1, p.383-401.

BARROS, A.L.M. Capital, produtividade e crescimento da agricultura: o Brasil de 1970 a 1995. Piracicaba, 1999. 149p. Tese (Doutorado) - Escola Superior de Agricultura “Luiz de Queiroz”, Universidade de São Paulo.

BARROS, J.R.M. Política e desenvolvimento agrícola no Brasil. In: VEIGA, A. (Coord.) Ensaios sobre política agrícola brasileira. São Paulo: Secretaria da Agricultura do Estado de São Paulo, 1979. p.9-36.

BLANCHARD, O.J.; SUMMERS, L.H. Hysteresis and the European unemployment. NBER Macroeconomics Annual, 1986, p.15-78.

BLISS, C.; STERN, N. Productivity, wages and nutrition part I: the theory. Journal of Development Economics, v.5, p.331-362, 1978.

BONELLI, R.; FONSECA, R. Ganhos de produtividade e de eficiência: novos resultados para a economia brasileira. Rio de Janeiro: IPEA, 1998. 42p. (Texto para Discussão, 557)

BOWLES, S. The production process in a competitive economy: walrasian, neohobbesian, marxian models. American Economic Review, v.75, n.1, p.16-36, 1985. 
BRANT, C.V. População e força de trabalho no desenvolvimento da agricultura brasileira. São Paulo: CEBRAP, 1979. 33p.

CACCIAMALI, M.C. A legislação trabalhista no campo e sua aplicação entre os "bóiasfrias" no estado de São Paulo: uma contribuição para o debate. In: DUARTE, D. (Org.). Emprego rural e migrações na América Latina. Recife: Editora Massangana/Fundação Joaquim Nabuco, 1986. p.51-64.

CAMPELL III, C.M. Do firms pay efficiency wages? Evidence with data at the firm level. Journal of Labor Economic, v.11, n.31, p.442-470, 1993.

CAMPOS, S.H. O salário mínimo e a determinação da taxa de salários na economia brasileira: uma revisão da literatura existente. Ensaios FEE, v.13, n.1, p.316-340, 1992.

CARD, C.; KRUEGER, A. Minimum wages and employment: a case study of the fastfood industry in New Jersey and Pennsylvania. American Economic Review, v.84, n.4, p.773-793, 1994.

CARD, C.; KRUEGER, A. Minimum wages and employment: a case study of the fastfood industry in New Jersey and Pennsylvania: reply. The American Economic Review, v.90, n.5, p.1397-1420, 2000.

CARNEIRO, F.G. Efficiency wages, insiders-outsiders e determinação de salário: teorias e evidências. Revista de Economia Política, v.17, n.2(66), p.110-129. abr./jun. 1997.

CARVALHO, D. Mercado de trabalho na agricultura brasileira: década dos oitenta. Piracicaba, 1993. 160p. Dissertação (Mestrado) - Escola Superior de Agricultura "Luiz de Queiroz", Universidade de São Paulo.

CASTRO, P.R. Barões \& bóias-frias: repensando a questão a agrária no Brasil. Rio de Janeiro: APEC, 1982. 224p. 
CONCEIÇÃO, P.H.Z. Produtividade total e mudança técnica na agricultura brasileira, período 1955-1994. Piracicaba, 1998. 88p. Tese (Doutorado) - Escola Superior de Agricultura "Luiz de Queiroz”, Universidade de São Paulo.

CORRÊA, A.M.C.J. Distribuição de rendimento e pobreza na agricultura brasileira: 1981-1990. Piracicaba, 1995. 353p. Tese (Doutorado) - Escola Superior de Agricultura "Luiz de Queiroz", Universidade de São Paulo.

CORRÊA, A.M.C.J; HOFFMANN, R. Fatores condicionantes da desigualdade de rendimentos na agricultura paulista: 1981-90. Revista Brasileira de Economia, v.51, n.4, p.471-487, 1997.

CUNHA, A.M.; MAIA, M.M. Modernização, tecnologia e emprego rural: evidência da década de 70 na região Centro-Sul do Brasil. In: CONFERÊNCIA LATINOAMERICANA DE ECONOMIA AGRÍCOL, Piracicaba, 1984. Anais. Piracicaba: ESALQ, 1984. v.3, p.1-53.

DEL GROSSI, M.E.; SILVA, J, G. Ocupação nas famílias agrícolas e rurais no Brasil (compact disc). In: CONGRESSO BRASILEIRO DE ECONOMIA E SOCIOLOGIA RURAL, 38., Foz do Iguaçu, 1999. Anais. Foz de Iguaçu: SOBER, 1999.

DIAS, R. S.; BACHA, C. J. C. Produtividade e progresso na agricultura brasileira: 19701985. In: CONGRESSO BRASILEIRO DE ECONOMIA E SOCIOLOGIA RURAL, 36., Poços de Caldas, 1998. Anais. Brasília: SOBER, 1998. p.211-221.

DICKENS, R.; MACHIN, S.; MANNING, A.; METCALF, D.; WADSWORTTH, J.; WOODLAND, S. The effect of minimum wage on UK agriculture. Journal of Agricultural Economics, v.46, n.1, p.1-19, 1995.

DIXIT, A.K. Entry and exit decisions under uncertainty. Journal of Political Economy, v.97, n.37, p.620-638, June 1989.

DOERINGER, P.; PIORE, M. Internal labor market and manpower analysis. Lexington: Massachusetts, 1971. 214p. 
DRAPER, N.R.; SMITH, H. Applied regression analysis. Nova York: John Wiley \& Sons Inc., 1981. 709p.

DROBNY, A.; WELLS, J. Salário mínimo e distribuição de renda no Brasil: uma análise do setor de construção civil. Pesquisa e Planejamento Econômico, v.2, n.13, p.415464, 1983.

FERGUSON, C.E. Microeconomia. 15.ed. Rio de Janeiro: Forense Universitária, 1991. $610 \mathrm{p}$.

FONSECA, L.S.; STADUTO, J.A.R. A evolução das políticas agrícolas: de 1964 a 1994. In: ENCONTRO DE ECONOMISTAS DE LÍNGUA PORTUGUESA, 2., Rio de Janeiro, 1995. Anais. Rio de Janeiro: UFRJ, 1995. p.560-564.

FREITAS, C.A. Contribuição do capital humano para o crescimento da agropecuária brasileira: período 1970 a 1996. Piracicaba, 2001. 150p. Tese (Doutorado) - Escola Superior de Agricultura "Luiz de Queiroz”, Universidade de São Paulo.

FUNDAÇÃO INSTITUTO BRASILIERO DE GEOGRAFIA E ESTATÍSTICA. Pesquisa nacional por amostra de domicílio. Rio de Janeiro: IBGE, 1999. 113p.

FULLER, W.A.; BATTESE, G.E. Estimation of linear models with crossed-error structure. Journal of Econometrics, v.2, p.67-78, 1974.

FURTADO, C. Análise do modelo brasileiro. Rio de Janeiro: Civilização Brasileira, 1972. 122p.

GALLASCH, H.F.Jr. Minimum wages the farm labor market. South Economic Journal, v.41, p.480-491, 1975.

GARDNER, B. Minimum wages and the farm labor market. American Journal of Agricultural Economic, v.54, n.3, p.473-476, Aug. 1972.

GASQUES, J.G. Crescimento econômico, salários urbanos e rurais: o caso do Brasil comentário. Pesquisa e Planejamento Econômico, v.10, n.2, p.637-664, 1980. 
GASQUES, J.G. Oferta e demanda de mão-de-obra volante no estado de São Paulo. Piracicaba, 1975. 163p. Dissertação (Mestrado) - Escola Superior de Agricultura “Luiz de Queiroz”, Universidade de São Paulo.

GASQUES, J.G. Uma análise dos fatores que afetam os salários na agricultura. São Paulo, 1981. 139p. Tese (Doutorado) - Instituto de Pesquisa Econômica, Universidade de São Paulo.

GASQUES, J.G.; CONCEIÇÃO, J. C. P. R. Crescimento e produtividade da agricultura brasileira. Brasília: IPEA, 1997. 21p. (Texto para Discussão, 502)

GASQUES, J.G.; CONCEIÇÃO, J. C. P. R. Transformações estruturais da agricultura e produtividade total dos fatores. Brasília: IPEA, 2000. 60p. (Texto para Discussão, 768)

GONÇALVES, J.S. Salário, emprego, modernização e sazonalidade na agropecuária: as contradições do progresso excludente do desenvolvimento brasileiro. Informações Econômicas, v.26, n.1, p.23-37, 1996.

GOODMAN, D.E.; SORJ, B.; WILKINSON, J. Agroindústria, políticas públicas e estruturas sociais rurais: análise recente sobre a agricultura brasileira. Revista de Economia Política, v.3, n.4, p.31-55, 1985.

GOULD, B.W.; SAUPE, W.E. Off- farm labor market entry and exit. American Journal of Agricultural Economics, v.71, n.4, p. 960-969, Nov. 1989.

GREENE, W. H. Econometric analysis. 3.ed. Englewood: Prentice-Hall, 1997. 1075p.

GUERREIRO, E. Produtividade do trabalho e da terra na agropecuária paranaense. Piracicaba, 1995. 136p. Dissertação (Mestrado) - Escola Superior de Agricultura "Luiz de Queiroz", Universidade de São Paulo.

GUILKEY, D.K. Alternative tests for a first-order vector autogressive error specification. Journal of Econometrics, v.2, p.95-104, 1974. 
GUILKEY, D.K.; SCHMIDT. Estimation of seemingly unrelated regressions with vector autoregressive errors. Journal of the American Statistical Association, v.68, n.343, p. 642-647, 1973.

HICKS, J.R. Mr. Keynes theory and classics. Econometrica, Apr. 1937.

HOFFMANN, R. Vinte anos de desigualdade e pobreza na agricultura brasileira. Revista de Economia e Sociologia Rural, v.30, n.2, p.97-113, 1992.

HOFFMANN, R. Desigualdade e pobreza no Brasil 1979/97 e a influência da inflação e do salário mínimo. Economia e Sociedade, n.11, p.199-221, 1998.

HOFFMANN, R. Distribuição de renda e pobreza na agricultura brasileira. In: DELGADO, G.C.; GASQUES, J.G.; VILLA VERDE, C.M. (Org.) Agricultura e políticas públicas. Brasília: IPEA, 1990. p.3-111. (Série IPEA, 127)

HOFFMANN，R; CARVALHO, A.V.; KAGEYAMA，A.; WIENDL，M.L.T.B.; QUEDA, O. Inovações tecnológicas e transformações recentes na agricultura brasileira. Piracicaba: INEP-FEALQ/ESALQ, 1985. 778p. (Relatório de Pesquisa)

HOFFMANN, R.; JAMAS, A.L. A produtividade da terra e do trabalho na agricultura de 332 microrregiões do Brasil. In: CONGRESSO BRASILEIRO DE ECONOMIA E SOCIOLOGIA RURAL, 28., Florianópolis, 1990. Anais. Brasília, SOBER, 1990. v.2, p. 21-40.

HOFFMANN, R.; VIEIRA, S. Análise de regressão: uma introdução à econometria. São Paulo: Editora Hucitec, 1998. 379p.

HOFFMANN, R. SILVA, J.G. O Censo Agropecuário de 1995-1996 e a distribuição da posse da terra no Brasil (compact disc). In: CONGRESSO BRASILEIRO DE ECONOMIA E SOCIOLOGIA RURAL, 38., Foz do Iguaçu, 1999. Anais. Foz de Iguaçu: SOBER, 1999.

ISTAKE, M. Transformações na agropecuária paranaense e suas implicações sobre o emprego e salários rurais: 1977-96. Piracicaba, 1999. 112p. Dissertação (Mestrado) - Escola Superior de Agricultura “Luiz de Queiroz”, Universidade de São Paulo. 
JORGENSON, D.W. Teste de teorias alternativas de desenvolvimento em economia dualista. In: ARAÚJO, P.F.C.; SCHUH, G.E. Desenvolvimento da agricultura: natureza do processo e modelos dualistas. São Paulo: Pioneira, 1975. p.137-152. (Série Estudos Agrícolas)

JUDGE, G.G.; HILL, R.C.; GRIFFITHS, W.E.; LUTKEPOHL, H.; LEE, TSOUNGCHAO. Introduction to the theory and practice of econometrics. 2.ed. New York: John Wiley \& Sons, 1988. 1024p.

KAGEYAMA, A. Modernização, produtividade e emprego na agricultura: uma análise regional. Campinas, 1986. 389p. Tese (Doutorado) - Universidade de Campinas.

KAGEYAMA, A. O subemprego agrícola nos anos 90. Campinas: IE/UNICAMP, mar. 1997. 16p. (Texto para Discussão, 57)

KATZ, L. Efficiency wage theories: a partial evolution. NBER Macroeconomics Annual, 1986. p.235-276.

KEYNES, M.J. A teoria geral do emprego, do juro e da moeda. São Paulo: Nova Cultural, 1996. 352p. (Coleção Os Economistas)

KMENTA, J. Elementos de econometria. São Paulo: Atlas, 1990. v.2, 696p.

KRUEGER, A.B.; SUMMERS, L.H. Efficiency wages and the inter-industry wage structure. Econometrica, v.56, n.2, p.259-293, Mar. 1988.

KUMBHAKAR, S. A farm-level study of labor use and efficiency wages in Indian agriculture. Journal of Econometrics, v.72, p.177-195, 1996.

LEIBENSTEIN, H. The theory of underemployment in backward economies. The Journal of Political Economy, n.2, p.91-103, Apr. 1957.

LEWIS, A. O desenvolvimento econômico com oferta ilimitada de mão-de-obra. In: AGARWALA, N.A., SINGH, S.P. (Coord.) A economia do desenvolvimento. São Paulo: Companhia e Editora Forense, 1969. p.406-456. 
LIANOS, T.P. Impact of minimum wages upon the level and composition of agricultural employment. American Journal of Agricultural Economic, v.54, n.3, p.477-484, Aug. 1972.

LIMA, G.T. Em busca do tempo perdido: a recuperação pós-keynesiana da economia do emprego de Keynes. Rio de Janeiro: Gabinete da Presidência, Departamento de Relações Institucionais, 1992. 178p. (Prêmio BNDES de Economia, 16)

LINDBECK, A.; SNOWER, D. Cooperation, harassment, and involuntary unemployment: an insider-outsider approach. American Economic Review, v.78, n.1, p.167-188, Mar. 1988.

LOPEZ, M.R. O desemprego disfarçado na agricultura. Revista Brasileira de Economia, v.23, n.4, p.23-44, 1969.

MACEDO, R.B.M.; GARCIA, M.E. Observações sobre a política brasileira de salário mínimo. São Paulo: IPE/USP, 1978. 56p. (Texto para Discussão, 27)

MACEDO, R.B.M.; GARCIA, M.E. Salário mínimo e a taxa salarial no Brasil: comentário. Pesquisa e Planejamento Econômico, v.10, n.3, p.1013-1044, 1980.

MARTINS, J.S. Exclusão social e a nova desigualdade. São Paulo: Paulus, 1997. $144 \mathrm{p}$.

MELLO, D.M.C. "Bóia-fria”: acumulação e miséria. Petrópolis: Vozes, 1975. 154p.

MELO, F.H. A agricultura de exportação e o problema da produção de alimentos. Estudos Econômicos, v.9, n.3, p.101-22, 1979.

MÜLLER, G. Complexo agroindustrial e modernização agrária. São Paulo: Hucitec/Educ, 1989. 149p.

NERI, M. O reajuste do salário mínimo de maio de 1995. In: ENCONTRO BRASILEIRO DE ECONOMETRIA, 11., Recife, 1997. Anais. Recife: SBE, 1997. v.2, p.645-666. 
NEUMARK, D.; WASCHER, W. Minimum wages and employment: a case study of the fast-food industry in New Jersey and Penns ylvania: comment. American Economic Review, v.90, n.5, p.1363-1396, 2000.

NICHOLLS, W.; PAIVA, R.M. Ninety-nine fazendas: the structure and produtivity of brasilian agriculture, 1963: the Agreste Region of Pernambuco: Caruru Nashville: Graduate Center for Latin American Studies-Vanderbilt University; Rio de Janeiro: FGV, 1967. 280p. Chap.4.

NICHOLLS, W.; PAIVA, R.M. Ninety-nine fazendas: the structure and productivity of brazilian agriculture, 1963: the Cariri Region of Ceará. Nashville: Graduate Center for Latin American Studies-Vanderbilt University; Rio de Janeiro: FGV, 1966. 221p. Chap.3.

PALMER-JONES, R.; PARIKH, A. The determination of agricultural wage in Bangladesh. Journal of Agricultural Economic, v.49, n.1, p.111-133, 1998.

PARKS, R.W. Efficient estimation of a system of regression equations when disturbances are both serially and contemporaneously correlated. Journal of the American Statistical Association, v.62, p.500-509,1967.

PERLOFF, J.M. The impact of wage differentials on choosing to work in agriculture. American Journal of Agricultural Economics, v.71, n.3, p.671-680, 1991.

REICH, M.; GORDON, D.M.; EDWARDS, R.C. A theory of labor market segmentation. American Economic Review, v.63, n.2, p.359-365, 1973.

RESENDE, G.C. Interação entre mercados de trabalhos e razão entre salários rurais e urbanos no Brasil. Estudos Econômicos, v.15, n.1, p.47-67, 1985.

RICHARDS, T.J.; PATTERSON, P.M. Hysteresis and the shortage of agricultural labor. American Journal of Agricultural Economics, v.80, n.4, p.683-695, Nov. 1998.

SABÓIA, J.L.M. A controvérsia sobre o salário-mínimo e a taxa de salários na economia brasileira novas evidências. Revista de Economia Política, v.5, n.2, p.3966, 1985. 
SAS INSTITUTE. SAS/ETS Software applications guide 2: econometrics modeling, simulation and forecasting, version 6. Cary, 1993a. 429p.

SAS INSTITUTE. SAS/ETS User's guide, versino 6. Cary, 1993b. 1022p.

SAYLOR, R.G. Procura e oferta de mão-de-obra agrícola no estado de São Paulo. Agricultura em São Paulo, v.21, n.3, p.129-146, 1974.

SCHUH, E.G.; ALVES, E.R. O desenvolvimento da agricultura no Brasil. Rio de Janeiro: APEC, 1971.369p.

SCHUH, G.E. An econometric investigation of the market of hired labor in agriculture. Journal Farm Economic, v.44, n.2, p. 307-321, May 1962.

SCHULTZ, T.W. A transformação da agricultura tradicional. São Paulo: Zahar, 1965. 207p.

SHAPIRO, C.; STIGLITZ, J.E. Equilibrium unemployment as a worker discipline device. American Economic Review, v.74, n.3, p.433-444, June 1984.

SILVA, J.G. O "bóia-fria": entre aspas e com os pingos nos is. In: A mão-de-obra volante na agricultura. Botucatu: FCA/Departamento de Economia Rural, 1982. p.137-177.

SILVA, J.G. Urbanização e pobreza no campo. In: RAMOS, P.; REYDON, B.P. (Org.) Agropecuária e agroindústria no Brasil: ajuste, situação atual e perspectivas. Campinas: ABRA, 1995. p.127-150.

SILVA, J.G. O novo rural brasileiro. Campinas: UNICAMP/IE, 1999. 153p.

SKOUFIAS, E. Using shadow wages to estimate labor supply of agricultural households. American Journal of Agricultural Economics, v.76, n.2, p.215-277, May 1994.

SOLIMANO, A. Mercado de trabalho: quatro enfoques em busca de um paradigma. Pesquisa e Planejamento Econômico, v.18, n.3, p.561-594, 1988. 
SONODA, T.; MARUYAMA, Y. Effects of internal wage on output supply: a structural estimation for japanese rice farmers. American Journal of Agricultural Economics, v.81, n.1, p.131-143, Feb. 1999.

SORJ, B. Estado e classes sociais na agricultura brasileira. Rio de Janeiro: Zahar, 1980. 152p.

SOUZA, P.R. Emprego, salário e pobreza. São Paulo: Hucitec-Funcamp,1980. 193p.

SOUZA, P.R.; BALTAR, P.E. Salário mínimo e a taxa de salários no Brasil. Pesquisa e Planejamento Econômico, v.9, n.3, p.629-659, 1979.

SOUZA,P.R.; BALTAR, P.E. Salário mínimo e taxa salarial no Brasil: réplica. Pesquisa e Planejamento Econômico, v.10, n.3, p.1045-1058, 1980.

STADUTO, J.A.R. Contratos no mercado de trabalho agrícola: o caso das cooperativas de trabalhadores rurais. In: CONGRESSO INTERNACIONAL DE ECONOMIA E GESTÃO DE NEGÓCIOS/NETWORKS AGROALIMENTARES, 3., Ribeirão Preto, 2001. Anais. Ribeirão Preto: PENSA, 2001. http://www.ferarp.usp.br/egna

STADUTO, J.A.R.; FREITAS, C.A. Uma avaliação da mudança estrutural da produção agrícola brasileira no período 1959-1995 (compact disc). In: CONGRESSO BRASILEIRO DE ECONOMIA E SOCIOLOGIA RURAL, 39., Recife, 2001. Anais. Recife: SOBER, 2001.

STIGLITZ, J.E. Alternative theories of wage determination and unemployment in LDCs: Quarterly Journal of Economics, v.28, n.2, p.194-227, May 1974.

STIGLITZ, J.E. The efficiency wage hypothesis, surplus labour, and the distribution of income in LCDs. Oxford Economic Papers, v.28, n.2, p.185-239, July 1976.

SUMNER, D. The off-farm labor supply of farmers. American Journal of Agricultural Economics, v.64, n.3, p.499-709, Aug. 1982. 
SWAELEN, E.J.A. Desemprego, salários e preços: um estudo comparativo de Keynes e o pensamento macroeconômico da década de 1970. Rio de Janeiro: BNDES, 1982. 134p. (Prêmio BNDES de Economia, 6)

TAUBMAN, P.; WACHTER, M.L. Segmented labor markets. In: ASHENFELTER, O.C.; LAYARD, R. Handbook of labor economic. Amsterdam: North-Holland, 1986. v.2, p.1183-1217.

VANDERMAN, A.; SADOULET, E.; JANVRY, A. Labor contracting and a theory of contract choice in California agriculture. American Journal of Agricultural Economics, v.73, n.3, p.681-692, Aug. 1991.

VICENTE, J.R. Área de culturas no Estado de São Paulo, comparações entre os resultados do Censo Agropecuário 1995-1996, do Projeto Lupa e do levantamento subjetivo IEA/CATI. Informações Econômicas, v.28, n.7, p.7-10, 1998.

WADHWANI, S.; WALL, M. A direct test of efficiency wage model using UK microdate. Oxford Economic Papers, v.43, p.529-548, 1991.

WALLACE, T.D.; HUSSAIN, A. The use error components models in combining crosssection and time-series data. Econometrica, v.37, p.55-72, 1969.

YELLEN, J. Efficiency wage models of unemployment. American Economic Review, v.17, n.21, p.351-379, 1984.

YOUMANS, R.; SCHUH, G.E. An empirical study of the agricultural labor market in a developing country, Brasil. American Journal of Agricultural Economics, v.50, n.4, p.943-961, Nov. 1968.

ZELLNER, A. An efficient method of estimating seemingly unrelated regressions and tests for aggregations bias. Journal of the American Statistical Association, v.57, p.348-368, June 1962. 
APÊNDICES 
APÊNDICE 1 - Outros estudos sobre o mercado de trabalho agrícola.

Atualmente, por meio da avaliação da literatura internacional sobre o mercado de trabalho agrícola, nota-se que os pesquisadores dos países desenvolvidos estão com suas atenções voltadas para os problemas da oferta de mão-de-obra, evidenciando a falta de trabalhadores para o setor. Por exemplo, no caso dos Estados Unidos, os imigrantes clandestinos contribuem com a oferta de mão-de-obra agrícola. Com o maior rigor à entrada destes indivíduos nos últimos anos, ocorreu retração da oferta de trabalhadores agrícolas em algumas regiões daquele país.

Cabe também ressaltar que, principalmente na literatura internacional, há uma tendência dos pesquisadores em aplicar alguns modelos de comportamento dos salários agrícolas que são, normalmente, utilizados para o setor urbano-industrial. Esta situação demonstra que há uma tendência em ampliar os espaços teóricos nos estudos do mercado de trabalho agrícola, como é apresentado a seguir. No entanto, o ferramental analítico neoclássico, basicamente a teoria da escolha, ainda ocupa amplo espaço no conjunto das pesquisas publicadas.

Perloff (1991) analisou o diferencial de salários entre as atividades agrícolas e não-agrícolas. O autor considera que essa diferença torna-se uma variável fundamental na decisão do trabalhador no momento de optar por qual setor da economia teria preferência em empregar-se. Para tanto, o autor aplicou um modelo que procura verificar os determinantes que levam o trabalhador a empregar-se em um determinado ramo industrial em detrimento de outro. Por meio desta metodologia, foi possível examinar os efeitos relativos dos fatores salariais e, também, não-salariais que influenciariam a mobilidade dos trabalhadores entre os setores da economia, ou seja, da atividade agrícola para a não-agrícola ou vice-versa. Os resultados da pesquisa indicaram que a mudança dos trabalhadores da atividade não-agrícola para a agrícola não necessitaria de reduções substanciais no diferencial de salário. 
Considerando que os mercados de trabalho agrícola e não-agrícola são integrados, conseqüentemente, deve existir uma condição de arbitragem (a diferença entre os salários recebidos é o custo Marshalliano ou estático) para que ocorra mobilidade entre os dois setores. Segundo Richards \& Patterson (1998), a violação dessa condição de arbitragem é atribuída a um valor de "opção real" do trabalhador em deixar o seu emprego corrente e passar para outro.

Conforme Richards \& Patterson (1998), a teoria da hysteresis pode oferecer explicação plausível para o fenômeno da falta de mão-de-obra agrícola observada nos anos 90 nos Estados Unidos, apesar de existir significativo nível de desemprego em muitos municípios agrícolas. Segundo Dixit (1989), a teoria da hysteresis ${ }^{33}$ refere-se à falta de reversão do fenômeno, uma vez que as suas causas iniciais são removidas. Portanto, considerando esse cenário, constata-se que as previsões de Perloff (1991) sobre a mobilidade da mão-de-obra de outros setores para a atividade agropecuária americana, motivada pela redução do diferencial dos salários entre os setores, de fato não deve ter ocorrido ao longo dos anos 90.

Vandeman et al. (1991) analisaram os modelos de contratos sazonais aplicados à agricultura do Estado da Califórnia nos Estados Unidos. Os autores constataram que os produtores rurais tinham duas modalidades para contratar mão-deobra: de forma direta, fazendo o seu assalariamento; ou contratando os serviços de indivíduos que subalocam a mão-de-obra. Na pesquisa são consideradas ainda duas formas possíveis do produtor rural ou do contratante extrair trabalho da mão-de-obra: por meio da supervisão, que é considerada a forma mais primária de influenciar a qualidade do trabalho; ou exercendo pressão para o aumento da qualidade do trabalho por meio de ameaça da perda do emprego. Esta possibilidade está associada com as idéias dos modelos de salário-eficiência.

${ }^{33}$ Blanchard \& Summers (1986) aplicaram a idéia de hysteresis na macroeconômica para explicar a substancial persistência do desemprego nos países da Europa ocidental e os efeitos prolongados sobre o desemprego. Esses eventos não são facilmente explicados pelas teorias macroeconômicas clássicas e keynesianas convencionais. 
A supervisão envolve acompanhamento direto e coordenação do processo produtivo. A efetivação da supervisão depende da habilidade de gerência sobre o processo de produção. A outra forma de afetar o esforço do trabalhador é pelo controle do custo da perda de trabalho. Segundo Shapiro \& Stiglitz (1984) e Bowles (1985), este custo é definido pela diferença entre o salário atual e o salário de oportunidade. Dessa forma, um aumento no custo da perda do emprego acarretaria aumento no esforço do trabalhador, motivado, justamente, pelo custo do seu desligamento da empresa.

Há um outro grande grupo de pesquisas, publicadas na literatura internacional, sobre o mercado de trabalho agrícola que tem como objeto de análise a oferta de mão-de-obra oriunda da agricultura familiar. As publicações que analisaram a relação entre pequena produção (ou produção familiar) e mercado de trabalho utilizaram suposições e métodos analíticos diferenciados, mas, basicamente, são abordados por meio do corpo teórico neoclássico de alocação dos fatores.

Sumner (1982) e Gould \& Saupe (1989) analisaram o fenômeno do trabalho fora da propriedade agrícola familiar, considerando as causas de entrada e saída dos seus membros no mercado de trabalho, através de um modelo de alocação do tempo. A problemática envolve uma decisão de quais membros iriam empregar-se fora da propriedade, ou seja, fazer parte do mercado de trabalho. As motivações para isto estão na expectativa de aumentar a renda no período presente; reduzir o risco de flutuações da renda; e desenvolver experiência e habilidades para aumento futuro da renda.

Os trabalhos de Skoufias (1994) e Sonoda \& Maruyama (1999) apresentaram outra formulação para estimar a oferta de trabalho oriundas das propriedades familiares, a partir da aplicação do conceito de salário sombra (shadow wage) ou salário interno. Esse conceito, basicamente, consiste no produto marginal do trabalho dos membros ou das famílias para uma amostra de propriedades rurais. Considerando o salário sombra nos seus modelos, os autores estimaram equações de oferta de trabalho oriundas das propriedades familiares. 
Kumbhakar (1996) também aplicou o conceito de salário sombra para estimar uma função de produção para os produtores de arroz na Índia. O modelo deste autor tem pressupostos que o diferencia dos apresentados acima, pois aplica o conceito de salário-eficiência ${ }^{34}$. O sentido causal das variáveis considera que o salário é que determina a produtividade do trabalho. A pressuposição teórica do modelo desenvolvido pelo autor tem o seguinte mecanismo de ajuste: caso ocorra redução dos salários, o poder de compra se reduz e, conseqüentemente, a nutrição da mão-de-obra diminui, o que, por sua vez, influenciaria no produto marginal do trabalho.

${ }^{34}$ Ver capítulo 2 (item 2.2) e detalhes empíricos em Wadhwani \& Wall (1991) e Campebel llI (1993). 
APÊNDICE 2 - Dados utilizados na estimação das equações (18) e (25).

Tabela 5. Dados utilizados na estimação das equações (18) e (25).

\begin{tabular}{|c|c|c|c|c|c|c|c|}
\hline U.F. & Ano & $W T$ & $W P$ & $W M$ & $W U$ & $\mathrm{~Pa}$ & Pmo \\
\hline $\mathrm{AC}$ & 1971 & 6,27 & 159,07 & 133,10 & 0,85 & 0,42 & 96,80 \\
\hline$A C$ & 1972 & 6,38 & 139,63 & 138,58 & 0,91 & 0,83 & 93,76 \\
\hline$A C$ & 1973 & 7,37 & 168,39 & 141,42 & 0,90 & 0,47 & 90,70 \\
\hline$A C$ & 1974 & 7,56 & 186,10 & 133,01 & 0,86 & 0,47 & 87,80 \\
\hline$A C$ & 1975 & 8,03 & 175,31 & 174,43 & 0,92 & 0,40 & 85,00 \\
\hline$A C$ & 1976 & 7,70 & 152,99 & 149,00 & 0,83 & 0,40 & 86,16 \\
\hline$A C$ & 1977 & 8,10 & 213,98 & 144,82 & 0,94 & 0,43 & 87,35 \\
\hline$A C$ & 1978 & 8,60 & 234,49 & 148,42 & 1,04 & 0,44 & 88,55 \\
\hline$A C$ & 1979 & 7,91 & 219,93 & 151,23 & 1,09 & 0,44 & 89,76 \\
\hline$A C$ & 1980 & 7,78 & 190,47 & 144,06 & 0,99 & 0,42 & 91,00 \\
\hline$A C$ & 1981 & 8,96 & 210,61 & 141,27 & 1,42 & 0,37 & 88,46 \\
\hline$A C$ & 1982 & 7,77 & 208,20 & 148,72 & 0,97 & 0,28 & 85,99 \\
\hline$A C$ & 1983 & 6,65 & 185,29 & 131,09 & 1,01 & 0,31 & 83,59 \\
\hline$A C$ & 1984 & 6,07 & 149,60 & 119,55 & 0,60 & 0,30 & 81,26 \\
\hline$A C$ & 1985 & 6,68 & 186,98 & 125,87 & 0,56 & 0,38 & 79,00 \\
\hline$A C$ & 1986 & 8,92 & 176,25 & 127,24 & 0,71 & 0,50 & 81,28 \\
\hline$A C$ & 1987 & 5,29 & 105,35 & 105,94 & 0,51 & 0,46 & 83,62 \\
\hline$A C$ & 1988 & 4,02 & 113,46 & 101,21 & 0,47 & 0,42 & 86,03 \\
\hline$A C$ & 1989 & 4,79 & 112,96 & 106,29 & 0,49 & 0,63 & 88,52 \\
\hline$A C$ & 1990 & 3,82 & 85,48 & 80,18 & 0,39 & 0,57 & 91,07 \\
\hline$A C$ & 1991 & 3,75 & 100,43 & 95,06 & 0,40 & 0,48 & 93,70 \\
\hline$A C$ & 1992 & 3,18 & 83,18 & 85,45 & 0,35 & 0,71 & 96,41 \\
\hline$A C$ & 1993 & 3,21 & 83,36 & 88,55 & 0,37 & 0,75 & 99,19 \\
\hline$A C$ & 1994 & 3,62 & 80,29 & 75,92 & 0,35 & 1,04 & 102,05 \\
\hline$A C$ & $1995 / 96$ & 6,11 & 105,90 & 81,76 & 0,38 & 1,04 & 105,00 \\
\hline MA & 1971 & 3,53 & 106,36 & 118,60 & 0,49 & 2,52 & 100,39 \\
\hline MA & 1972 & 4,09 & 108,92 & 122,10 & 0,50 & 2,84 & 100,79 \\
\hline MA & 1973 & 4,21 & 115,64 & 125,58 & 0,52 & 2,78 & 101,19 \\
\hline MA & 1974 & 5,13 & 131,16 & 119,50 & 0,49 & 2,99 & 101,59 \\
\hline MA & 1975 & 5,59 & 133,50 & 143,67 & 0,55 & 2,74 & 102,00 \\
\hline MA & 1976 & 5,54 & 124,54 & 129,68 & 0,54 & 2,26 & 104,83 \\
\hline MA & 1977 & 5,30 & 119,79 & 131,14 & 0,55 & 1,88 & 107,75 \\
\hline MA & 1978 & 5,08 & 129,42 & 134,48 & 0,55 & 2,43 & 110,75 \\
\hline MA & 1979 & 5,56 & 132,09 & 138,11 & 0,55 & 2,74 & 113,83 \\
\hline MA & 1980 & 6,00 & 137,94 & 133,28 & 0,59 & 2,26 & 117,00 \\
\hline MA & 1981 & 5,62 & 133,53 & 136,95 & 0,60 & 2,03 & 117,00 \\
\hline MA & 1982 & 4,75 & 124,86 & 143,57 & 0,67 & 1,78 & 117,00 \\
\hline MA & 1983 & 4,28 & 105,20 & 130,20 & 0,81 & 1,97 & 117,00 \\
\hline MA & 1984 & 4,44 & 104,77 & 119,55 & 0,52 & 1,65 & 117,00 \\
\hline MA & 1985 & 4,27 & 112,67 & 125,87 & 0,60 & 2,21 & 117,00 \\
\hline MA & 1986 & 5,37 & 137,36 & 127,24 & 0,53 & 2,14 & 119,11 \\
\hline MA & 1987 & 3,59 & 90,23 & 105,94 & 0,42 & 1,78 & 121,27 \\
\hline MA & 1988 & 2,83 & 77,60 & 101,21 & 0,44 & 1,97 & 123,47 \\
\hline MA & 1989 & 3,50 & 90,99 & 106,29 & 0,46 & 1,02 & 125,70 \\
\hline MA & 1990 & 2,86 & 69,77 & 80,18 & 0,38 & 0,86 & 127,98 \\
\hline MA & 1991 & 2,85 & 69,53 & 95,06 & 0,38 & 0,66 & 130,30 \\
\hline MA & 1992 & 2,47 & 69,02 & 85,45 & 0,35 & 0,77 & 132,66 \\
\hline MA & 1993 & 2,25 & 74,18 & 88,55 & 0,37 & 0,92 & 135,06 \\
\hline MA & 1994 & 2,77 & 64,47 & 75,92 & 0,34 & 0,98 & 137,51 \\
\hline MA & $1995 / 96$ & 3,62 & 88,70 & 81,76 & 0,40 & 0,99 & 140,00 \\
\hline
\end{tabular}


Tabela 5. Dados utilizados na estimação das equações (18) e (25).

\begin{tabular}{|c|c|c|c|c|c|c|c|}
\hline U.F. & Ano & $W T$ & $W P$ & $W M$ & $W U$ & $P a$ & Pmo \\
\hline $\mathrm{CE}$ & 1971 & 2,61 & 75,55 & 118,60 & 0,49 & 1,15 & 110,67 \\
\hline CE & 1972 & 2,73 & 79,31 & 122,10 & 0,51 & 1,18 & 122,47 \\
\hline CE & 1973 & 3,18 & 94,25 & 125,58 & 0,53 & 1,25 & 135,54 \\
\hline CE & 1974 & 4,29 & 108,55 & 119,50 & 0,50 & 1,26 & 150,00 \\
\hline CE & 1975 & 4,26 & 105,61 & 143,67 & 0,56 & 1,02 & 166,00 \\
\hline CE & 1976 & 4,32 & 108,33 & 129,68 & 0,49 & 1,07 & 162,01 \\
\hline CE & 1977 & 4,61 & 116,70 & 131,14 & 0,56 & 0,90 & 158,12 \\
\hline CE & 1978 & 4,45 & 115,06 & 134,48 & 0,54 & 0,94 & 154,32 \\
\hline CE & 1979 & 4,32 & 122,00 & 138,11 & 0,55 & 1,02 & 150,62 \\
\hline CE & 1980 & 4,35 & 116,92 & 133,28 & 0,56 & 0,95 & 147,00 \\
\hline CE & 1981 & 4,44 & 112,67 & 132,80 & 0,60 & 0,85 & 152,04 \\
\hline CE & 1982 & 3,97 & 110,44 & 143,57 & 0,61 & 0,75 & 157,26 \\
\hline CE & 1983 & 3,08 & 82,78 & 130,20 & 0,51 & 0,83 & 162,65 \\
\hline CE & 1984 & 3,19 & 83,82 & 119,55 & 0,29 & 0,74 & 168,23 \\
\hline CE & 1985 & 3,24 & 88,68 & 125,87 & 0,60 & 0,75 & 174,00 \\
\hline CE & 1986 & 4,97 & 116,56 & 127,24 & 0,52 & 0,74 & 178,61 \\
\hline CE & 1987 & 2,71 & 73,05 & 105,94 & 0,42 & 0,94 & 183,34 \\
\hline CE & 1988 & 2,19 & 65,24 & 101,21 & 0,42 & 0,99 & 188,20 \\
\hline CE & 1989 & 2,59 & 72,82 & 106,29 & 0,44 & 0,86 & 193,18 \\
\hline CE & 1990 & 2,18 & 53,67 & 80,18 & 0,37 & 0,88 & 198,30 \\
\hline CE & 1991 & 2,67 & 62,40 & 95,06 & 0,39 & 0,74 & 203,56 \\
\hline CE & 1992 & 2,01 & 58,03 & 85,45 & 0,46 & 0,95 & 208,95 \\
\hline CE & 1993 & 1,91 & 63,66 & 88,55 & 0,43 & 1,10 & 214,48 \\
\hline CE & 1994 & 2,59 & 60,28 & 75,92 & 0,42 & 0,95 & 220,17 \\
\hline CE & $1995 / 96$ & 3,54 & 79,01 & 81,76 & 0,49 & 0,85 & 226,00 \\
\hline RN & 1971 & 2,95 & 81,55 & 118,60 & 0,50 & 0,65 & 107,11 \\
\hline $\mathrm{RN}$ & 1972 & 3,28 & 81,41 & 122,10 & 0,53 & 0,64 & 114,73 \\
\hline $\mathrm{RN}$ & 1973 & 3,77 & 95,91 & 125,58 & 0,51 & 0,68 & 122,89 \\
\hline RN & 1974 & 5,40 & 111,40 & 119,50 & 0,53 & 0,71 & 131,64 \\
\hline $\mathrm{RN}$ & 1975 & 4,82 & 112,47 & 143,67 & 0,56 & 0,56 & 141,00 \\
\hline RN & 1976 & 5,39 & 114,49 & 129,68 & 0,55 & 0,59 & 139,15 \\
\hline RN & 1977 & 5,54 & 124,73 & 131,14 & 0,57 & 0,57 & 137,33 \\
\hline RN & 1978 & 5,84 & 134,08 & 134,48 & 0,58 & 0,54 & 135,53 \\
\hline $\mathrm{RN}$ & 1979 & 5,46 & 127,76 & 138,11 & 0,57 & 0,58 & 133,75 \\
\hline RN & 1980 & 5,53 & 134,52 & 133,28 & 0,60 & 0,62 & 132,00 \\
\hline RN & 1981 & 5,83 & 133,61 & 132,80 & 0,63 & 0,52 & 137,69 \\
\hline RN & 1982 & 5,38 & 130,55 & 143,57 & 0,72 & 0,44 & 143,62 \\
\hline $\mathrm{RN}$ & 1983 & 3,86 & 103,31 & 130,20 & 0,54 & 0,43 & 149,81 \\
\hline RN & 1984 & 3,78 & 97,46 & 119,55 & 0,33 & 0,46 & 156,27 \\
\hline RN & 1985 & 3,81 & 100,79 & 125,87 & 0,60 & 0,44 & 163,00 \\
\hline $\mathrm{RN}$ & 1986 & 5,13 & 123,25 & 127,24 & 0,57 & 0,44 & 169,71 \\
\hline $\mathrm{RN}$ & 1987 & 3,34 & 80,68 & 105,94 & 0,51 & 0,60 & 176,70 \\
\hline RN & 1988 & 2,64 & 76,82 & 101,21 & 0,45 & 0,72 & 183,97 \\
\hline RN & 1989 & 3,17 & 74,81 & 106,29 & 0,45 & 0,72 & 191,54 \\
\hline $\mathrm{RN}$ & 1990 & 2,62 & 72,27 & 80,18 & 0,39 & 0,98 & 199,43 \\
\hline RN & 1991 & 2,91 & 65,69 & 95,06 & 0,41 & 0,94 & 207,64 \\
\hline RN & 1992 & 2,75 & 64,71 & 85,45 & 0,44 & 1,02 & 216,19 \\
\hline $\mathrm{RN}$ & 1993 & 2,34 & 63,28 & 88,55 & 0,45 & 1,25 & 225,09 \\
\hline RN & 1994 & 2,88 & 69,18 & 75,92 & 0,42 & 0,98 & 234,35 \\
\hline RN & $1995 / 96$ & 3,93 & 86,73 & 81,76 & 0,42 & 0,83 & 244,00 \\
\hline
\end{tabular}


Tabela 5. Dados utilizados na estimação das equações (18) e (25).

\begin{tabular}{|c|c|c|c|c|c|c|c|}
\hline U.F. & Ano & $W T$ & $W P$ & $W M$ & $W U$ & $P a$ & Pmo \\
\hline PB & 1971 & 3,50 & 74,66 & 118,60 & 0,49 & 0,58 & 105,39 \\
\hline PB & 1972 & 3,28 & 78,01 & 122,10 & 0,50 & 0,57 & 111,07 \\
\hline PB & 1973 & 3,71 & 89,10 & 125,58 & 0,49 & 0,62 & 117,05 \\
\hline PB & 1974 & 5,43 & 113,04 & 119,50 & 0,49 & 0,62 & 123,35 \\
\hline PB & 1975 & 5,35 & 111,67 & 143,67 & 0,56 & 0,51 & 130,00 \\
\hline PB & 1976 & 5,37 & 113,74 & 129,68 & 0,51 & 0,52 & 130,20 \\
\hline PB & 1977 & 5,65 & 110,38 & 131,14 & 0,55 & 0,50 & 130,40 \\
\hline PB & 1978 & 5,59 & 125,04 & 134,48 & 0,57 & 0,49 & 130,60 \\
\hline PB & 1979 & 5,50 & 123,64 & 138,11 & 0,55 & 0,51 & 130,80 \\
\hline PB & 1980 & 5,50 & 119,29 & 133,28 & 0,56 & 0,56 & 131,00 \\
\hline PB & 1981 & 5,29 & 114,60 & 132,80 & 0,49 & 0,49 & 136,00 \\
\hline PB & 1982 & 4,59 & 104,79 & 143,57 & 0,62 & 0,40 & 141,20 \\
\hline PB & 1983 & 3,99 & 92,14 & 130,20 & 0,64 & 0,43 & 146,59 \\
\hline PB & 1984 & 3,77 & 83,03 & 119,55 & 0,37 & 0,43 & 152,19 \\
\hline PB & 1985 & 3,80 & 87,36 & 125,87 & 0,60 & 0,38 & 158,00 \\
\hline PB & 1986 & 5,46 & 119,78 & 127,24 & 0,59 & 0,38 & 162,48 \\
\hline PB & 1987 & 3,34 & 73,53 & 105,94 & 0,48 & 0,51 & 167,09 \\
\hline PB & 1988 & 2,11 & 57,98 & 101,21 & 0,51 & 0,67 & 171,83 \\
\hline PB & 1989 & 3,04 & 68,72 & 106,29 & 0,57 & 0,67 & 176,71 \\
\hline PB & 1990 & 2,43 & 57,35 & 80,18 & 0,42 & 0,72 & 181,72 \\
\hline PB & 1991 & 2,79 & 61,74 & 95,06 & 0,48 & 0,67 & 186,87 \\
\hline PB & 1992 & 2,38 & 60,62 & 85,45 & 0,44 & 0,82 & 192,18 \\
\hline PB & 1993 & 2,09 & 55,74 & 88,55 & 0,45 & 0,99 & 197,63 \\
\hline PB & 1994 & 2,56 & 55,71 & 75,92 & 0,43 & 0,96 & 203,23 \\
\hline PB & $1995 / 96$ & 3,80 & 83,03 & 81,76 & 0,46 & 0,75 & 209,00 \\
\hline$P E$ & 1971 & 2,98 & 83,49 & 135,95 & 0,59 & 0,53 & 105,39 \\
\hline$P E$ & 1972 & 2,92 & 76,98 & 138,58 & 0,66 & 0,54 & 111,07 \\
\hline PE & 1973 & 3,43 & 90,14 & 141,42 & 0,67 & 0,61 & 117,05 \\
\hline PE & 1974 & 5,06 & 102,23 & 133,01 & 0,69 & 0,60 & 123,35 \\
\hline PE & 1975 & 5,23 & 111,90 & 159,22 & 0,65 & 0,50 & 130,00 \\
\hline PE & 1976 & 4,83 & 107,92 & 143,49 & 0,66 & 0,51 & 133,42 \\
\hline PE & 1977 & 5,04 & 112,39 & 144,82 & 0,60 & 0,52 & 136,92 \\
\hline$P E$ & 1978 & 5,08 & 128,57 & 151,82 & 0,76 & 0,53 & 140,52 \\
\hline$P E$ & 1979 & 5,22 & 141,95 & 152,64 & 0,75 & 0,56 & 144,21 \\
\hline PE & 1980 & 5,20 & 139,30 & 144,06 & 0,67 & 0,57 & 148,00 \\
\hline PE & 1981 & 6,07 & 167,63 & 141,27 & 0,63 & 0,50 & 153,04 \\
\hline PE & 1982 & 5,95 & 185,36 & 148,72 & 0,75 & 0,44 & 158,26 \\
\hline PE & 1983 & 4,85 & 158,42 & 131,09 & 0,53 & 0,39 & 163,65 \\
\hline PE & 1984 & 4,31 & 139,93 & 119,55 & 0,31 & 0,43 & 169,23 \\
\hline PE & 1985 & 4,89 & 149,87 & 125,87 & 0,69 & 0,42 & 175,00 \\
\hline PE & 1986 & 5,91 & 149,37 & 127,24 & 0,64 & 0,41 & 176,54 \\
\hline$P E$ & 1987 & 3,78 & 108,90 & 105,94 & 0,53 & 0,51 & 178,09 \\
\hline PE & 1988 & 3,17 & 109,46 & 101,21 & 0,58 & 0,63 & 179,65 \\
\hline PE & 1989 & 3,76 & 107,01 & 106,29 & 0,58 & 0,58 & 181,23 \\
\hline PE & 1990 & 2,88 & 77,32 & 80,18 & 0,43 & 0,67 & 182,83 \\
\hline PE & 1991 & 3,16 & 84,13 & 95,06 & 0,47 & 0,65 & 184,43 \\
\hline PE & 1992 & 2,81 & 83,71 & 85,45 & 0,53 & 0,82 & 186,05 \\
\hline PE & 1993 & 2,62 & 87,99 & 88,55 & 0,52 & 0,97 & 187,69 \\
\hline PE & 1994 & 2,96 & 83,33 & 75,92 & 0,55 & 0,96 & 189,34 \\
\hline PE & 1995/96 & 4,07 & 98,35 & 81,76 & 0,58 & 0,76 & 191,00 \\
\hline
\end{tabular}


Tabela 5. Dados utilizados na estimação das equações (18) e (25).

\begin{tabular}{|c|c|c|c|c|c|c|c|}
\hline U.F. & Ano & $W T$ & $W P$ & $W M$ & $W U$ & $\mathrm{~Pa}$ & Pmo \\
\hline $\mathrm{AL}$ & 1971 & 3,10 & 104,61 & 118,60 & 0,61 & 0,46 & 106,96 \\
\hline$A L$ & 1972 & 3,33 & 112,57 & 122,10 & 0,60 & 0,45 & 114,41 \\
\hline$A L$ & 1973 & 4,05 & 120,59 & 125,58 & 0,56 & 0,48 & 122,37 \\
\hline$A L$ & 1974 & 5,37 & 116,50 & 119,50 & 0,53 & 0,45 & 130,89 \\
\hline$A L$ & 1975 & 5,83 & 137,81 & 143,67 & 0,53 & 0,41 & 140,00 \\
\hline$A L$ & 1976 & 6,24 & 135,80 & 129,68 & 0,63 & 0,41 & 143,43 \\
\hline$A L$ & 1977 & 6,31 & 129,55 & 131,14 & 0,60 & 0,42 & 146,94 \\
\hline$A L$ & 1978 & 6,09 & 139,83 & 134,48 & 0,62 & 0,39 & 150,54 \\
\hline$A L$ & 1979 & 5,60 & 150,55 & 138,11 & 0,59 & 0,35 & 154,22 \\
\hline$A L$ & 1980 & 5,97 & 128,10 & 138,52 & 0,60 & 0,36 & 158,00 \\
\hline$A L$ & 1981 & 6,55 & 150,20 & 132,80 & 0,61 & 0,34 & 163,94 \\
\hline$A L$ & 1982 & 6,56 & 160,78 & 143,57 & 0,71 & 0,33 & 170,10 \\
\hline$A L$ & 1983 & 5,33 & 118,74 & 130,20 & 0,70 & 0,29 & 176,49 \\
\hline$A L$ & 1984 & 4,44 & 120,78 & 119,55 & 0,38 & 0,31 & 183,12 \\
\hline$A L$ & 1985 & 4,99 & 136,54 & 125,87 & 0,60 & 0,33 & 190,00 \\
\hline AL & 1986 & 6,47 & 141,68 & 127,24 & 0,53 & 0,28 & 193,58 \\
\hline$A L$ & 1987 & 4,02 & 97,82 & 105,94 & 0,46 & 0,35 & 197,23 \\
\hline$A L$ & 1988 & 2,81 & 95,51 & 101,21 & 0,44 & 0,41 & 200,95 \\
\hline$A L$ & 1989 & 3,30 & 97,64 & 106,29 & 0,45 & 0,35 & 204,73 \\
\hline$A L$ & 1990 & 3,15 & 90,78 & 80,18 & 0,37 & 0,41 & 208,59 \\
\hline AL & 1991 & 3,83 & 92,75 & 95,06 & 0,39 & 0,42 & 212,52 \\
\hline AL & 1992 & 2,90 & 79,74 & 85,45 & 0,43 & 0,71 & 216,53 \\
\hline$A L$ & 1993 & 3,21 & 79,82 & 88,55 & 0,48 & 0,85 & 220,61 \\
\hline$A L$ & 1994 & 3,52 & 82,58 & 75,92 & 0,43 & 0,96 & 224,76 \\
\hline$A L$ & $1995 / 96$ & 3,84 & 85,33 & 81,76 & 0,47 & 0,93 & 229,00 \\
\hline SE & 1971 & 3,55 & 109,08 & 118,60 & 0,48 & 0,36 & 101,36 \\
\hline SE & 1972 & 3,60 & 110,20 & 122,10 & 0,50 & 0,41 & 102,74 \\
\hline SE & 1973 & 4,23 & 126,94 & 125,58 & 0,50 & 0,43 & 104,14 \\
\hline SE & 1974 & 5,36 & 128,68 & 119,50 & 0,50 & 0,40 & 105,56 \\
\hline SE & 1975 & 6,41 & 136,92 & 143,67 & 0,55 & 0,39 & 107,00 \\
\hline SE & 1976 & 6,03 & 131,05 & 129,68 & 0,54 & 0,31 & 112,09 \\
\hline SE & 1977 & 5,58 & 122,11 & 131,14 & 0,55 & 0,42 & 117,43 \\
\hline SE & 1978 & 6,35 & 131,82 & 134,48 & 0,57 & 0,47 & 123,01 \\
\hline SE & 1979 & 6,48 & 139,36 & 138,11 & 0,58 & 0,33 & 128,87 \\
\hline SE & 1980 & 6,11 & 136,62 & 133,28 & 0,61 & 0,30 & 135,00 \\
\hline SE & 1981 & 6,01 & 140,34 & 132,80 & 0,61 & 0,28 & 135,59 \\
\hline SE & 1982 & 6,28 & 143,39 & 143,57 & 0,66 & 0,25 & 136,19 \\
\hline SE & 1983 & 4,75 & 115,73 & 130,20 & 0,60 & 0,22 & 136,79 \\
\hline SE & 1984 & 4,25 & 104,53 & 119,55 & 0,36 & 0,31 & 137,39 \\
\hline SE & 1985 & 4,68 & 120,55 & 125,87 & 0,60 & 0,32 & 138,00 \\
\hline SE & 1986 & 7,36 & 138,50 & 127,24 & 0,57 & 0,30 & 140,49 \\
\hline SE & 1987 & 4,43 & 87,16 & 105,94 & 0,42 & 0,37 & 143,02 \\
\hline SE & 1988 & 3,32 & 84,03 & 101,21 & 0,45 & 0,57 & 145,60 \\
\hline SE & 1989 & 4,79 & 102,87 & 106,29 & 0,44 & 0,53 & 148,22 \\
\hline SE & 1990 & 3,49 & 79,36 & 80,18 & 0,38 & 0,55 & 150,90 \\
\hline SE & 1991 & 3,76 & 79,74 & 95,06 & 0,39 & 0,58 & 153,62 \\
\hline SE & 1992 & 3,05 & 88,43 & 85,45 & 0,39 & 0,71 & 156,39 \\
\hline SE & 1993 & 2,52 & 70,25 & 88,55 & 0,44 & 0,85 & 159,21 \\
\hline SE & 1994 & 3,31 & 69,03 & 75,92 & 0,40 & 0,96 & 162,08 \\
\hline SE & $1995 / 96$ & 3,89 & 79,93 & 81,76 & 0,42 & 0,76 & 165,00 \\
\hline
\end{tabular}


Tabela 5. Dados utilizados na estimação das equações (18) e (25).

\begin{tabular}{|c|c|c|c|c|c|c|c|}
\hline U.F. & Ano & $W T$ & $W P$ & $W M$ & $W U$ & $P a$ & Pmo \\
\hline BA & 1971 & 3,95 & 107,44 & 135,95 & 0,59 & 0,40 & 101,55 \\
\hline BA & 1972 & 3,82 & 108,43 & 138,58 & 0,57 & 0,43 & 103,13 \\
\hline BA & 1973 & 4,48 & 118,42 & 141,42 & 0,62 & 0,53 & 104,73 \\
\hline BA & 1974 & 5,69 & 132,81 & 133,01 & 0,57 & 0,47 & 106,35 \\
\hline BA & 1975 & 6,64 & 140,81 & 159,22 & 0,66 & 0,39 & 108,00 \\
\hline BA & 1976 & 6,31 & 142,17 & 143,49 & 0,67 & 0,46 & 109,55 \\
\hline BA & 1977 & 6,35 & 152,65 & 144,82 & 0,67 & 0,77 & 111,13 \\
\hline BA & 1978 & 6,82 & 168,74 & 138,63 & 0,74 & 0,71 & 112,73 \\
\hline BA & 1979 & 7,05 & 172,68 & 147,17 & 0,69 & 0,57 & 114,35 \\
\hline BA & 1980 & 6,58 & 139,45 & 138,82 & 0,73 & 0,45 & 116,00 \\
\hline BA & 1981 & 6,16 & 139,98 & 141,28 & 0,64 & 0,36 & 115,80 \\
\hline BA & 1982 & 4,95 & 137,07 & 148,72 & 0,65 & 0,29 & 115,60 \\
\hline BA & 1983 & 4,26 & 116,46 & 131,09 & 0,56 & 0,30 & 115,40 \\
\hline BA & 1984 & 4,28 & 121,01 & 119,55 & 0,33 & 0,45 & 115,20 \\
\hline BA & 1985 & 4,82 & 135,02 & 125,87 & 0,50 & 0,44 & 115,00 \\
\hline BA & 1986 & 6,27 & 139,90 & 127,24 & 0,57 & 0,43 & 116,15 \\
\hline BA & 1987 & 3,80 & 95,02 & 105,94 & 0,42 & 0,48 & 117,31 \\
\hline BA & 1988 & 3,23 & 96,64 & 101,21 & 0,44 & 0,55 & 118,48 \\
\hline BA & 1989 & 4,14 & 114,20 & 106,29 & 0,49 & 0,45 & 119,66 \\
\hline BA & 1990 & 2,95 & 74,02 & 80,18 & 0,51 & 0,56 & 120,85 \\
\hline BA & 1991 & 3,02 & 75,97 & 95,06 & 0,41 & 0,64 & 122,06 \\
\hline BA & 1992 & 2,79 & 77,04 & 85,45 & 0,48 & 0,70 & 123,27 \\
\hline BA & 1993 & 2,81 & 82,59 & 88,55 & 0,49 & 0,85 & 124,50 \\
\hline BA & 1994 & 2,75 & 68,10 & 75,92 & 0,45 & 0,93 & 125,75 \\
\hline $\mathrm{BA}$ & $1995 / 96$ & 3,57 & 82,24 & 81,76 & 0,51 & 0,93 & 127,00 \\
\hline MG & 1971 & 3,79 & 114,91 & 169,22 & 0,71 & 0,36 & 99,39 \\
\hline$M G$ & 1972 & 4,19 & 121,52 & 178,24 & 0,77 & 0,39 & 98,79 \\
\hline MG & 1973 & 5,37 & 153,85 & 183,94 & 0,77 & 0,45 & 98,19 \\
\hline$M G$ & 1974 & 6,37 & 160,33 & 170,79 & 0,72 & 0,41 & 97,59 \\
\hline MG & 1975 & 6,84 & 170,22 & 203,16 & 0,85 & 0,41 & 97,00 \\
\hline MG & 1976 & 6,61 & 167,32 & 182,97 & 0,83 & 0,42 & 97,40 \\
\hline MG & 1977 & 6,90 & 181,61 & 184,48 & 0,87 & 0,54 & 97,80 \\
\hline MG & 1978 & 6,71 & 182,72 & 188,86 & 0,86 & 0,47 & 98,20 \\
\hline MG & 1979 & 6,82 & 186,09 & 190,37 & 0,84 & 0,50 & 98,60 \\
\hline MG & 1980 & 6,58 & 168,98 & 175,44 & 0,85 & 0,45 & 99,00 \\
\hline$M G$ & 1981 & 6,31 & 163,91 & 168,10 & 0,83 & 0,36 & 106,10 \\
\hline MG & 1982 & 5,49 & 159,89 & 171,80 & 0,86 & 0,34 & 113,72 \\
\hline MG & 1983 & 4,46 & 137,06 & 148,99 & 0,50 & 0,20 & 121,88 \\
\hline MG & 1984 & 4,31 & 123,57 & 124,20 & 0,30 & 0,40 & 130,63 \\
\hline MG & 1985 & 5,08 & 137,01 & 125,87 & 0,55 & 0,42 & 140,00 \\
\hline MG & 1986 & 7,27 & 154,38 & 127,24 & 0,80 & 0,54 & 144,11 \\
\hline MG & 1987 & 5,03 & 114,76 & 105,94 & 0,64 & 0,46 & 148,34 \\
\hline MG & 1988 & 3,68 & 105,44 & 101,21 & 0,51 & 0,52 & 152,70 \\
\hline MG & 1989 & 4,34 & 112,80 & 106,29 & 0,60 & 0,53 & 157,19 \\
\hline MG & 1990 & 3,81 & 89,56 & 80,18 & 0,55 & 0,62 & 161,80 \\
\hline MG & 1991 & 4,88 & 110,37 & 95,06 & 0,50 & 0,57 & 166,55 \\
\hline MG & 1992 & 3,18 & 83,85 & 85,45 & 0,49 & 0,60 & 171,45 \\
\hline MG & 1993 & 3,13 & 85,39 & 88,55 & 0,50 & 0,75 & 176,48 \\
\hline MG & 1994 & 4,05 & 83,11 & 75,92 & 0,49 & 0,98 & 181,66 \\
\hline MG & $1995 / 96$ & 5,02 & 98,99 & 81,76 & 0,55 & 0,84 & 187,00 \\
\hline
\end{tabular}


Tabela 5. Dados utilizados na estimação das equações (18) e (25).

\begin{tabular}{|c|c|c|c|c|c|c|c|}
\hline U.F. & Ano & $W T$ & $W P$ & $W M$ & $W U$ & $P a$ & Pmo \\
\hline ES & 1971 & 3,88 & 110,49 & 147,51 & 0,61 & 0,28 & 101,55 \\
\hline ES & 1972 & 4,14 & 112,90 & 151,06 & 0,62 & 0,29 & 103,13 \\
\hline ES & 1973 & 4,90 & 122,44 & 154,28 & 0,64 & 0,32 & 104,73 \\
\hline ES & 1974 & 6,29 & 141,89 & 144,93 & 0,61 & 0,26 & 106,35 \\
\hline ES & 1975 & 6,79 & 162,08 & 173,08 & 0,68 & 0,24 & 108,00 \\
\hline ES & 1976 & 7,12 & 161,37 & 156,00 & 0,74 & 0,32 & 108,59 \\
\hline ES & 1977 & 7,37 & 173,04 & 157,59 & 0,88 & 0,47 & 109,19 \\
\hline ES & 1978 & 7,66 & 187,94 & 171,29 & 0,87 & 0,36 & 109,79 \\
\hline ES & 1979 & 7,22 & 185,34 & 177,50 & 0,88 & 0,41 & 110,39 \\
\hline ES & 1980 & 7,05 & 177,66 & 172,13 & 0,89 & 0,35 & 111,00 \\
\hline ES & 1981 & 6,59 & 170,57 & 168,10 & 0,98 & 0,22 & 117,41 \\
\hline ES & 1982 & 6,31 & 170,60 & 171,80 & 1,05 & 0,22 & 124,20 \\
\hline ES & 1983 & 5,60 & 140,76 & 148,99 & 0,68 & 0,25 & 131,38 \\
\hline ES & 1984 & 4,95 & 127,54 & 124,20 & 0,39 & 0,33 & 138,97 \\
\hline ES & 1985 & 5,94 & 145,90 & 125,87 & 0,62 & 0,39 & 147,00 \\
\hline ES & 1986 & 8,20 & 162,96 & 127,24 & 0,68 & 0,54 & 152,19 \\
\hline ES & 1987 & 4,88 & 104,73 & 105,94 & 0,60 & 0,31 & 157,57 \\
\hline ES & 1988 & 3,64 & 98,67 & 101,21 & 0,56 & 0,31 & 163,13 \\
\hline ES & 1989 & 4,92 & 110,92 & 106,29 & 0,57 & 0,32 & 168,89 \\
\hline ES & 1990 & 3,60 & 76,80 & 80,18 & 0,44 & 0,32 & 174,86 \\
\hline ES & 1991 & 4,29 & 80,77 & 95,06 & 0,44 & 0,32 & 181,04 \\
\hline ES & 1992 & 3,61 & 82,02 & 85,45 & 0,44 & 0,37 & 187,43 \\
\hline ES & 1993 & 3,40 & 85,28 & 88,55 & 0,39 & 0,47 & 194,05 \\
\hline ES & 1994 & 4,26 & 80,06 & 75,92 & 0,44 & 0,84 & 200,90 \\
\hline ES & 1995/96 & 5,59 & 94,93 & 81,76 & 0,49 & 0,76 & 208,00 \\
\hline RJ & 1971 & 3,95 & 119,35 & 177,25 & 0,77 & 0,58 & 107,11 \\
\hline RJ & 1972 & 4,06 & 125,06 & 180,62 & 0,75 & 0,57 & 114,73 \\
\hline RJ & 1973 & 4,91 & 145,90 & 183,94 & 0,76 & 0,59 & 122,89 \\
\hline RJ & 1974 & 5,58 & 150,87 & 170,79 & 0,76 & 0,51 & 131,64 \\
\hline RJ & 1975 & 6,41 & 166,49 & 203,16 & 0,82 & 0,51 & 141,00 \\
\hline RJ & 1976 & 6,62 & 165,41 & 182,97 & 0,84 & 0,56 & 141,59 \\
\hline RJ & 1977 & 6,92 & 179,29 & 184,48 & 0,89 & 0,54 & 142,19 \\
\hline RJ & 1978 & 7,47 & 192,35 & 188,86 & 0,92 & 0,48 & 142,79 \\
\hline RJ & 1979 & 7,21 & 187,44 & 190,37 & 0,88 & 0,50 & 143,39 \\
\hline RJ & 1980 & 6,51 & 180,61 & 175,44 & 0,88 & 0,45 & 144,00 \\
\hline RJ & 1981 & 6,27 & 179,65 & 168,10 & 0,86 & 0,40 & 144,79 \\
\hline RJ & 1982 & 6,26 & 182,08 & 171,80 & 0,88 & 0,40 & 145,59 \\
\hline RJ & 1983 & 5,42 & 147,57 & 148,99 & 0,81 & 0,37 & 146,39 \\
\hline RJ & 1984 & 4,58 & 131,43 & 124,20 & 0,42 & 0,41 & 147,19 \\
\hline RJ & 1985 & 4,77 & 149,61 & 125,87 & 0,60 & 0,39 & 148,00 \\
\hline RJ & 1986 & 6,28 & 143,26 & 127,24 & 0,71 & 0,47 & 148,97 \\
\hline RJ & 1987 & 4,68 & 103,74 & 105,94 & 0,55 & 0,48 & 149,95 \\
\hline RJ & 1988 & 3,78 & 104,54 & 101,21 & 0,61 & 0,50 & 150,93 \\
\hline RJ & 1989 & 5,37 & 124,21 & 106,29 & 0,61 & 0,58 & 151,92 \\
\hline RJ & 1990 & 3,73 & 81,12 & 80,18 & 0,49 & 0,63 & 152,92 \\
\hline RJ & 1991 & 4,45 & 89,70 & 95,06 & 0,52 & 0,62 & 153,92 \\
\hline RJ & 1992 & 3,77 & 90,78 & 85,45 & 0,60 & 0,63 & 154,93 \\
\hline RJ & 1993 & 3,61 & 91,75 & 88,55 & 0,63 & 0,79 & 155,95 \\
\hline RJ & 1994 & 3,78 & 77,22 & 75,92 & 0,64 & 0,98 & 156,97 \\
\hline RJ & $1995 / 96$ & 5,85 & 93,04 & 81,76 & 0,70 & 0,99 & 158,00 \\
\hline
\end{tabular}


Tabela 5. Dados utilizados na estimação das equações (18) e (25).

\begin{tabular}{|c|c|c|c|c|c|c|c|}
\hline U.F. & Ano & $W T$ & $W P$ & $W M$ & $W U$ & $P a$ & Pmo \\
\hline $\mathrm{SP}$ & 1971 & 5.65 & 161,23 & 177.25 & 0,76 & 0,50 & 107.11 \\
\hline SP & 1972 & 6,22 & 158,30 & 180,62 & 0,77 & 0,53 & 114,73 \\
\hline SP & 1973 & 7,44 & 167,81 & 183,94 & 0,82 & 0,62 & 122,89 \\
\hline SP & 1974 & 8,23 & 162,67 & 170,79 & 0,95 & 0,44 & 131,64 \\
\hline SP & 1975 & 8,47 & 176,58 & 203,16 & 1,03 & 0,41 & 141,00 \\
\hline SP & 1976 & 8,45 & 179,08 & 182,97 & 1,02 & 0,34 & 147,73 \\
\hline SP & 1977 & 9,42 & 188,69 & 184,48 & 1,01 & 0,37 & 154,77 \\
\hline SP & 1978 & 9,09 & 206,42 & 188,86 & 1,01 & 0,33 & 162,16 \\
\hline SP & 1979 & 8,23 & 184,60 & 190,37 & 0,99 & 0,32 & 169,89 \\
\hline SP & 1980 & 7,78 & 169,16 & 175,44 & 1,00 & 0,29 & 178,00 \\
\hline SP & 1981 & 7,50 & 171,37 & 168,10 & 1,03 & 0,25 & 188,65 \\
\hline SP & 1982 & 7,29 & 181,25 & 171,80 & 1,08 & 0,23 & 199,93 \\
\hline SP & 1983 & 5,89 & 145,33 & 148,99 & 0,72 & 0,26 & 211,89 \\
\hline SP & 1984 & 4,80 & 124,78 & 124,20 & 0,41 & 0,29 & 224,57 \\
\hline SP & 1985 & 6,42 & 147,34 & 125,87 & 0,71 & 0,29 & 238,00 \\
\hline SP & 1986 & 9,14 & 174,20 & 127,24 & 0,99 & 0,41 & 238,69 \\
\hline SP & 1987 & 5,80 & 104,91 & 105,94 & 0,72 & 0,37 & 239,38 \\
\hline SP & 1988 & 4,78 & 111,50 & 101,21 & 0,73 & 0,46 & 240,08 \\
\hline SP & 1989 & 6,02 & 136,23 & 106,29 & 0,78 & 0,46 & 240,78 \\
\hline SP & 1990 & 4,57 & 95,96 & 80,18 & 0,61 & 0,49 & 241,47 \\
\hline SP & 1991 & 4,76 & 97,07 & 95,06 & 0,60 & 0,53 & 242,18 \\
\hline SP & 1992 & 5,01 & 109,26 & 85,45 & 0,64 & 0,58 & 242,88 \\
\hline SP & 1993 & 4,50 & 101,89 & 88,55 & 0,68 & 0,75 & 243,58 \\
\hline SP & 1994 & 4,78 & 93,28 & 75,92 & 0,76 & 0,98 & 244,29 \\
\hline SP & $1995 / 96$ & 7,05 & 124,43 & 81,76 & 0,93 & 0,95 & 245,00 \\
\hline PR & 1971 & 5,84 & 144,63 & 163,20 & 0,74 & 0,32 & 114,75 \\
\hline PR & 1972 & 6,22 & 154,60 & 167,55 & 0,73 & 0,34 & 131,69 \\
\hline PR & 1973 & 7,35 & 165,86 & 170,11 & 0,75 & 0,38 & 151,12 \\
\hline RP & 1974 & 8,81 & 176,04 & 158,44 & 0,77 & 0,29 & 173,41 \\
\hline PR & 1975 & 8,87 & 186,53 & 188,62 & 1,18 & 0,27 & 199,00 \\
\hline PR & 1976 & 8,18 & 182,88 & 169,81 & 0,70 & 0,37 & 210,57 \\
\hline PR & 1977 & 8,38 & 179,82 & 171,26 & 0,82 & 0,66 & 222,82 \\
\hline PR & 1978 & 7,40 & 181,16 & 175,45 & 0,81 & 0,51 & 235,78 \\
\hline PR & 1979 & 6,87 & 172,12 & 177,50 & 0,77 & 0,45 & 249,49 \\
\hline PR & 1980 & 7,99 & 175,37 & 172,13 & 0,89 & 0,36 & 264,00 \\
\hline RP & 1981 & 8,45 & 182,83 & 168,10 & 0,88 & 0,28 & 274,36 \\
\hline PR & 1982 & 7,73 & 176,88 & 171,80 & 0,99 & 0,27 & 285,12 \\
\hline PR & 1983 & 6,09 & 151,76 & 148,99 & 0,82 & 0,30 & 296,30 \\
\hline PR & 1984 & 5,37 & 135,78 & 124,20 & 0,46 & 0,38 & 307,92 \\
\hline PR & 1985 & 6,48 & 151,43 & 125,87 & 0,79 & 0,43 & 320,00 \\
\hline PR & 1986 & 7,90 & 140,96 & 127,24 & 0,83 & 0,68 & 326,23 \\
\hline PR & 1987 & 5,50 & 101,79 & 105,94 & 0,67 & 0,55 & 332,57 \\
\hline RP & 1988 & 3,69 & 97,81 & 101,21 & 0,70 & 0,62 & 339,04 \\
\hline PR & 1989 & 5,11 & 105,66 & 106,29 & 0,85 & 0,59 & 345,64 \\
\hline PR & 1990 & 4,31 & 79,76 & 80,18 & 0,65 & 0,66 & 352,36 \\
\hline PR & 1991 & 4,63 & 85,78 & 95,06 & 0,60 & 0,70 & 359,22 \\
\hline PR & 1992 & 4,01 & 87,90 & 85,45 & 0,63 & 0,69 & 366,21 \\
\hline PR & 1993 & 3,58 & 84,29 & 88,55 & 0,62 & 0,84 & 373,33 \\
\hline PR & 1994 & 4,35 & 79,37 & 75,92 & 0,65 & 0,99 & 380,60 \\
\hline PR & $1995 / 96$ & 5,65 & 98,26 & 81,76 & 0,73 & 1,03 & 388,00 \\
\hline
\end{tabular}


Tabela 5. Dados utilizados na estimação das equações (18) e (25).

\begin{tabular}{|c|c|c|c|c|c|c|c|}
\hline U.F. & Ano & $W T$ & $W P$ & $W M$ & $W U$ & $P a$ & Pmo \\
\hline SC & 1971 & 5,70 & 134,31 & 163,20 & 0,75 & 0,60 & 105,06 \\
\hline SC & 1972 & 5,94 & 145,20 & 167,55 & 0,75 & 0,65 & 110,38 \\
\hline SC & 1973 & 6,87 & 156,19 & 170,11 & 0,80 & 0,71 & 115,96 \\
\hline SC & 1974 & 8,37 & 162,71 & 158,44 & 0,68 & 0,59 & 121,83 \\
\hline SC & 1975 & 9,54 & 178,67 & 188,62 & 0,73 & 0,57 & 128,00 \\
\hline SC & 1976 & 9,12 & 176,51 & 169,81 & 0,89 & 0,67 & 139,24 \\
\hline SC & 1977 & 8,83 & 183,09 & 171,26 & 0,95 & 0,70 & 151,47 \\
\hline SC & 1978 & 8,85 & 186,20 & 175,45 & 0,96 & 0,69 & 164,78 \\
\hline SC & 1979 & 8,63 & 182,46 & 177,50 & 0,86 & 0,70 & 179,25 \\
\hline SC & 1980 & 9,09 & 188,52 & 172,13 & 0,94 & 0,72 & 195,00 \\
\hline SC & 1981 & 8,71 & 186,51 & 168,10 & 0,94 & 0,58 & 202,41 \\
\hline SC & 1982 & 8,88 & 187,39 & 171,80 & 1,03 & 0,54 & 210,11 \\
\hline SC & 1983 & 7,95 & 153,56 & 148,99 & 0,94 & 0,59 & 218,10 \\
\hline SC & 1984 & 6,29 & 138,84 & 124,20 & 0,54 & 0,63 & 226,39 \\
\hline SC & 1985 & 6,85 & 154,62 & 125,87 & 0,80 & 0,58 & 235,00 \\
\hline SC & 1986 & 10,01 & 168,70 & 127,24 & 0,95 & 0,59 & 244,48 \\
\hline SC & 1987 & 7,08 & 113,69 & 105,94 & 0,78 & 0,45 & 254,34 \\
\hline SC & 1988 & 4,88 & 105,86 & 101,21 & 0,62 & 0,61 & 264,60 \\
\hline SC & 1989 & 7,32 & 139,19 & 106,29 & 0,77 & 0,62 & 275,28 \\
\hline SC & 1990 & 6,71 & 106,33 & 80,18 & 0,57 & 0,66 & 286,38 \\
\hline SC & 1991 & 7,03 & 104,63 & 95,06 & 0,48 & 0,77 & 297,94 \\
\hline SC & 1992 & 5,56 & 98,84 & 85,45 & 0,42 & 0,83 & 309,95 \\
\hline SC & 1993 & 5,33 & 104,44 & 88,55 & 0,45 & 0,98 & 322,46 \\
\hline SC & 1994 & 6,31 & 100,43 & 75,92 & 0,47 & 1,00 & 335,47 \\
\hline SC & $1995 / 96$ & 8,11 & 122,48 & 81,76 & 0,73 & 0,94 & 349,00 \\
\hline RS & 1971 & 5,58 & 146,71 & 163,20 & 0,68 & 0,62 & 102,83 \\
\hline RS & 1972 & 6,16 & 160,56 & 167,55 & 0,68 & 0,67 & 105,75 \\
\hline RS & 1973 & 7,11 & 166,98 & 170,11 & 0,71 & 0,75 & 108,75 \\
\hline RS & 1974 & 7,72 & 159,77 & 158,44 & 0,73 & 0,66 & 111,83 \\
\hline RS & 1975 & 8,60 & 175,17 & 188,62 & 0,80 & 0,55 & 115,00 \\
\hline RS & 1976 & 8,36 & 168,11 & 169,81 & 0,84 & 0,58 & 118,92 \\
\hline RS & 1977 & 8,74 & 183,09 & 171,26 & 0,90 & 0,82 & 122,98 \\
\hline RS & 1978 & 7,87 & 186,00 & 175,45 & 0,87 & 0,80 & 127,18 \\
\hline RS & 1979 & 7,90 & 191,19 & 177,50 & 0,86 & 0,75 & 131,51 \\
\hline RS & 1980 & 7,98 & 182,66 & 172,13 & 0,94 & 0,63 & 136,00 \\
\hline RS & 1981 & 7,60 & 186,61 & 168,10 & 0,97 & 0,50 & 139,06 \\
\hline RS & 1982 & 7,76 & 186,54 & 171,80 & 1,01 & 0,47 & 142,19 \\
\hline RS & 1983 & 7,27 & 155,29 & 148,99 & 0,77 & 0,53 & 145,39 \\
\hline RS & 1984 & 6,72 & 142,60 & 124,20 & 0,44 & 0,67 & 148,66 \\
\hline RS & 1985 & 6,71 & 156,91 & 125,87 & 0,80 & 0,68 & 152,00 \\
\hline RS & 1986 & 7,52 & 146,07 & 127,24 & 0,88 & 0,70 & 155,67 \\
\hline RS & 1987 & 6,02 & 104,78 & 105,94 & 0,65 & 0,58 & 159,44 \\
\hline RS & 1988 & 4,46 & 105,27 & 101,21 & 0,64 & 0,74 & 163,29 \\
\hline RS & 1989 & 6,22 & 114,94 & 106,29 & 0,78 & 0,70 & 167,24 \\
\hline RS & 1990 & 4,77 & 84,15 & 80,18 & 0,61 & 0,75 & 171,28 \\
\hline RS & 1991 & 5,40 & 92,58 & 95,06 & 0,55 & 0,84 & 175,42 \\
\hline RS & 1992 & 4,79 & 90,09 & 85,45 & 0,51 & 0,82 & 179,66 \\
\hline RS & 1993 & 4,48 & 94,94 & 88,55 & 0,52 & 0,94 & 184,00 \\
\hline RS & 1994 & 4,64 & 82,49 & 75,92 & 0,52 & 1,00 & 188,45 \\
\hline RS & $1995 / 96$ & 6,69 & 112,52 & 81,76 & 0,62 & 1,06 & 193,00 \\
\hline
\end{tabular}


Tabela 5. Dados utilizados na estimação das equações (18) e (25).

\begin{tabular}{|c|c|c|c|c|c|c|c|}
\hline U.F. & Ano & $\overline{W T}$ & $W P$ & $W M$ & $\overline{W U}$ & $P a$ & $P m o$ \\
\hline MT & 1971 & 5,53 & 121,96 & 135,95 & 0,59 & 0,74 & 93,53 \\
\hline MT & 1972 & 6,21 & 121,90 & 138,58 & 0,60 & 0,76 & 87,89 \\
\hline MT & 1973 & 7,10 & 133,51 & 141,42 & 0,71 & 0,86 & 82,99 \\
\hline MT & 1974 & 8,76 & 130,64 & 133,01 & 0,83 & 0,76 & 78,72 \\
\hline MT & 1975 & 10,35 & 131,94 & 159,22 & 0,87 & 0,69 & 75,00 \\
\hline MT & 1976 & 9,24 & 132,31 & 143,49 & 0,81 & 0,75 & 81,93 \\
\hline MT & 1977 & 8,46 & 157,46 & 144,82 & 0,74 & 0,64 & 89,53 \\
\hline MT & 1978 & 7,95 & 170,64 & 148,42 & 0,78 & 0,75 & 97,86 \\
\hline MT & 1979 & 7,87 & 188,42 & 151,23 & 0,74 & 0,91 & 106,99 \\
\hline MT & 1980 & 8,36 & 195,38 & 144,06 & 0,85 & 0,72 & 117,00 \\
\hline MT & 1981 & 8,39 & 192,79 & 141,27 & 0,85 & 0,54 & 127,88 \\
\hline MT & 1982 & 7,74 & 178,97 & 148,72 & 0,89 & 0,50 & 139,88 \\
\hline MT & 1983 & 7,05 & 174,29 & 131,09 & 0,79 & 0,57 & 153,13 \\
\hline MT & 1984 & 6,44 & 171,81 & 119,55 & 0,46 & 0,61 & 167,79 \\
\hline MT & 1985 & 7,21 & 176,16 & 125,87 & 0,56 & 0,58 & 184,00 \\
\hline MT & 1986 & 10,66 & 168,93 & 127,24 & 0,79 & 0,66 & 197,50 \\
\hline MT & 1987 & 7,74 & 140,78 & 105,94 & 0,58 & 0,59 & 212,07 \\
\hline MT & 1988 & 4,31 & 137,39 & 101,21 & 0,49 & 0,66 & 227,79 \\
\hline MT & 1989 & 5,63 & 151,83 & 106,29 & 0,59 & 0,68 & 244,77 \\
\hline MT & 1990 & 5,18 & 175,96 & 80,18 & 0,44 & 0,76 & 263,10 \\
\hline MT & 1991 & 5,48 & 132,34 & 95,06 & 0,43 & 0,89 & 282,90 \\
\hline MT & 1992 & 4,52 & 106,18 & 85,45 & 0,40 & 0,82 & 304,30 \\
\hline MT & 1993 & 4,26 & 128,99 & 88,55 & 0,45 & 0,96 & 327,43 \\
\hline MT & 1994 & 5,15 & 96,28 & 75,92 & 0,48 & 1,01 & 352,44 \\
\hline MT & $1995 / 96$ & 6,65 & 109,92 & 81,76 & 0,56 & 0,99 & 379,50 \\
\hline GO & 1971 & 4,11 & 112,16 & 135,95 & 0,56 & 0,79 & 93,53 \\
\hline GO & 1972 & 4,43 & 120,11 & 138,58 & 0,58 & 0,84 & 87,89 \\
\hline GO & 1973 & 6,03 & 146,71 & 141,42 & 0,59 & 0,90 & 82,99 \\
\hline GO & 1974 & 7,10 & 163,55 & 133,01 & 0,74 & 0,80 & 78,72 \\
\hline GO & 1975 & 8,25 & 183,87 & 159,22 & 0,68 & 0,79 & 75,00 \\
\hline GO & 1976 & 7,77 & 166,41 & 143,49 & 0,71 & 0,78 & 81,93 \\
\hline $\mathrm{GO}$ & 1977 & 6,96 & 155,81 & 144,82 & 0,71 & 0,67 & 89,53 \\
\hline GO & 1978 & 6,84 & 161,36 & 148,42 & 0,65 & 0,72 & 97,86 \\
\hline $\mathrm{GO}$ & 1979 & 6,80 & 159,81 & 151,23 & 0,66 & 0,87 & 106,99 \\
\hline $\mathrm{GO}$ & 1980 & 7,72 & 161,38 & 144,06 & 0,71 & 0,74 & 117,00 \\
\hline $\mathrm{GO}$ & 1981 & 7,09 & 157,40 & 141,27 & 0,69 & 0,57 & 127,88 \\
\hline $\mathrm{GO}$ & 1982 & 6,14 & 146,39 & 148,72 & 0,73 & 0,51 & 139,88 \\
\hline $\mathrm{GO}$ & 1983 & 5,59 & 129,75 & 131,09 & 0,70 & 0,63 & 153,13 \\
\hline $\mathrm{GO}$ & 1984 & 5,61 & 129,04 & 119,55 & 0,41 & 0,65 & 167,79 \\
\hline GO & 1985 & 6,15 & 140,85 & 125,87 & 0,56 & 0,64 & 184,00 \\
\hline $\mathrm{GO}$ & 1986 & 10,44 & 180,87 & 127,24 & 0,62 & 0,72 & 197,50 \\
\hline $\mathrm{GO}$ & 1987 & 6,27 & 116,85 & 105,94 & 0,45 & 0,66 & 212,07 \\
\hline $\mathrm{GO}$ & 1988 & 3,57 & 96,17 & 101,21 & 0,44 & 0,75 & 227,79 \\
\hline $\mathrm{GO}$ & 1989 & 5,69 & 129,09 & 106,29 & 0,45 & 0,70 & 244,77 \\
\hline $\mathrm{GO}$ & 1990 & 4,04 & 85,35 & 80,18 & 0,40 & 0,78 & 263,10 \\
\hline $\mathrm{GO}$ & 1991 & 4,42 & 89,40 & 95,06 & 0,38 & 0,82 & 282,90 \\
\hline $\mathrm{GO}$ & 1992 & 3,56 & 88,75 & 85,45 & 0,41 & 0,76 & 304,30 \\
\hline $\mathrm{GO}$ & 1993 & 3,81 & 104,02 & 88,55 & 0,50 & 0,93 & 327,43 \\
\hline $\mathrm{GO}$ & 1994 & 4,32 & 83,87 & 75,92 & 0,44 & 1,02 & 352,44 \\
\hline $\mathrm{GO}$ & $1995 / 96$ & 4,87 & 98,59 & 81,76 & 0,52 & 1,02 & 379,50 \\
\hline
\end{tabular}

Fonte: Descrita no texto.

$W T$ = salário real dos trabalhadores temporários (Reais de agosto de 1994); WP = salário real dos trabalhadores permanentes (Reais de agosto de 1994); WM = salário mínimo real (Reais de agosto de 1994); $W U=$ salário real do emprego urbano alternativo (Reais de agosto de 1994); $P a=$ índice de relação de preços recebidos e pagos pelos produtores rurais; $P m o=$ produtividade do trabalho.

$W P$ e $W M$ são valores por mês; $W T$ é valor por dia; $W U$ é valor por hora, $P a$ é índice com base 1 em agosto de 1994; Pmo é índice com 100 em 1970. 
APÊNDICE 3 - Procedimento metodológico de Fuller \& Battese (1974).

PARTE A - Descrição do método de Fuller \& Battese:

Como apresentado no item 4.2, o modelo econométrico com os dados em pooling tem a seguinte formulação:

$$
\begin{aligned}
& y_{i t}=\sum_{k=1}^{p} X_{i t k} \beta_{k}+u_{i t} \\
& i=1, \ldots, N \\
& t=1, \ldots, T
\end{aligned}
$$

onde:

$N=$ número de unidades de cross section;

$T$ = número de observações de cada cross section;

$k=$ número de variáveis exógenas;

$y$ = variável endógena;

$X$ = variável exógena;

$\beta=$ parâmetro;

$u=$ termo de erro.

$u_{i t}=\mu_{i}+\lambda_{t}+v_{i t} \quad(i=1 \ldots N ; t=1 \ldots T)$

sendo:

$\mu_{i}=$ características específicas não-observáveis de cada unidade de cross section; 
$\lambda_{1}=$ eventos ocorridos em qualquer unidade de tempo que afeta todas as unidades de cross section;

$v_{i t}=$ resultante do erro estocástico.

O melhor estimador não-viesado de $\beta$ é estimado pelo método dos Mínimos Quadrados Generalizados (MQG):

$$
\hat{\boldsymbol{\beta}}=\left(X^{\prime} \cdot V^{-1} \cdot X\right)^{-1} \cdot X \cdot V^{-1} \cdot Y
$$

e apresenta a seguinte variância:

$\operatorname{Var}(\hat{\beta})=\left(X^{\prime} \cdot V^{-1} \cdot X\right)^{-1}$

A matriz de covariância do vetor do termo de erro $u$ pode ser expressa:

$$
\begin{aligned}
& V=E\left(u \cdot u^{\prime}\right)=\sigma_{v}^{2} \cdot I_{N T}+\sigma_{\mu}^{2} \cdot A+\sigma_{\lambda}^{2} \cdot B \\
& A=I_{N} \otimes J_{T} \\
& B=J_{N} \otimes I_{T}
\end{aligned}
$$

onde, $I_{N T}, I_{N}$ e $I_{T}$ são matrizes identidades de ordem $N \mathrm{x} T, N$ e $T$, respectivamente; $J_{N}$ e $J_{T}$ são matrizes e todos os seus elementos são iguais a 1 e de ordem $N \times N$ e $T \mathrm{x} T$, respectivamente; e $\otimes$ representa o produto Kronecker.

As matrizes $M$ são quadradas e definidas como:

$$
\begin{aligned}
& M_{. .}=\frac{J_{N T}}{N . T} \\
& M_{1 .}=\frac{A}{T}-\frac{J_{N T}}{N \cdot T}
\end{aligned}
$$




$$
\begin{aligned}
& M_{.2}=\frac{B}{N}-\frac{J_{N T}}{N . T} \\
& M_{12}=I_{N T}-\frac{A}{T}-\frac{B}{N}-\frac{J_{N T}}{N . T}
\end{aligned}
$$

As quatro matrizes $M s$ são idempotentes simétricas e mutuamente ortogonais.

Os elementos it-ésimos da $k$-ésima coluna das matrizes $M_{. .}, M_{1 .}, M_{.2}$ e $M_{12}$ são $\bar{x}_{. . k},\left(\bar{x}_{i . k}-\bar{x}_{. . k}\right),\left(\bar{x}_{. t k}-\bar{x}_{. . k}\right)$ e $\left(x_{i t k}-\bar{x}_{i . k}-\bar{x}_{. t k}+\bar{x}_{. . k}\right)$, respectivamente. Onde, $\bar{x}_{. k}$ é a média da variável $x$ de $N x T$ observações da $k$-éssima coluna, $\bar{x}_{i . k}$ é a média da variável $x$ de $T$ observações do $i$-nésimo cross section da $k$-éssima coluna e $\bar{x}_{. t k}$ é média da variável $x$ de $N$ observações do $t$-éssimo período da $k$-éssima coluna.

Considerando as propriedades das matrizes $M s$, a matriz $V$ pode ser expressa:

$$
V=\sigma_{v}^{2} \cdot M_{12}+\left(\sigma_{v}^{2}+T \sigma_{\mu}^{2}\right) \cdot M_{1 .}+\left(\sigma_{v}^{2}+N \sigma_{\lambda}^{2}\right) \cdot M_{.2}+\left(\sigma_{v}^{2}+T \sigma_{\mu}^{2}+N \sigma_{\lambda}^{2}\right) \cdot M_{.}
$$

A matriz inversa de $V$ é expressa:

$$
V^{-1}=\frac{M_{12}}{\sigma_{v}^{2}}+\frac{M_{1 .}}{\sigma_{v}^{2}+T \sigma_{\mu}^{2}}+\frac{M_{.2}}{\sigma_{v}^{2}+N \sigma_{\lambda}^{2}}+\frac{M_{. .}}{\sigma_{v}^{2}+T \sigma_{\mu}^{2}+N \sigma_{\lambda}^{2}}
$$

Os três vetores do termo de erro são definidos como:

$$
\begin{aligned}
& \hat{v}=C_{1} \cdot\left(I_{N T}-X \cdot\left(X^{\prime} \cdot C_{1} \cdot X\right)^{-} \cdot X_{1} \cdot C_{1}\right) \cdot Y \\
& \hat{\mu}=C_{2} \cdot\left(I_{N T}-X \cdot\left(X^{\prime} \cdot C_{2} \cdot X\right)^{-} \cdot X \cdot C_{2}\right) \cdot Y \\
& \hat{\lambda}=C_{3} \cdot\left(I_{N T}-X \cdot\left(X^{\prime} \cdot C_{3} \cdot X\right)^{-} \cdot X \cdot C_{3}\right) \cdot Y
\end{aligned}
$$

onde, $A^{-}$denomina a inversa generalizada de $A$, 
$C_{1}=M_{12}$

$C_{2}=M_{12}+M_{1}$

$C_{3}=M_{12}+M_{.2}$

Então, os estimadores não-viesados dos componentes da variância são expressos como:

$\hat{\sigma}_{v}^{2}=\frac{\hat{v}^{\prime} \hat{v}}{(N-1)(T-1)-\operatorname{rank}\left(X^{\prime} M_{12} X\right)}$

$\hat{\boldsymbol{\sigma}}_{\mu}^{2}=\frac{\hat{\mu} \hat{\prime} \hat{\mu}-\left(T \cdot(N-1)-\operatorname{rank}\left(X^{\prime} \cdot M_{.2} \cdot X\right)\right) \hat{\sigma}_{v}^{2}}{T \cdot(N-1)-T \cdot \operatorname{traço}\left(\left(X^{\prime} \cdot C_{2} \cdot X\right)^{-} X^{\prime} \cdot M_{1} \cdot X\right)}$

$\hat{\boldsymbol{\sigma}}_{\lambda}^{2}=\frac{\hat{\lambda^{\prime}} \hat{\lambda}-\left(N \cdot(T-1)-\operatorname{rank}\left(X^{\prime} \cdot M_{1} \cdot X\right)\right) \hat{\sigma}_{v}^{2}}{N \cdot(T-1)-N \cdot \operatorname{traço}\left(\left(X^{\prime} \cdot C_{3} \cdot X\right)^{-} X^{\prime} \cdot M_{.2} \cdot X\right)}$

Os modelos com a configuração em pooling podem assumir efeito fixo ou aleatório. Conforme Greene (1997), o modelo com efeito fixo capta as diferenças entre as unidades de cross section, por meio do termo constante, ou seja, para cada unidade de cross section estima-se o termo constante. Nesta situação, cada unidade de cross section teria um termo constante. $\mathrm{O}$ modelo com efeito aleatório pode ser aplicado quando as unidades de cross section não apresentam diferenças entre si, e caso essas diferenças existam, elas são captadas apenas pelos parâmetros das variáveis explicativas. Nesta situação, o modelo econométrico tem apenas um único termo constante. Segundo Baltagi (1995), a abordagem do efeito fixo acarreta enormes perdas de grau de liberdade dependendo da dimensão da amostra.

Os testes estatísticos indicam qual é o modelo mais adequado para determinado conjunto de dados: efeito fixo ou aleatório. Entretanto, segundo Greene (1997), deve-se preferencialmente aplicar os modelos com efeito fixo, a menos que haja 
impedimentos graves em termos de perdas de graus de liberdade, no caso dos pooling típicos (reduzido número de observações ao longo do tempo e grande número de unidades de cross section).

No modelo Fuller \& Battese (1974), segundo os próprios autores que o desenvolveram e Baltagi ( 1995), em vez de se inverter uma matriz de grandes proporções para obter o efeito fixo na estimação dos parâmetros das variáveis explicativas ( $\beta$ ), é preferível aplicar as transformações proposta por Wallace \& Hussain (1969) (apresentado pela expressão: $x_{i j k}-\bar{x}_{i . k}-\bar{x}_{. j k}-\bar{x}_{. k}$, onde $k=1, \ldots, p$ ), as quais podem captar o efeito fixo proporcionado pela utilização de constantes para cada unidade de cross section.

Segundo Baltagi (1995), seria um grave problema nos modelos econométricos com estrutura de "componentes" do termo de erro do tipo two way (no qual o termo de erro $u_{i t}$ é formado por três tipos de erro, $\mu_{i}, \lambda_{t}$ e $v_{i t}$ ) caso alguma das variâncias $\left(\sigma_{\mu}^{2}, \sigma_{\lambda}^{2}\right.$ e $\left.\sigma_{v}^{2}\right)$ não fosse positiva. Conforme o autor, caso alguma dessas variâncias seja negativa, é impossibilitada a distinção entre a situação em que o modelo estimado está mal especificado - dado que pelo menos um dos componentes da variância é zero - e a situação em que o modelo é devidamente especificado - dado que pelo menos um dos componentes da variância seja relativamente pequeno, mas diferente de zero. Diante desta problemática, é preferível que as três variâncias sejam positivas e próximas de zero, pois, nestas circunstâncias, o modelo não apresentaria problemas de especificação.

PARTE B - Detalhamento dos passos dos cálculos para estimar o modelo de Fuller \& Battese (1974) pelo método dos Mínimos Quadrados Generalizados:

$1^{\mathrm{o}}$ passo - Obtenção das constantes usando os estimadores dos componentes da variância (os procedimentos desses estimadores são descritos na Parte A): 


$$
\begin{aligned}
& \hat{\boldsymbol{\alpha}}_{1}=1-\left(\frac{\hat{\boldsymbol{\sigma}}_{v}^{2}}{\left(\hat{\boldsymbol{\sigma}}_{v}^{2}+T \cdot \hat{\sigma}_{\mu}^{2}\right)}\right)^{\frac{1}{2}} \\
& \hat{\boldsymbol{\alpha}}_{2}=1-\left(\frac{\hat{\boldsymbol{\sigma}}_{v}^{2}}{\left(\hat{\sigma}_{v}^{2}+N \cdot \hat{\sigma}_{\lambda}^{2}\right)}\right)^{\frac{1}{2}} \\
& \left.\hat{\boldsymbol{\alpha}}_{3}=\hat{\boldsymbol{\alpha}}_{1}+\hat{\boldsymbol{\alpha}}_{2}-1+\left(\frac{\hat{\boldsymbol{\sigma}}_{v}^{2}}{\left(\hat{\boldsymbol{\sigma}}_{v}^{2}+T \cdot \hat{\sigma}_{\mu}^{2}+N \cdot \hat{\sigma}_{\lambda}^{2}\right.}\right)\right)^{\frac{1}{2}}
\end{aligned}
$$

$2^{\circ}$ passo- Transformação das variáveis utilizando-se as constantes $\hat{\alpha}_{1}, \hat{\alpha}_{2}$ e $\hat{\alpha}_{3}$, como as seguintes expressões:

$$
\begin{aligned}
& y_{i t}^{*}=y_{i t}-\hat{\alpha}_{1} \cdot y_{1 .}-\hat{\alpha}_{2} \cdot y_{. t}+\hat{\alpha}_{3} \cdot y_{. .} \\
& x_{i t}^{*}=x_{i t}-\hat{\alpha}_{1} \cdot x_{1 .}-\hat{\alpha}_{2} \cdot x_{. t}+\hat{\alpha}_{3} \cdot x_{. .}
\end{aligned}
$$

onde: $y_{. .}, y_{i .}$ e $y_{. t}$ são definidos da mesma forma foram definidos $x_{. .}, x_{i .}$ e $x_{. t}$.

$3^{\mathrm{o}}$ passo - A regressão de $y_{i t}^{*}$ em relação a $x_{i t}^{*}$ pelo método dos Mínimos Quadrados Ordinários 
APÊNDICE 4 - Equações (18) e (25) estimadas em dois períodos.

Os procedimentos metodológicos para testar mudanças de tendência são descritos por Hoffmann \& Vieira (1998). Estes procedimentos baseiam-se na utilização de variáveis instrumentais para representar o correr do tempo em cada "quebra" de tendência. No presente estudo, foram testadas duas "quebra" de tendências.

$Y_{t}=\alpha_{0}+\theta_{1} \cdot Z \cdot(t-v)+\theta_{2} \cdot(1-Z) \cdot(t-v)+u_{t}$

onde:

$Y_{t}=$ salários dos trabalhadores agrícolas temporários ou permanentes (é a variável dependente); $\quad t=1, \ldots, \mathrm{T}$

$\alpha_{0}=$ intercepto;

$\theta_{1}=$ parâmetro do $1^{\circ}$ período;

$\boldsymbol{\theta}_{2}=$ parâmetro do $2^{\circ}$ período;

$v=$ ano (número da observação) que ocorre a inflexão entre os períodos, ou seja, "quebra" de tendência;

$Z$ é igual 1 no primeiro período e igual 0 no segundo período;

$u_{t}=$ termo do erro;

Teste de hipótese:

$H_{0}: \theta_{2}=\theta_{1}$

Hipótese alternativa: 
$H_{1}: \theta_{2} \neq \theta_{1}$

Se $H_{0}$ for rejeitada, estatisticamente há "quebra" de tendência, ou seja, aceita-se $H_{1}$, representando que os coeficientes das regressões entre dois períodos subseqüentes são estatisticamente diferentes.

Os dados da Tabela 6 evidenciam que a hipótese nula deve ser rejeitada a $1 \%$ de significância estatística. Assim, regressões devem ser realizadas para cada subperíodo.

Tabela 6. Resultados das estimativas das equações de "quebra" de tendência dos salários dos trabalhadores agrícolas temporários e permanentes para as regiões menos e mais tecnificadas.

\begin{tabular}{lcccc}
\hline & \multicolumn{2}{c}{ Temporários } & \multicolumn{2}{c}{ Permanentes } \\
\hline & Menos Tecnificada & Mais Tecnificada & Menos Tecnificada & Mais Tecnificada \\
\hline $1^{\mathrm{o}}$ período & $1971-1981$ & $1971-1975$ & $1971-1978$ & $1971-1982$ \\
$2^{\mathrm{o}}$ período & $1981-1995 / 96$ & $1975-1995 / 96$ & $1978-1995 / 96$ & $1982-1995 / 96$ \\
\hline Intercepto & 5,902 & 8,245 & 140,960 & 186,876 \\
& $(19,219)^{\mathrm{a}}$ & $(24,552)^{\mathrm{a}}$ & $(26,674)^{\mathrm{a}}$ & $(36,653)^{\mathrm{a}}$ \\
$\boldsymbol{\theta}_{1}$ & 0,156 & 0,815 & 2,782 & 7,315 \\
$\boldsymbol{\theta}_{2}$ & $(2,657)^{\mathrm{d}}$ & $(4,707)^{\mathrm{a}}$ & $(3,070)^{\mathrm{a}}$ & $(4,949)^{\mathrm{a}}$ \\
$\mathrm{R}^{2}$ & $-0,156$ & $-0,194$ & $-6,394$ & $-6,415$ \\
$\mathrm{~F}$ & $(-6,444)^{\mathrm{a}}$ & $(-6,657)^{\mathrm{a}}$ & $(-8,552)^{\mathrm{a}}$ & $(-12,069)^{\mathrm{a}}$ \\
$\mathrm{DW}$ & 0,6647 & 0,6809 & 0,7874 & 0,8726 \\
& $21,81^{\mathrm{a}}$ & $23,47^{\mathrm{a}}$ & $39,801^{\mathrm{a}}$ & $75,37^{\mathrm{a}}$ \\
$\mathrm{H}_{0}: \boldsymbol{\theta}_{2}=\boldsymbol{\theta}_{1}$ & $1,18^{\mathrm{a}}$ & $1,67^{\mathrm{a}}$ & $1,31^{\mathrm{a}}$ & $1,66^{\mathrm{a}}$ \\
& inconclusivo & não autocor. & inconclusivo & não autocor. \\
\hline
\end{tabular}

Fonte: dados da pesquisa.

${ }^{a}$ nível de significância de $1 \% ;{ }^{b}$ nível de significância de 5\%; ${ }^{c}$ nível de significância de $10 \%$; d nível de significância de $20 \%{ }^{\text {ns }}$ não-significativo.

A Tabela 7 apresenta os resultados das regressões por subperíodos. Os resultados apresentam melhores valores de $\mathrm{R}^{2}$ do que os apresentados nas Tabelas 3 e 4 . No entanto, os níveis de significância estatística dos coeficientes na Tabela 7 são piores do que os apresentados nas Tabelas 3 e 4. 
Tabela 7. Resultados das estimativas das equações de determinação dos salários dos trabalhadores temporários e permanentes pelo método Fuller \& Battese para dois períodos*.

\begin{tabular}{|c|c|c|c|c|c|c|c|c|}
\hline \multirow[b]{3}{*}{ Período } & \multicolumn{4}{|c|}{ Trabalhadores Temporários } & \multicolumn{4}{|c|}{ Trabalhadores Permanentes } \\
\hline & \multicolumn{2}{|c|}{ Região menos tecnific. } & \multicolumn{2}{|c|}{ Região mais tecnific. } & \multicolumn{2}{|c|}{ Região menos tecnific. } & \multicolumn{2}{|c|}{ Região mais tecnific. } \\
\hline & $1971-81$ & 1982-95/96 & $1971-75$ & $1976-95 / 96$ & $1971-78$ & $1979-95 / 96$ & $1971-82$ & $1983-95 / 96$ \\
\hline Interc & $\begin{array}{c}-2,785 \\
(-1,604)^{d}\end{array}$ & $\begin{array}{c}-1,902 \\
(-1,434)^{\mathrm{d}}\end{array}$ & $\begin{array}{c}-4,017 \\
(-1,356)^{d}\end{array}$ & $\begin{array}{c}-1,145 \\
(-2,175)^{b}\end{array}$ & $\begin{array}{c}3,268 \\
(1,853)^{\mathrm{c}}\end{array}$ & $\begin{array}{c}-0,170 \\
(-0,141)^{\mathrm{ns}}\end{array}$ & $\begin{array}{c}0,513 \\
(0,456)^{\mathrm{ns}}\end{array}$ & $\begin{array}{c}-0,277 \\
(-0,530)^{\mathrm{ns}}\end{array}$ \\
\hline$W M$ & $\begin{array}{c}0,400 \\
(1,150)^{\mathrm{ns}}\end{array}$ & $\begin{array}{c}0,839 \\
(3,511)^{\mathrm{a}}\end{array}$ & $\begin{array}{c}1,214 \\
(2,173)^{b}\end{array}$ & $\begin{array}{c}0,628 \\
(6,655)^{\mathrm{a}}\end{array}$ & $\begin{array}{c}0,001 \\
(0,003)^{\mathrm{ns}}\end{array}$ & $\begin{array}{c}0,954 \\
(5,405)^{\mathrm{a}}\end{array}$ & $\begin{array}{c}0,823 \\
(3,776)^{\mathrm{a}}\end{array}$ & $\begin{array}{c}1,001 \\
(13,900)^{\mathrm{a}}\end{array}$ \\
\hline$W U$ & $\begin{array}{c}0,361 \\
(3,361)^{\mathrm{a}}\end{array}$ & $\begin{array}{c}0,168 \\
(2,046)^{b}\end{array}$ & $\begin{array}{c}-0,080 \\
(-0,924)^{\mathrm{ns}}\end{array}$ & $\begin{array}{c}0,110 \\
(1,695)^{\mathrm{c}}\end{array}$ & - & - & - & - \\
\hline $\mathrm{Pa}$ & $\begin{array}{c}0,060 \\
(1,071)^{\mathrm{ns}}\end{array}$ & $\begin{array}{c}-0,022 \\
(-0,498)^{\mathrm{ns}}\end{array}$ & $\begin{array}{c}0,299 \\
(2,496)^{\mathrm{b}}\end{array}$ & $\begin{array}{c}0,117 \\
(2,853)^{\mathrm{b}}\end{array}$ & $\begin{array}{c}0,025 \\
(0,357)^{\mathrm{ns}}\end{array}$ & $\begin{array}{c}-0,106 \\
(-2,339)^{b}\end{array}$ & $\begin{array}{c}0,051 \\
(1,138)^{\mathrm{ns}}\end{array}$ & $\begin{array}{c}0,075 \\
(1,964)^{\mathrm{c}}\end{array}$ \\
\hline Pmo & $\begin{array}{c}0,558 \\
(4,860)^{\mathrm{a}}\end{array}$ & $\begin{array}{c}-0,114 \\
(-1,008)^{\mathrm{ns}}\end{array}$ & $\begin{array}{c}-0,040 \\
(-0,425)^{\mathrm{ns}}\end{array}$ & $\begin{array}{c}0,005 \\
(0,104)^{\mathrm{ns}}\end{array}$ & $\begin{array}{c}0,328 \\
(2,372)^{b}\end{array}$ & $\begin{array}{c}0,045 \\
(0,343)^{\mathrm{ns}}\end{array}$ & $\begin{array}{c}0,076 \\
(1,089)^{\mathrm{ns}}\end{array}$ & $\begin{array}{c}0,078 \\
(1,450)^{d}\end{array}$ \\
\hline$\sigma_{\mu}^{2}$ & 0,0136 & 0,0119 & 0,0352 & 0,0122 & 0,0183 & 0,0160 & 0,0031 & 0,0074 \\
\hline$\sigma_{\lambda}^{2}$ & 0,0126 & 0,0242 & 0,0514 & 0,0142 & 0,0070 & 0,0088 & 0,0076 & 0,0037 \\
\hline$\sigma_{v}^{2}$ & 0,0032 & 0,0059 & 0,0017 & 0,0060 & 0,0061 & 0,0058 & 0,0038 & 0,0058 \\
\hline $\mathrm{R}^{2}$ & 0,2503 & 0,1902 & 0,2656 & 0,2766 & 0,0550 & 0,3263 & 0,1939 & 0,6435 \\
\hline
\end{tabular}

Fonte: Dados da pesquisa.

* os valores entre parênteses são os $t$-student calculados.

** corrigido pelo IGP-DI agosto de 1994.

$W M=$ salário mínimo; $W U=$ salário do trabalho alternativo (servente de pedreiro); $P a=$ relação de preços recebidos e pagos pelos produtores rurais; $P m o=$ produtividade do trabalho; $\sigma_{\mu}^{2}=$ variância de $\mu_{i} ; \sigma_{\lambda}^{2}=$ variância de $\lambda_{t} ; \sigma_{v}^{2}=$ variância de $v_{i t}$.

a significativo ao nível de $1 \%{ }^{\text {b }}$ significativo ao nível de $5 \%$; $^{\mathrm{c}}$ significativo ao nível de $10 \%{ }^{\mathrm{d}}$ significativo ao nível de $20 \% ;{ }^{\text {ns }}$ não-significativo. 
APÊNDICE 5 - Equações (18) e (25) com a variável tendência.

A Tabela 8 apresenta as estimativas das equações (18) e (25) com a inclusão da variável tendência. Os resultados são bem próximos aos apresentados nas Tabelas 3 e 4, havendo, no entanto, valores mais altos de $\mathrm{R}^{2}$ quando se inclui a tendência como variável explicativa.

Tabela 8. Resultados das estimativas das equações de determinação dos salários dos trabalhadores temporários e permanentes pelo método Fuller \& Battese com a variável tendência no período de 1971 a 1996*.

\begin{tabular}{|c|c|c|c|c|c|c|}
\hline & \multicolumn{3}{|c|}{ Trabalhadores Temporários } & \multicolumn{3}{|c|}{ Trabalhadores Permanentes } \\
\hline & Brasil & $\begin{array}{l}\text { Região menos } \\
\text { tecnific. }\end{array}$ & $\begin{array}{l}\text { Região mais } \\
\text { tecnific. }\end{array}$ & Brasil & $\begin{array}{l}\text { Região menos } \\
\text { tecnific. }\end{array}$ & $\begin{array}{l}\text { Região mais } \\
\text { tecnific. }\end{array}$ \\
\hline Interc & $\begin{array}{c}1,671^{\mathrm{a}} \\
(3,760)\end{array}$ & $\begin{array}{l}-1,477^{\mathrm{d}} \\
(-1,538)\end{array}$ & $\begin{array}{l}-0,763^{\mathrm{d}} \\
(-1,413)\end{array}$ & $\begin{array}{l}0,839^{\mathrm{b}} \\
(2,081)\end{array}$ & $\begin{array}{l}0,612^{\mathrm{ns}} \\
(0,758)\end{array}$ & $\begin{array}{c}-0,756^{\mathrm{b}} \\
(-1,979)\end{array}$ \\
\hline$W M$ & $\begin{array}{l}-0,026^{\text {ns }} \\
(-0,375)\end{array}$ & $\begin{array}{l}0,526^{\mathrm{a}} \\
(2,910)\end{array}$ & $\begin{array}{l}0,626^{\mathrm{a}} \\
(6,241)\end{array}$ & $\begin{array}{c}0,646^{\mathrm{a}} \\
(10,211)\end{array}$ & $\begin{array}{c}0,675^{\mathrm{a}} \\
(4,478)\end{array}$ & $\begin{array}{c}1,045^{\mathrm{a}} \\
(17,223)\end{array}$ \\
\hline$W U$ & $\begin{array}{c}0,167^{\mathrm{a}} \\
(4,072)\end{array}$ & $\begin{array}{l}0,137^{\mathrm{b}} \\
(2,323)\end{array}$ & $\begin{array}{c}0,087^{\mathrm{d}} \\
(1,451)\end{array}$ & - & - & - \\
\hline $\mathrm{Pa}$ & $\begin{array}{l}-0,001^{\text {ns }} \\
(-0,047)\end{array}$ & $\begin{array}{l}0,020^{\text {ns }} \\
(0,552)\end{array}$ & $\begin{array}{l}0,043^{\text {ns }} \\
(1,219)\end{array}$ & $\begin{array}{l}-0,035^{\mathrm{d}} \\
(-1,305)\end{array}$ & $\begin{array}{l}-0,042^{\text {ns }} \\
(-1,000)\end{array}$ & $\begin{array}{c}0,027 \mathrm{~ns} \\
(0,868)\end{array}$ \\
\hline Pmo & $\begin{array}{l}0,078^{\mathrm{b}} \\
(2,216)\end{array}$ & $\begin{array}{c}0,123^{\mathrm{d}} \\
(1,614)\end{array}$ & $\begin{array}{l}-0,142^{\mathrm{a}} \\
(-3,290)\end{array}$ & $\begin{array}{l}0,181^{\mathrm{a}} \\
(5,084)\end{array}$ & $\begin{array}{l}0,188^{\mathrm{b}} \\
(2,243)\end{array}$ & $\begin{array}{l}0,072^{\mathrm{c}} \\
(1,895)\end{array}$ \\
\hline Tend & $\begin{array}{l}-0,101^{\mathrm{b}} \\
(-2,420)\end{array}$ & $\begin{array}{l}-0,038^{\text {ns }} \\
(-0,730)\end{array}$ & $\begin{array}{c}0,129^{\mathrm{a}} \\
(3,002)\end{array}$ & $\begin{array}{l}-0,040^{\mathrm{d}} \\
(-1,535)\end{array}$ & $\begin{array}{l}-0,046^{\mathrm{ns}} \\
(-1,076)\end{array}$ & $\begin{array}{c}0,099^{\mathrm{a}} \\
(4,281)\end{array}$ \\
\hline$\sigma_{\mu}^{2}$ & 0,0317 & 0,0113 & 0,0142 & 0,0218 & 0,0180 & 0,0034 \\
\hline$\sigma_{\lambda}^{2}$ & 0,0225 & 0,0239 & 0,0150 & 0,0074 & 0,0118 & 0,0028 \\
\hline$\sigma_{v}^{2}$ & 0,0078 & 0,0058 & 0,0065 & 0,0086 & 0,0071 & 0,0074 \\
\hline $\mathrm{R}^{2}$ & 0,0605 & 0,1540 & 0,2299 & 0,2738 & 0,1744 & 0,6644 \\
\hline
\end{tabular}

Fonte: Dados da pesquisa.

* os valores entre parênteses são os $t$-student calculados.

** corrigido pelo IGP-DI agosto de 1994.

$W M=$ salário mínimo; $W U=$ salário do trabalho alternativo (servente de pedreiro); $P a=$ relação de preços recebidos e pados pelos produtores rurais; $P m o=$ produtividade do trabalho; Tend=tendência; $\sigma_{\mu}^{2}=$ variância de $\mu_{i} ; \sigma_{\lambda}^{2}=$ variância de $\lambda_{t} ; \sigma_{v}^{2}=$ variância de $v_{i t}$.

a significativo ao nível de $1 \%$; ${ }^{\mathrm{b}}$ significativo ao nível de $5 \%$; $^{\mathrm{c}}$ significativo ao nível de $10 \%$; significativo ao nível de $20 \% ;{ }^{\text {ns }}$ não-significativo. 